\title{
REVIEW
}

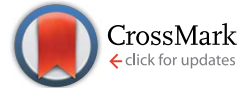

Cite this: Nat. Prod. Rep., 2016, 33, 491

\section{Synthetic approaches towards alkaloids bearing $\alpha$-tertiary amines}

\author{
Anastasia Hager, $\uparrow$ Nina Vrielink, $\uparrow$ Dominik Hager, Julien Lefranc and Dirk Trauner*
}

Covering: up to August 2015

Alkaloids account for some of the most beautiful and biologically active natural products. Although they are usually classified along biosynthetic criteria, they can also be categorized according to certain structural motifs. Amongst these, the $\alpha$-tertiary amine (ATA), i.e. a tetrasubstituted carbon atom surrounded by

Received 15th August 2015 three carbons and one nitrogen, is particularly interesting. A limited number of methods have been described to access this functional group and fewer still are commonly used in synthesis. Herein, we

DOI: $10.1039 / c 5 n p 00096 c$

www.rsc.org/npr review some approaches to asymmetrically access ATAs and provide an overview of alkaloid total syntheses where those have been employed.

1 Introduction

2 Methods used for the installation of $\alpha$-tertiary amines

2.1 A C,C-bond is formed in the step that generates the ATA

2.2 A C,N-bond is formed in the step that generates the ATA

3 Homotropane alkaloids

$4 \quad$ Histrionicotoxins

$5 \quad$ Lycopodium alkaloids

6 Hasubanan alkaloids

$7 \quad$ Stemona alkaloids

8 Indole alkaloids

9 Cephalotaxines

10 Erythrina alkaloids

11 Indolizidine and quinolizidine alkaloids

12 Lactacystine and salinosporamide

13 Manzacidins

14 Tetrodotoxin

15 Miscellaneous alkaloids

16 Conclusions

17 Acknowledgements

18 Notes and references

\section{Introduction}

Alkaloids have played an important role in the development of synthetic organic chemistry, pharmacology and medicine. Once considered to be metabolic waste products, they are now known to benefit their producers in various ways, e.g. as antimicrobials,

Fakultät für Chemie und Pharmazie, Ludwig-Maximilians-Universität München, and Munich Center for Integrated Protein Science, Butenandtstr. 5 - 13, 81377 München, Germany. E-mail: Dirk.Trauner@lmu.de

$\dagger$ The authors contributed equally to the review. antifeedants or as mediators of ecologically beneficial interactions. ${ }^{1}$ Though a limited number of amino acids are involved in their biosynthesis, alkaloids exhibit enormous structural variability, which is often increased through the incorporation of terpenoid and polyketide components and late-stage oxidative transformations. ${ }^{2}$ Reflecting their structural diversity and relatively weak basicity, alkaloids interact with a large variety of biological targets and have found many uses in human medicine. ${ }^{3,4}$ In addition, they have provided inspiration for countless synthetic drugs that borrow structural motifs from their natural counterparts.

The $\alpha$-tertiary amine (ATA) stands out among the structural features frequently found in alkaloids. ${ }^{5-8}$ For the purposes of

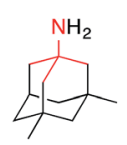

memantine

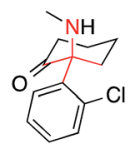

ketamine

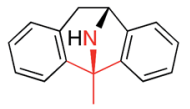

MK-801

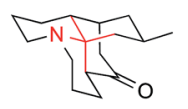

lycopodine

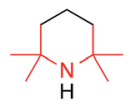

TMP

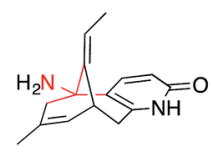

huperzine A

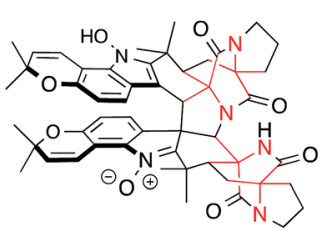

stephacidin B

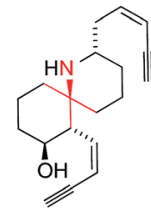

HTX 283A

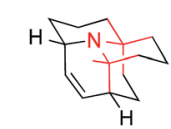

porantherine
Fig. 1 Alkaloids and synthetic molecules that contain the ATA motif 
this review and in keeping with the literature, we define an ATA as a nitrogen atom bound to a $\mathrm{sp}^{3}$-hybridized carbon that bears three additional carbon-carbon bonds. The nitrogen itself can be $\mathrm{sp}^{3}$-hybridized as part of a primary, secondary and tertiary amine. Broadening our definition, it can also be $\mathrm{sp}^{2}$ - or sphybridized, e.g. in an amide or isonitrile. The tetrasubstituted carbon from which the $\mathrm{C}, \mathrm{N}$-bond branches out is often stereogenic, which makes ATAs particularly interesting from a synthetic point of view. Our definition puts emphasis on this particular $\mathrm{C}, \mathrm{N}-$ bond and avoids the confusion that is often associated with the term 'quaternary stereocenter', which, strictly speaking, refers only to a carbon atom surrounded by four other carbons.

Fig. 1 shows some alkaloids and drugs with alkaloid-like properties that illustrate our definition and demonstrate that the nitrogen in ATAs (highlighted in red) can be substituted to various degrees. Memantine and huperzine A contain primary ATAs, whereas ketamine, MK-801 and histrionicotoxin 283A (HTX

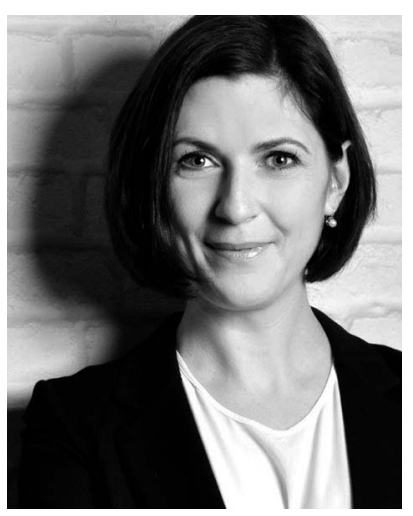

Anastasia Hager studied chemistry in Würzburg, conducting her Diploma thesis on natural product isolation and synthesis with Prof. G. Bringmann. After joining Prof. D. Trauner's research group for an internship at UC Berkeley, she moved to Munich for her PhD work that was centered on the development of biomimetic syntheses of complex natural products implementing cascade reactions.

From 2013 until 2015 she was a postdoctoral fellow with Prof. D. Fiedler at Princeton University developing novel chemical tools to allow for investigations of inositol pyrophosphate signaling pathway. She now works as a laboratory head in process research at Bayer in Wuppertal.

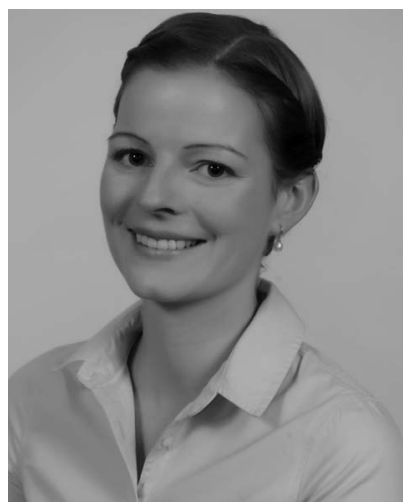

Nina Vrielink was born in 1987 in Nordhorn, Germany. She studied chemistry and biochemistry at LMU. During her Master's studies in chemistry in Munich, she joined the group of Prof. E. Tate at the Imperial College London for a research internship. In 2012, she joined the laboratory of Prof. D. Trauner for her Master's thesis and returned to conduct her Ph.D. studies starting in 2013. In 2014, she visited the laboratory of Prof. B. M. Stoltz for three months. She is currently pursuing natural product synthesis of $\alpha$ tertiary-amine-containing alkaloids, supported by a scholarship from the Deutsche Telekom Foundation.
283A) feature secondary ATAs, and lycopodine is representative of molecules containing a tertiary ATA. 2,2,6,6-Tetramethylpiperidine (TMP) and the alkaloid porantherine are examples for molecules featuring a twofold ATA. The dimeric alkaloid stephacidin B contains no fewer than four ATAs. Notably, the $\alpha$ carbons are stereogenic in the majority of these compounds.

In this review, we wish to provide a brief survey of synthetic methods used to install the ATA motif and discuss their application in the total synthesis of alkaloids. The syntheses included here have been selected based on their historical significance, the intriguing structure of their target molecule, and the elegance and efficiency of the method used. The order of their presentation is somewhat arbitrary, mixing biosynthetic and taxonomic categories (such as Lycopodium alkaloids), with purely structural ones (such as quinolizidine alkaloids). Generally, we have aimed to proceed from simpler target molecules to more complex ones. While our review is by no means comprehensive, we hope to feature the most instructive examples for the

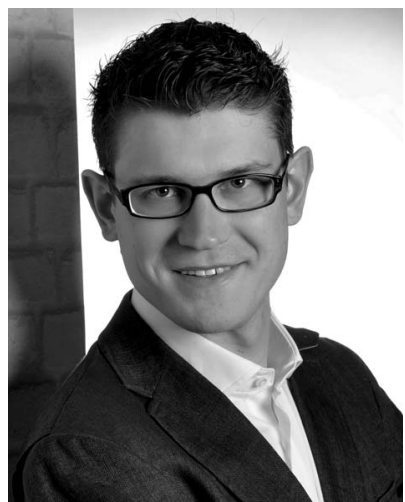

Dominik Hager studied chemistry in Würzburg, and in 2007, he joined the group of Prof. K. P. C. Vollhardt at UC Berkeley as a visiting researcher. Dominik performed his Diploma studies with Prof. G. Bringmann, working on the development of an axial-chirality transfer concept. For his graduate work he joined the laboratory of Prof. D. Trauner at the LMU. His research projects were centered on natural product synthesis. Between 2013 and 2015 he was a postdoctoral researcher with Prof. D. W. C. MacMillan at Princeton University developing new photochemical protocols. Currently, Dominik works as laboratory head for Bayer Cropscience $A G$.

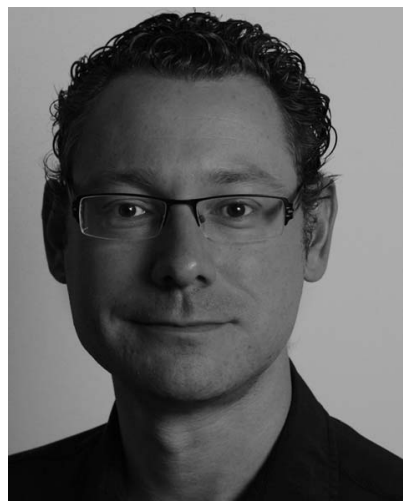

Julien Lefranc was born in 1984 in Marseille, France. He studied chemistry at the Université de la Mediterranée, Marseille, and then moved to the Ecole Nationale Supérieure de Chimie de Montpellier in 2006. In 2008, he joined the group of Prof. J. Clayden at the University of Manchester where he obtained his PhD working on the syntheses of $\alpha$-tertiary amines. In 2012, Julien joined the group of Prof. D. Trauner as a postdoctoral researcher where he worked on Natural Product synthesis. Since 2014, Julien has been working as a laboratory leader in Medicinal Chemistry for Bayer Healthcare in Berlin. 
establishment of ATAs and thus provide inspiration and valuable lessons for future work. We also hope that this review will benefit the design of synthetic pathways toward drugs and synthetic building blocks that contain $\alpha$-tertiary amines.

\section{Methods used for the installation of $\alpha$-tertiary amines}

Many approaches toward the installation of ATAs have been developed but only a relatively small subset of these has proven popular in alkaloid total synthesis. Here, we provide a brief survey of these methods, discussing them in general terms. We classify them according to the bond that is formed in the key step and the electronic nature of the nitrogen and carbon, respectively. However, it should be noted that not all of the syntheses discussed in this review fall into this simplified organizational scheme.

\subsection{A C,C-bond is formed in the step that generates the ATA}

- The $\alpha$-carbon is electrophilic. Some of the most commonly encountered methods involve the addition of carbon nucleophiles to activated imines and iminium ions (Scheme 1). They include Mannich reactions, Strecker reactions, aza-Prins reactions and the 1,2-addition of organometallic reagents to $\mathrm{C}, \mathrm{N}$ double bonds. $\mathrm{N}$-Acyliminium ions are particularly powerful electrophiles in reactions of this type. A variant of the Heck olefination that involves enamines also falls into this category.

- The $\alpha$-carbon is nucleophilic. In an Umpolung of the above situation, the $\alpha$-carbon can also serve as a nucleophile (Scheme 2). For instance, the alkylation of branched nitroalkanes or of deprotonated amino acid derivatives can be used to establish ATAs. Insertions of carbons into nucleophilic C,H-bonds next to a C,N-bond are a member of this general category as well.

- Pericyclic reactions. Pericyclic reactions that form a C,Cbond in the key step have occasionally been employed to form

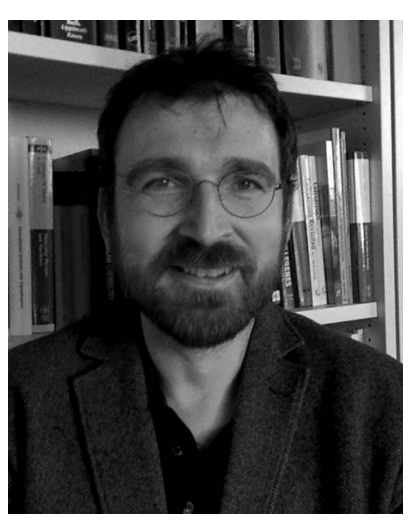

Dirk Trauner was born and grew up in Linz, Austria. After studying biology and biochemistry at the University of Vienna, he joined Professor Johann Mulzer's group at the Free University of Berlin to pursue natural product synthesis. Subsequently, he became a postdoctoral fellow with Professor Samuel J. Danishefsky at the Memorial Sloan-Kettering Cancer Center in New York City. In 2000, Dirk joined the University of California, Berkeley, where he became an Associate Professor of chemistry (with tenure). In the summer of 2008, he moved to the University of Munich, where he currently resides as a Professor of Chemistry and Chemical Biology. His research interests range from organic synthesis and natural product chemistry to chemical neurobiology, optogenetics and photopharmacology.

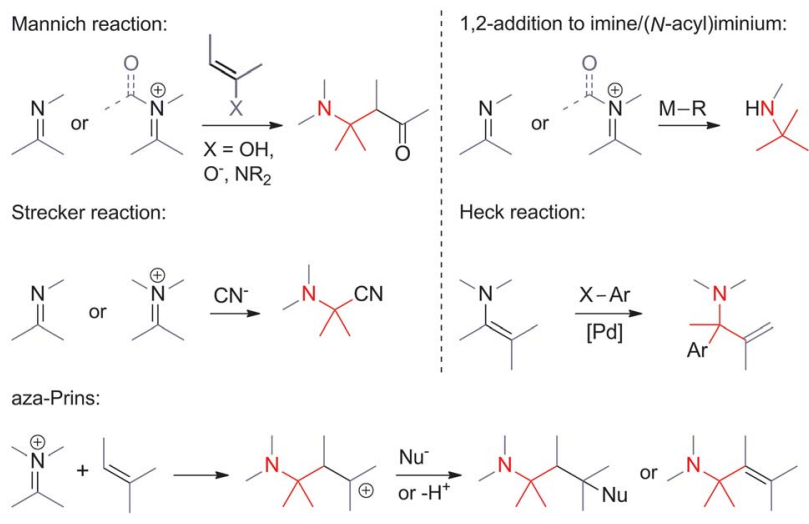

Scheme 1 C,C-bond formation involving electrophilic $\alpha$-carbons.

ATAs (Scheme 3). They include Diels-Alder cycloadditions involving 1 -aminodienes or 2-azadienes, as well as certain amino dienophiles, [2+2] cycloadditions, and 1,3-dipolar cycloadditions involving nitrones and azomethine imines.

- Radical reactions. Radical reactions establishing ATAs are relatively rare, but not unprecedented (Scheme 4). 5-endo-Trig and 6-endo-trig cyclizations as well as radical transfer allylations belong to this category.

\subsection{A C,N-bond is formed in the step that generates the ATA}

- The nitrogen is electrophilic. Rearrangements that involve electron-deficient nitrogen atoms are often encountered in the formation of ATAs (Scheme 5).

They include the Curtius, Schmidt, Hofmann, Beckmann and Stieglitz rearrangements. ${ }^{5}$ Often, these reactions can be classified as $[1,2]$ sigmatropic rearrangements. Related

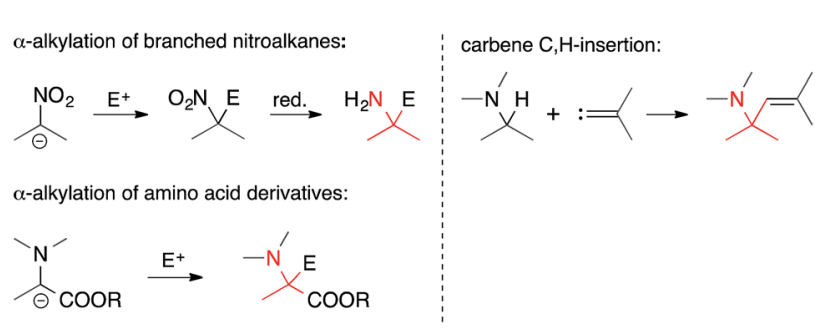

Scheme 2 C,C-bond formation involving nucleophilic $\alpha$-carbons.
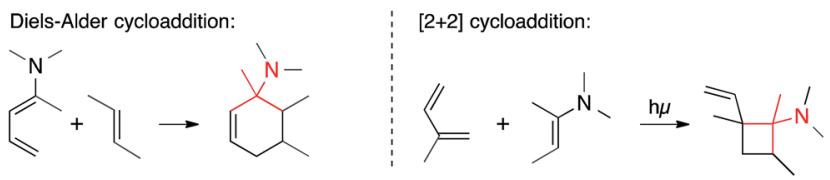

1,3-dipolar cycloaddition:

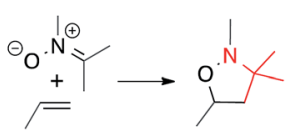

Scheme 3 C,C-bond formation involving pericyclic reactions. 


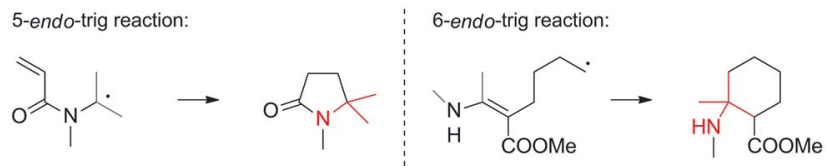

radical allylation:<smiles>C=CC[13CH2]CC[13CH2]C</smiles>

Scheme 4 C,C-bond formation via radical reactions.

nucleophilic substitutions involving $N$-haloamines have been used as well. An electron-deficient nitrogen atom also plays a role in the insertion of nitrenes into $\mathrm{C}, \mathrm{H}$-bonds.

- The nitrogen is nucleophilic. The formation of ATAs through nucleophilic additions or substitutions involving nitrogen is fairly common (Scheme 6). The classical Michael addition falls into this category, as do $\mathrm{S}_{\mathrm{N}} 2^{\prime}$ reactions and haloaminations. For obvious reasons, $\mathrm{S}_{\mathrm{N}} 2$ reactions are rare and mostly confined to intramolecular cases. Carbocations that react with a nucleophilic nitrogen occur in the aza-Prins reaction and the Ritter reaction. Oxidative dearomatizations have also been used in a few cases to establish ATAs.

- Pericyclic reactions. Pericyclic reactions in which a $\mathrm{C}, \mathrm{N}-$ bond is formed provide powerful means to establish ATAs (Scheme 7). Overman, Kazmaier-Claisen and [3,3] sigmatropic rearrangements of allylic isocyanides belong to this category. Divinyl cyclopropane rearrangements have also been used to establish ATAs. ${ }^{5}$

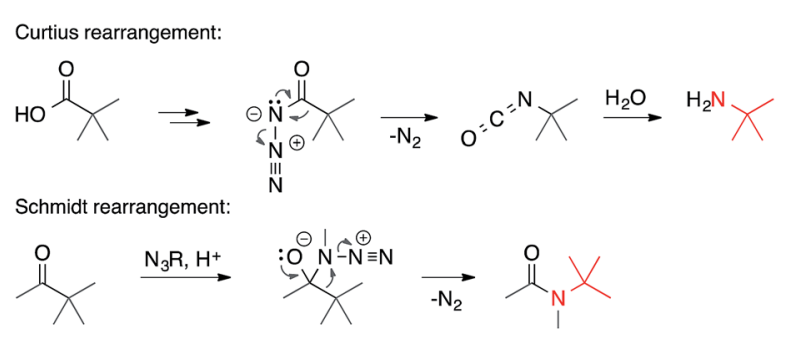

Hofmann rearrangement:

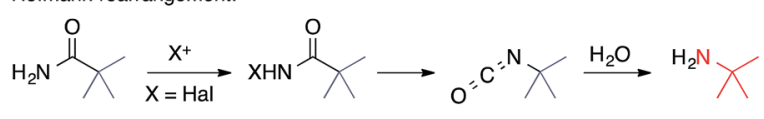

Beckmann rearrangement:

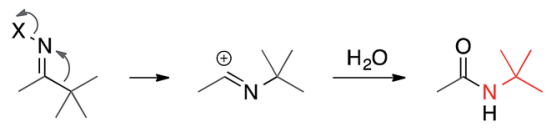

Stieglitz rearrangement:

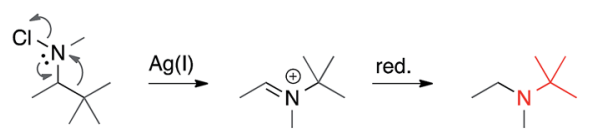

Nitrene $\mathrm{C}, \mathrm{H}$-insertion:

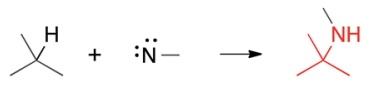

Scheme 5 C,N-bond formation involving electrophilic nitrogens.

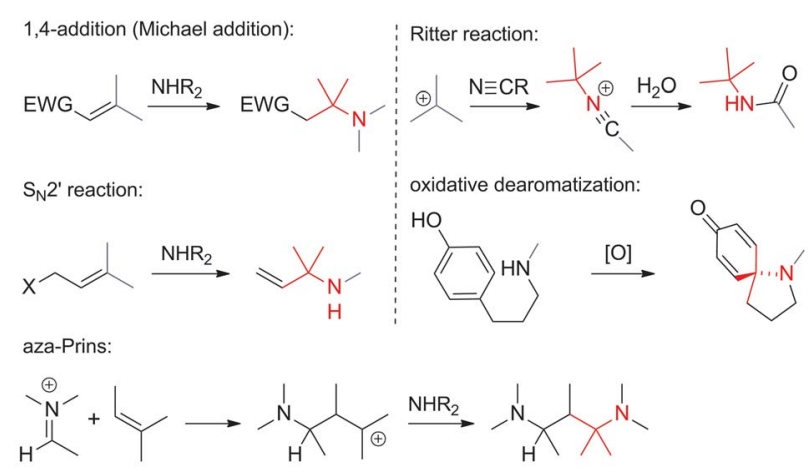

Scheme 6 C,N-bond formation involving nucleophilic nitrogens. $E W G=$ electron-withdrawing group.
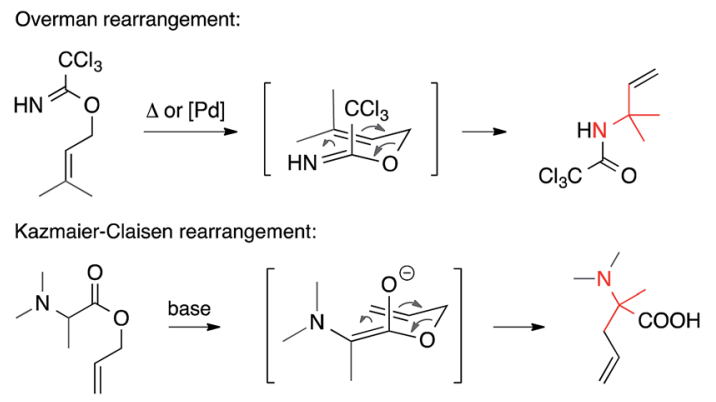

Allylic cyanate to isocyanate rearrangement:
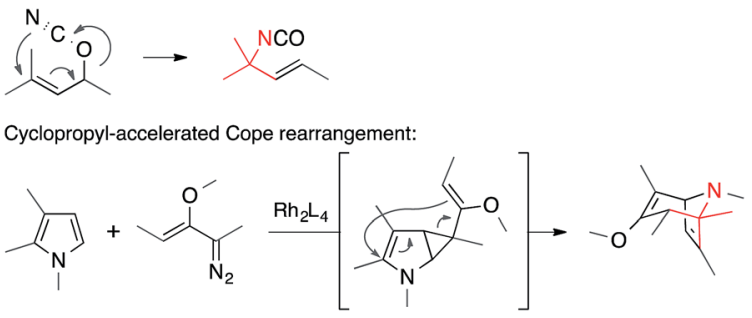

Scheme 7 C,N-bond formation involving pericyclic reactions.

Many more methods have emerged in recent years that can be used to create ATAs, such as reactions proceeding via $\mathrm{C}, \mathrm{H}$ activation ${ }^{9}$ and hydroaminations. ${ }^{\mathbf{1 0}}$ Since they have not yet been employed in the total synthesis of alkaloids, they are not featured in this review. Other methods, such as the Mannich reaction, Curtius rearrangement and Michael reaction, have proven to be so popular in the total synthesis of alkaloids that we cannot include all instances where they have been employed in this review.

\section{Homotropane alkaloids}

One of the first applications of Mannich reactions in the construction of ATAs occurred during the synthesis of certain homotropane alkaloids. Three representatives, euphococcinine, $N$-methyl euphococcine and adaline, feature an ATA in the bridgehead position of a bicyclic framework (Fig. 2). These simple natural products are excreted by lady beetles (coccinellids) when threatened. ${ }^{11,12}$ 

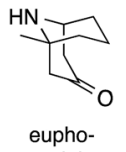
coccinine

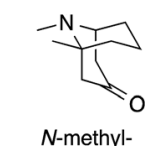

euphococcinine

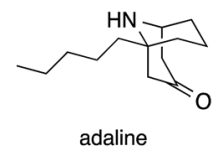

Fig. 2 Representative ATA-containing homotropane alkaloids.

a) Alder's synthesis of ( \pm )- $N$-methyl-euphococcinine

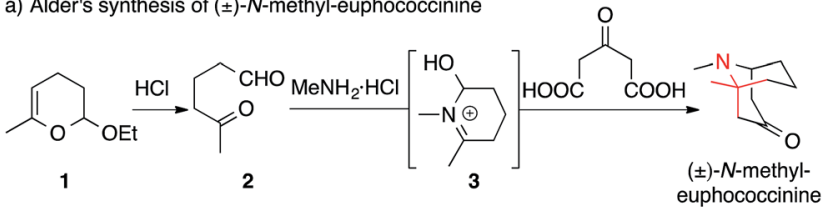

b) Davis' synthesis of (-)-euphococcinine and (-)-adaline

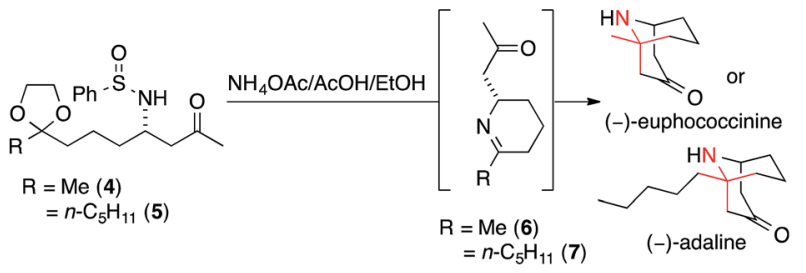

Scheme 8 Homotropane alkaloid syntheses by Alder (1959) and Davis (2010). Ac = acetyl.

In 1959, Alder synthesized $N$-methyl-euphococcinine using a protocol analogous to the famous tropinone syntheses of Robinson $^{13,14}$ and Schöpf ${ }^{15}$ (Scheme 8a). ${ }^{16}$ Dehydropyrane 1 was converted into ketoaldehyde 2 , which was then transformed into $\mathrm{N}$-methyl-euphococcinine in a one-pot process (via iminium-intermediate 3). ${ }^{17-19}$ A similar strategy was later adopted to synthesize the structurally related alkaloid adaline. ${ }^{20}$

Throughout the years, this biomimetic Mannich strategy was adopted in other syntheses of euphococcinine and adaline. ${ }^{21-23}$ Alternative approaches involved a 1,3-dipolar cycloaddition, ${ }^{24}$ addition to an $\mathrm{N}$-acyliminium ion, ${ }^{25}$ Michael addition ${ }^{26,27}$ and allylic rearrangement of a cyanate to an isocyanate. ${ }^{28,29}$

In 2010, Davis published a biomimetic synthesis of (-)-euphococcinine and (-)-adaline in enantiopure form (Scheme $8 \mathrm{~b}) .{ }^{30}$ The key steps of these syntheses involved the stereoselective formation of piperideine 6 and 7 from the enantiomerically pure $N$-sulfinyl aminoketones $\mathbf{4}$ and $\mathbf{5}$, respectively. ${ }^{31}$ An ensuing intramolecular Mannich reaction afforded the azabicyclononane natural products.

\section{Histrionicotoxins}

In 1971, Daly isolated six different alkaloids, termed histrionicotoxins (HTXs), from skin extracts of the Colombian poison arrow frog Dendrobates histrionicus (Fig. 3). ${ }^{32,33}$ They all contain a unique spirocyclic piperidine core and differ mostly in the length and the degree of saturation of the two side chains. Several histrionicotoxins were identified as inhibitors of nicotinic acetylcholine receptors, ${ }^{34-38}$ which, together with their attractive structures, prompted significant attention from the synthetic community. ${ }^{39}$ The low natural abundance of these

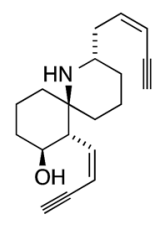

HTX 283A

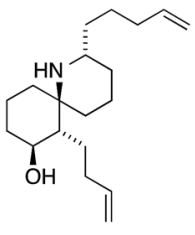

oHTX

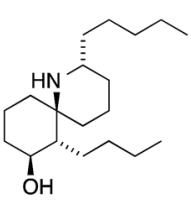

pHTX
Fig. 3 The major members of the histrionicotoxin family.

alkaloids and the fact that the frogs do not secrete HTXs in captivity made an efficient synthetic approach all the more desirable.

The first total synthesis of histrionicotoxin alkaloids was reported by Kishi in 1975 (Scheme 9a). ${ }^{\mathbf{4 0 - 4 2}}$ His synthesis of octahydrohistrionicotoxin (oHTX) utilized an intramolecular acid-catalyzed aza-Michael addition to set the ATA. Amide 8 was converted to a $2: 1$ mixture of epimeric spiroketolactams 9 and 10. It was possible to transform 9 into the desired diastereoisomer 10 upon treatment with sodium methoxide.

In the same year, Corey reported the first racemic synthesis of perhydrohistrionicotoxin (pHTX), a synthetic HTX derivative (Scheme 9b). ${ }^{43}$ For the installation of the ATA, Corey used a Beckmann rearrangement that expanded spirocyclic oxime $\mathbf{1 1}$ to spirocyclic amide 12. Several other groups subsequently employed related ring expansion strategies. ${ }^{\mathbf{4 4 - 4 8}}$

Stork reported a synthesis of HTX 283A using a Hofmann rearrangement to set the ATA (Scheme 10a). ${ }^{49}$ During this transformation, amide $\mathbf{1 3}$ was oxidized with bis(trifluoroacetoxy)iodobenzene to promote the alkyl migration, giving amine $\mathbf{1 4}$ after decarboxylation. More recently, Fukuyama reported an asymmetric synthesis of HTX 283A (Scheme 10b). ${ }^{50,51}$ The key carboxylic acid 15 underwent a stereospecific Curtius rearrangement to yield bicyclo[5.4.0]undecane 16, which could be converted into HTX 283A.

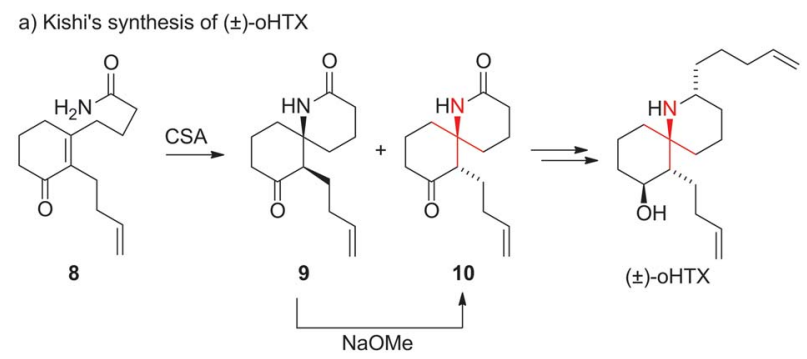

b) Corey's synthesis of ( \pm )-pHTX

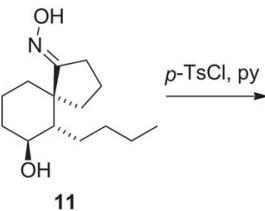

11

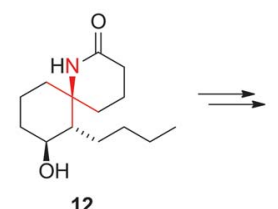

12

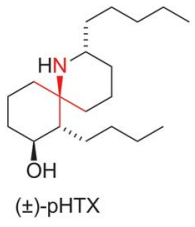

( \pm )-pHTX
Scheme 9 Early synthetic approaches to HTXs by Kishi (1975) and Corey (1975). CSA = camphorsulfonic acid, HTX = histrionicotoxin, $p$ $\mathrm{TsCl}=$ para-toluenesulfonyl chloride. 
a) Stork's synthesis of ( \pm )-HTX $283 \mathrm{~A}$<smiles>COCC1C2CCCC1C2(CCCC(Br)C/C=C\[IH]I)C(N)=O</smiles>

13

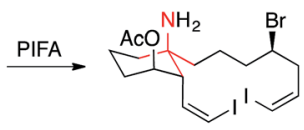

14

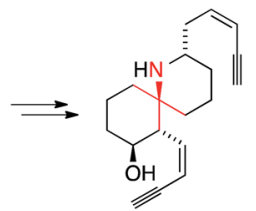

(士)-HTX 283A

b) Fukuyama's synthesis of (-)-HTX $283 \mathrm{~A}$

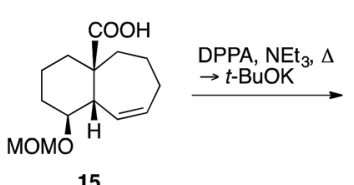

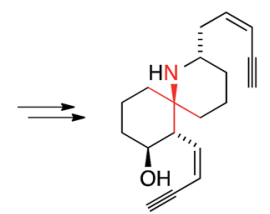

(-)-HTX 283A
Scheme 10 HTX 283A syntheses by Stork (1990) and Fukuyama (2011). $\mathrm{HTX}=$ histrionicotoxin, $\mathrm{Ac}=$ acetyl, Boc $=$ tert-butyloxycarbonyl, $t-\mathrm{Bu}$ = tert-butyl, $\mathrm{DPPA}=$ diphenylphosphoryl azide, $\mathrm{MOM}=$ methoxymethyl, PIFA = (bis(trifluoroacetoxy)iodo)benzene.

Stockman and Fuchs' synthesis of ( \pm )-HTX 283A

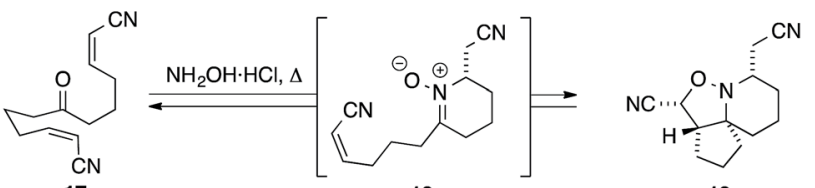

17

18

19

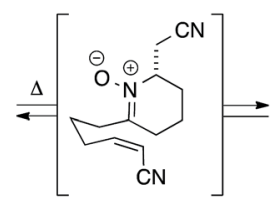

20

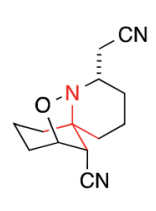

21

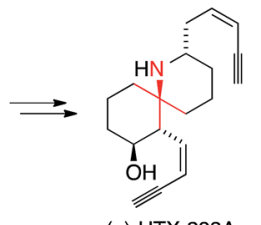

( \pm )-HTX 283A

Scheme 11 HTX 283A synthesis by Stockman and Fuchs (2006). HTX $=$ histrionicotoxin.

A particularly short and efficient synthesis of racemic HTX 283A was reported in 2006 by Stockman and Fuchs (Scheme 11)..$^{52}$ In their approach, the key intermediate 21 was formed from the symmetric ketodinitrile $\mathbf{1 7}$ using a cascade reaction. Ketone 17 was condensed with hydroxylamine yielding nitrone 18 after intramolecular Michael addition. Subsequent intramolecular [3+2] cycloaddition afforded isoxazolidine 19. Following its isolation, 19 was converted to its more stable regioisomer $\mathbf{2 1}$ through a retro-[3+2]/[3+2] cycloaddition process (via intermediate 20). This so-called 'Holmes dinitrile' (21) had been previously converted into HTX 283A..$^{53,54}$

Additional strategies to set the ATA in the histrionicotoxins involved Michael reactions, ${ }^{41,55,56}$ Tsuji-Trost amination, ${ }^{57,58}$ iodoetherification, ${ }^{59-61}$ oxidative dearomatizations, ${ }^{62}$ Henry reactions, ${ }^{63}$ diastereoselective aziridation, ${ }^{64}$ 1,2-carbon migration of hydroxyimines, ${ }^{65}[2,3]$ sigmatropic rearrangements, ${ }^{66}$ $[3,3]$ sigmatropic rearrangements (Kazmaier-Claisen rearrangement) $)^{67}$ and $[2+2]$ cycloadditions. ${ }^{68,69}$

\section{Lycopodium alkaloids}

The genus Lycopodium comprises more than 200 species of moss-like plants that have been used in traditional Chinese medicine for centuries. ${ }^{70}$ They have yielded a variety of ATAcontaining alkaloids, some of which are featured in Fig. 4. Lycopodine, the first member of the family described in the literature, ${ }^{71}$ has proven to be a particularly attractive target for chemical synthesis. In 1968, only seven years after its structural elucidation, Stork ${ }^{72}$ and Ayer ${ }^{73,74}$ simultaneously published the first syntheses of this natural product. Ayer established the ATA using an intermolecular addition of a racemic Grignard reagent to tricyclic, $C_{\mathrm{v}}$-symmetric iminium ion 22 to obtain 23 (Scheme 12a).

Stork's synthesis involved a Pictet-Spengler type reaction, furnishing tetracyclic amide $25(24 \rightarrow 25$, Scheme 12 b). A similar cyclization approach was also utilized almost 30 years later in Padwa's asymmetric synthesis of lycopodine (not shown). ${ }^{75}$ Wiesner published a synthesis of 12-epi-lycopodine and annotinine using an innovative photochemical strategy (Scheme 12c). ${ }^{76-79}$ This work involved the conversion of vinylogous imide 26 into exo-methylene cyclobutane 27 via a photochemical $[2+2]$ cycloaddition of allene.

Heathcock established one of the most elegant and influential routes to lycopodine in 1982 (Scheme 13a). ${ }^{80-82}$ In a remarkable sequence, intermediate $\mathbf{2 8}$ underwent deprotection, condensation and intramolecular Mannich reaction to yield secondary amine 30, presumably via iminium ion 29 . The installation of the $\alpha$-tertiary amine and the formation of two out of four rings thus occurred in a single step, mimicking the proposed biosynthesis of this natural product. Subsequent optimization led to the shortest synthesis of lycopodine to date,

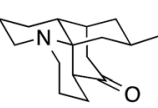

lycopodine

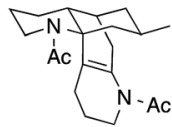

$\mathrm{N}$-acetylflabellidine

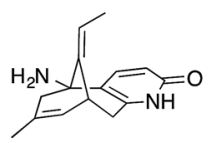

huperzine A

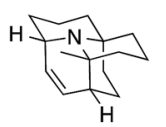

porantherine
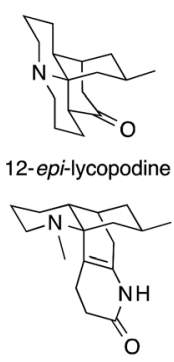

$\alpha$-obscurine

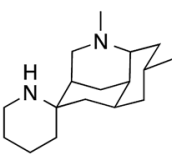

nankakurine $\mathrm{A}$

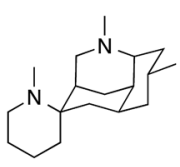

nankakurine $B$

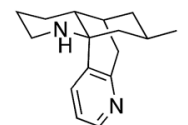

lycodine

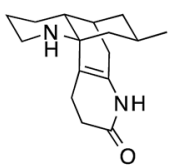

des- $N$-methyl$\alpha$-obscurine

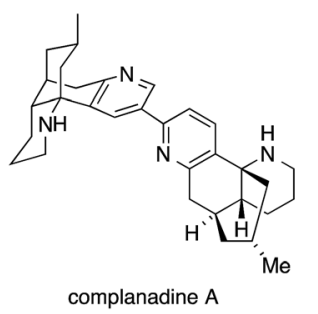

Fig. 4 Representative Lycopodium alkaloids 
a) Ayer's synthesis of $( \pm)$-lycopodine

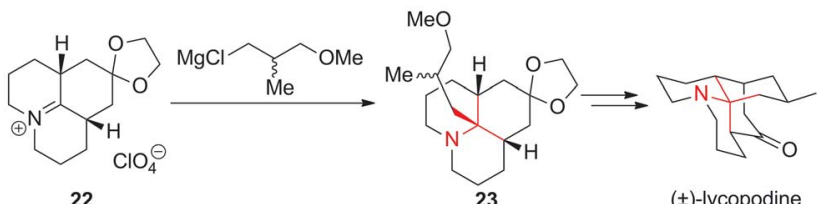

b) Stork's synthesis of ( \pm )-lycopodine

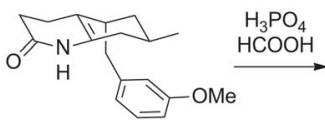

24

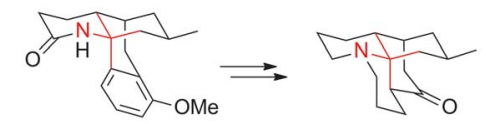

25

(士)-lycopodine c) Wiesner's synthesis of ( \pm )-12-epi-lycopodine

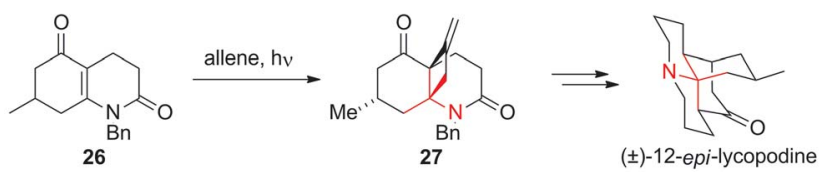

Scheme 12 Representative lycopodine syntheses by Ayer (1968), Stork (1968) and Wiesner (1967). Bn = benzyl.

consisting of only eight steps..$^{82}$ Using a similar sequence, lycodine and lycodoline were prepared as well. ${ }^{82}$

Variations of Heathcock's strategy have been used in other synthetic approaches toward Lycopodium alkaloids, e.g. in syntheses of clavolonine by Evans $(2005)^{84}$ and Fujioka (2011). ${ }^{83}$

One drawback of intramolecular Mannich reactions, however, is the need to simultaneously form an iminium ion and an enol. Thus, long reaction times of up to 18 days were needed. ${ }^{82}$ Recently, this problem was solved in an elegant way by Carter (Scheme 13b). ${ }^{85,86}$ Using an aza-Wittig approach, Carter was able to prepare and isolate the TBS-enol ether imine $\mathbf{3 1}$. Treatment of $\mathbf{3 1}$ with zinc triflate furnished the ATA and concomitantly resulted in the rearrangement of the sulfinyl residue yielding lycopodine precursor 32 .

In 1985, Kraus published a route towards lycopodine that was based on the formation of a bridgehead olefin (Scheme 14a). ${ }^{87}$ Tertiary alkyl bromide 33 was treated with DBU and 3-

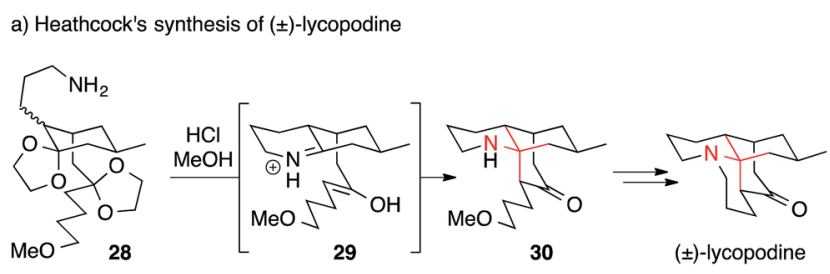

b) Carter's synthesis of (-)-lycopodine

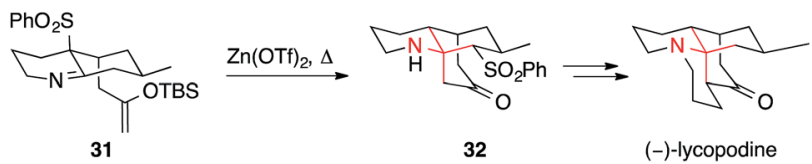

Scheme 13 Lycopodine syntheses by Heathcock (1982) and Carter (2008). OTf = trifluoromethanesulfonate, TBS $=$ tert-butyldimethylsilyl. a) Kraus' synthesis of $( \pm)$-lycopodine

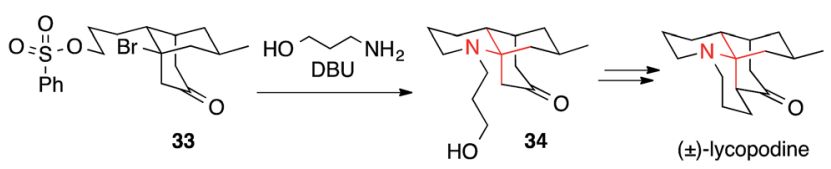

b) Grieco's synthesis of $( \pm)$-lycopodine

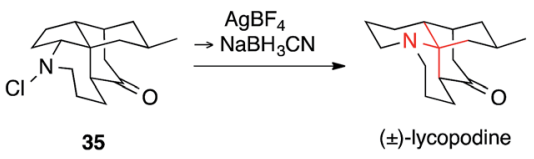

Scheme 14 Lycopodine syntheses by Kraus (1985) and Grieco (1998). $\mathrm{DBU}=1,8$-diazabicyclo[5.4.0]undec-7-ene.

amino-1-propanol to install amino ketone 34, which could be further transformed into the natural product in two additional steps using Heathcock's protocol. An equally unusual approach was reported by Grieco, who employed a Stieglitz rearrangement (Scheme 14b). ${ }^{88}$ To effect the reaction, $N$-chloroamine 35 was treated with silver tetrafluoroborate followed by cyanoborohydride. Many other syntheses of lycopodine have been accomplished utilizing different strategies, such as Michael additions, for the assembly of the ATA. ${ }^{89-91}$

Members of the lycodine class of natural products feature an ATA and a pyridine or pyridone moiety. The parent compound, lycodine,${ }^{92}$ was first isolated from $L$. annotinum in $1958 .{ }^{93}$ Apart Schumann's syntheses of $( \pm)$-lycodine, $( \pm)$ - $\alpha$-obscurine, $( \pm)$ - $N$-acetylflabellidine and
Sarpong's synthesis of $(+)$-complanadine A
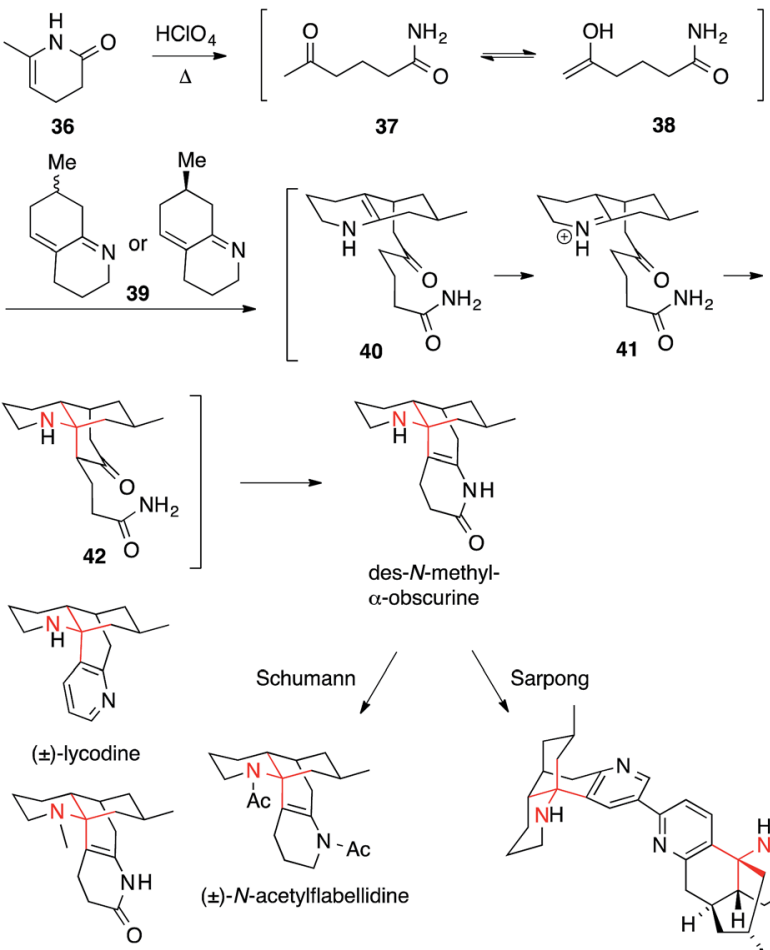

( \pm )- $\alpha$-obscurine

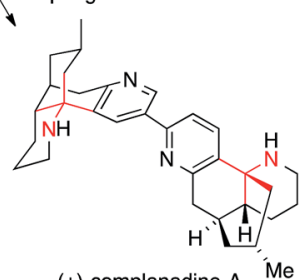

Scheme 15 Synthesis of various Lycopodium alkaloids by Schumann (1982) and Sarpong (2010). Ac = acetyl. 
a) Tsukano's and Hirama's synthesis of $( \pm)$-lycodine

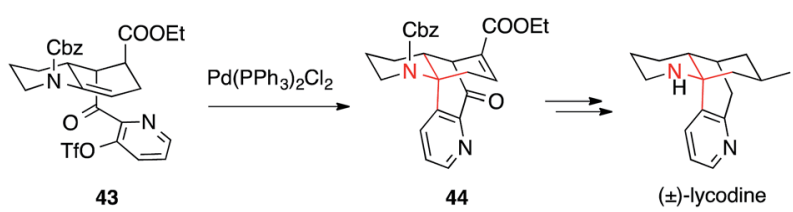

b) Takayama's synthesis of (+)-flabellidine and (-)-lycodine
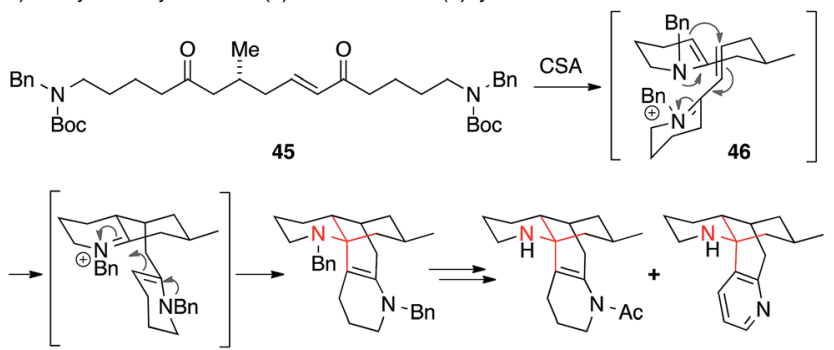

47
48

(1:1 mixture of diastereomers) (+)-flabellidine (-)-lycodine

Scheme 16 Syntheses of various Lycopodium alkaloids by Tsukano (2010) and Takayama (2014). Cbz = benzyloxycarbonyl, CSA = camphorsulfonic acid, Boc = tert-butyloxycarbonyl, $\mathrm{Bn}=$ benzyl, OTf = trifluoromethanesulfonate.

from the Heathcock synthesis mentioned above, ${ }^{82}$ several additional syntheses of lycodine have been achieved to date. ${ }^{94-97}$

Schumann used a classical Mannich strategy to access racemic lycodine, $\alpha$-obscurine and $N$-acetylflabellidine (Scheme 15). ${ }^{98-100}$

The mechanism of the key double Mannich reaction cascade was further explored almost 30 years later by Sarpong. ${ }^{94}$ He used the same cascade as an opening sequence in an asymmetric synthesis of enantiomerically pure (+)-complanadine A, a lycodine dimer, which was shown to enhance expression of nerve growth factor in human cells. ${ }^{101}$ It was found that cyclic enamide 36 opens to ketone $\mathbf{3 7}$ or enol 38 under acidic conditions, which adds to the unsaturated bicyclic imine 39. Protonation of the resulting enamine $\mathbf{4 0}$ triggers a second, intramolecular Mannich reaction to afford tricycle 42 via the iminium ion $\mathbf{4 1}$. Finally, an intramolecular enamide formation furnished tetracyclic des- $N$-methyl- $\alpha$-obscurine, containing the entire lycodine framework.

In an unusual approach, Tsukano and Hirama applied an intramolecular palladium-mediated Heck reaction between

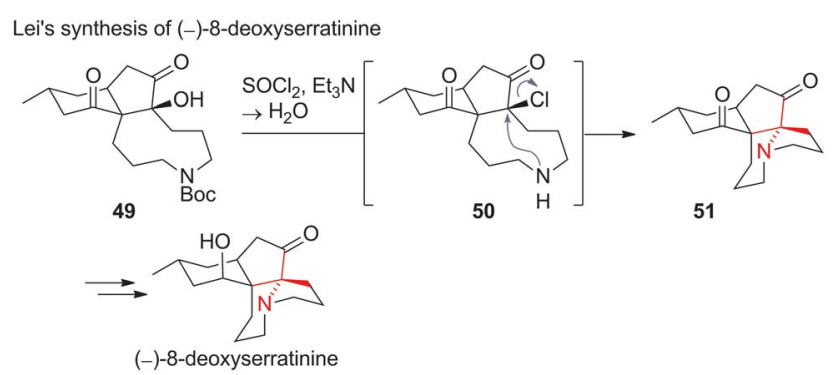

Scheme 17 Lei's synthesis of (-)-8-deoxyserratinine (2014). Boc $=$ tert-butyloxycarbonyl.
Kozikowski's synthesis of ( \pm )-huperzine A

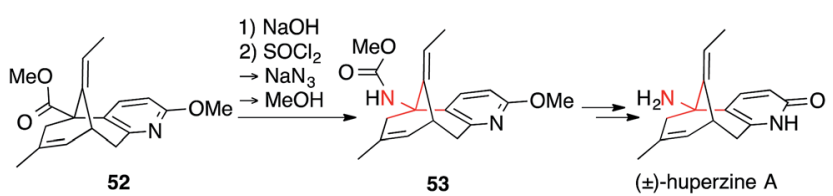

Scheme 18 Huperzine A synthesis by Kozikowski (1989).

enecarbamate and pyridine triflate $\mathbf{4 3}$ to form the ATA, which yielded lycodine precursor 44 (Scheme 16a)..$^{95}$

Recently, another very short synthesis of (-)-lycodine as well as the closely related (+)-flabellidine was accomplished by Takayama (Scheme 16b). ${ }^{97}$ Starting from a linear precursor $\mathbf{4 5}$, he was able to assemble the whole tetracyclic skeleton 48 of both alkaloids in a cascade reaction involving a double condensation (45 $\rightarrow$ 46), a conjugate addition $(46 \rightarrow 47)$ followed by a Mannich reaction $(47 \rightarrow 48)$. In addition, Shair published an approach towards several members of the 7membered-ring-containing Lycopodium alkaloids using a transannular Mannich reaction (not shown). ${ }^{\mathbf{1 0 2 , 1 0 3}}$

One of the rare cases of a $\mathrm{S}_{\mathrm{N}} 2$ reaction in ATA formation can be found in Lei's recent synthesis of (-)-8-deoxyserratinine (Scheme 17). ${ }^{\mathbf{1 0 4}}$ Tertiary alcohol 49 was converted into chloride 50, which was attacked intramolecularly by the free secondary amine $(\mathbf{5 0} \rightarrow \mathbf{5 1})$. In 2014, Lei extended his strategy to a synthesis of the oxidised congener (-)-serratinine. ${ }^{\mathbf{1 0 5}}$ Other approaches towards 8-deoxyserratinine and related alkaloids include a schmidt rearrangement and an intramolecular epoxide opening. ${ }^{106-108}$

In contrast to the multiple strategies used for the installation of ATAs in the Lycopodium alkaloids mentioned above, the

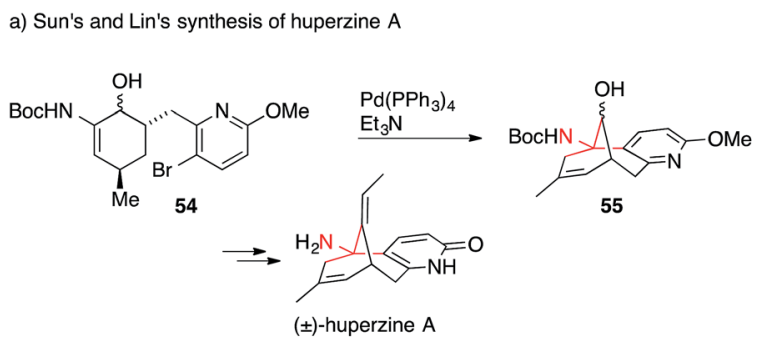

b) White's synthesis of $( \pm)$-huperzine $A$

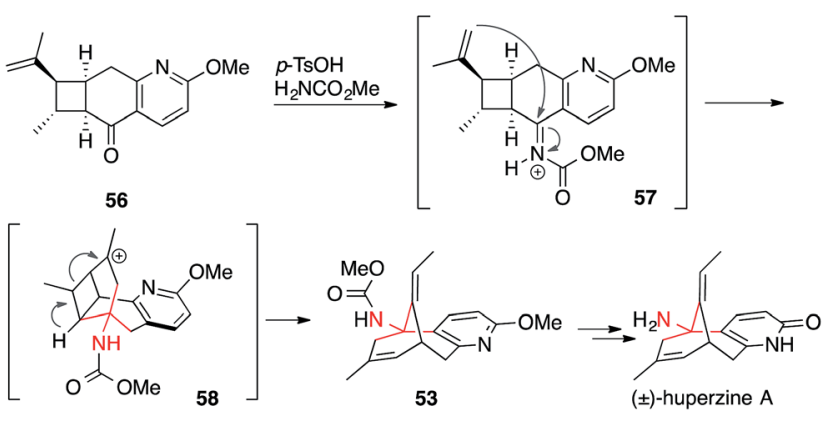

Scheme 19 Huperzine A syntheses by Sun/Lin (2012) and White (2013). Boc $=$ tert-butyloxycarbonyl, $p$-TsCl $=$ para-toluenesulfonic acid. 
a) Overman's synthesis of misassigned nankakurine $A(61)$

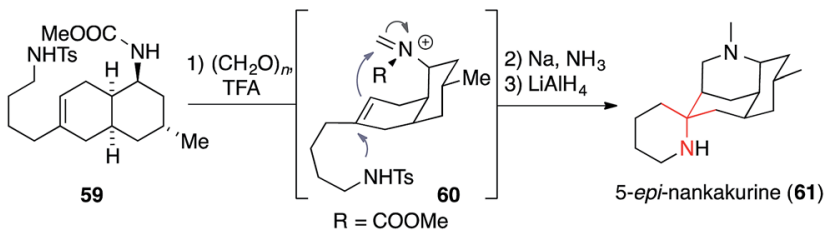

b) Overman's synthesis of (+)-nankakurines $A$ and $B$
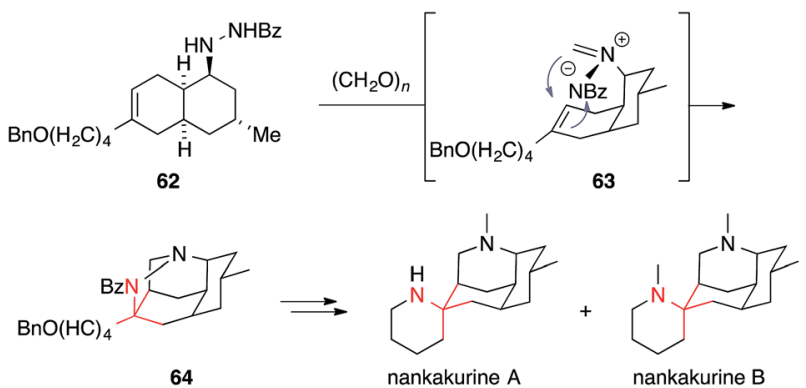

nankakurine $A$

nankakurine $B$

Scheme 20 Overman's syntheses of misassigned nankakurine $A$ (2008) and revised nankakurines A and B (2010). Bn = benzyl, Bz = benzoyl, TFA = trifluoroacetic acid, Ts = para-toluenesulfonyl.

methods used to access the medicinally important acetylcholine esterase inhibitor huperzine A are less diverse. Since the ATA in huperzine A is primary, it can be efficiently installed using a Curtius rearrangement. Indeed, synthetic efforts towards huperzine A were almost exclusively focused on carboxylic acid precursors, such as $\mathbf{5 2 .}{ }^{109-116}$

The first synthesis of huperzine A was published by Kozikowski in 1989 (Scheme 18). ${ }^{109}$ First, he completed the core $\mathbf{5 2}$ wherein the primary amine is replaced by a methyl ester. After saponification, Curtius rearrangement $(52 \rightarrow 53)$ followed by double deprotection provided racemic huperzine $\mathrm{A}$. In the following years, many huperzine A syntheses and several semisyntheses were published. ${ }^{117,118}$ All of them featured a racemic or enantiomerically pure carboxylic acid derivative of precursor 53, keeping the Curtius rearrangement as the key step for the formation of the ATA. ${ }^{109-116}$ These efforts culminated in the recently published large-scale asymmetric synthesis of huperzine A. ${ }^{119}$

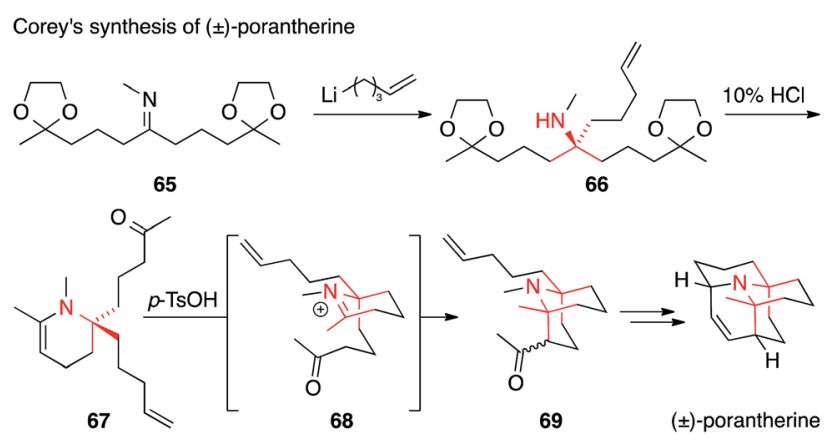

Scheme 21 Porantherine synthesis by Corey (1974). $p-\mathrm{TsOH}=$ paratoluenesulfonic acid.
A few groups, however, have been able to avoid Curtius rearrangements in the synthesis of huperzine A. Sun and Lin accessed the alkaloid using an intramolecular Heck reaction $(\mathbf{5 4} \rightarrow \mathbf{5 5})$ (Scheme 19a), ${ }^{120}$ whereas the White group performed an elegant tandem intramolecular aza-Prins cyclization/cyclobutane fragmentation $(\mathbf{5 6} \rightarrow \mathbf{5 3}$ ) to set the ATA in $\mathbf{5 3}$ (Scheme 19b). ${ }^{121}$

Two Lycopodium alkaloids recently isolated from Lycopodium hamiltonii, viz. the nankakurines A and B, have attracted broad interest in the synthetic community (Fig. 4). ${ }^{122,123}$ So far, two syntheses of these natural products have been reported. In 2008, Overman published an enantioselective synthesis of the misassigned original structure of nankakurine A (61) (Scheme 20a) followed by the syntheses of the reassigned structures of nankakurine A and B in 2010 (Scheme 20b). ${ }^{124,125}$

In the case of 5-epi-nankakurine (61), an aza-Prins reaction $(59 \rightarrow 60)$ was used, which allowed for the direct formation of both piperidine rings in $\mathbf{6 1}$ in one step starting from bicycle 59. ${ }^{124}$ This strategy, however could not be applied for the formation of actual nankakurine A. Its synthesis was accomplished utilizing an intramolecular 1,3-dipolar cycloaddition of an azomethine imine 63, formed in situ via condensation of $\mathbf{6 2}$ with formaldehyde. This reaction provided access to tetracyclic pyrazolidine 64, which, after $\mathrm{SmI}_{2}$ mediated $\mathrm{N}, \mathrm{N}$-bond cleavage, gave rise to nankakurines A and B. ${ }^{125}$ Two years later, Waters reported a racemic synthesis of nankakurines A and B using a Grignard addition to an iminium species derived from luciduline, which is easily accessible by total synthesis (not shown). ${ }^{126}$

Porantherine, the major alkaloid of the poisonous woody shrub Poranthera corymbosa, is structurally similar to the Lycopodium alkaloids, although not a member of the family (Fig. 4). ${ }^{127,128}$ Possessing two tertiary carbons attached to the same amine (twofold ATA), porantherine is a considerable synthetic challenge that has been met only twice thus far. ${ }^{129,130}$ Both syntheses are racemic and based on similar strategies for the assembly of the ATA motif, namely an addition to a ketimine followed by Mannich reaction. Corey published his synthesis of the natural product in 1974 (Scheme 21), ${ }^{129}$ only three years after its isolation. The first ATA was installed through addition of an organolithium compound to imine 65 to form 66, which then cyclized to the corresponding enamine $\mathbf{6 7}$ upon treatment with acid. The formation of the second ATA center through an intramolecular Mannich addition (via iminium ion 68) furnished ketone 69 , which was eventually converted to the natural product.

A second synthesis of porantherine, published by Stevens in 1987, involved the addition of two alkyllithium compounds to an iminoether (not shown). ${ }^{130}$

\section{Hasubanan alkaloids}

The hasubanan alkaloids, isolated from various plant sources, are structurally related to the better-known morphine alkaloids but feature a pyrrolidine ring instead of a piperidine ring. They are comprised of over 40 family members, all of which share the same aza-propellane skeleton (Fig. 5). ${ }^{131}$ 


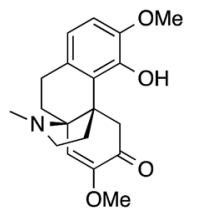

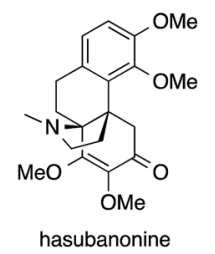

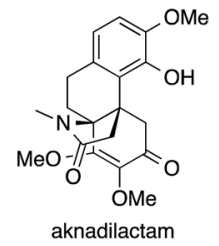

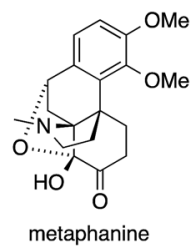

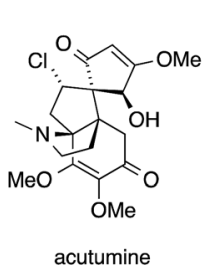

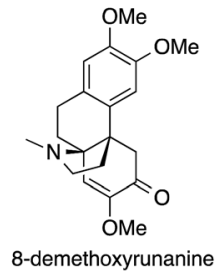

Fig. 5 Representative hasubanan alkaloids.

Although the physiological effects of the hasubanans are of less significance compared to the related morphine alkaloids, their beautiful structures stimulated numerous synthetic studies and several total syntheses have been reported to date. ${ }^{132-146}$

The first successful syntheses of $( \pm)$-cepharamine, ${ }^{132,135}$ $( \pm)$-hasubanonine, ${ }^{134,137} \quad( \pm)$-aknadilactam ${ }^{134}$ and $( \pm)$-metaphanine ${ }^{136,138}$ were published by Inubushi in the 1970s (Scheme 22a). Starting from tricyclic $\beta$-tetralone 70, the ATA was set via a cascade reaction involving an aza-Michael addition $(\mathbf{7 1} \rightarrow \mathbf{7 4})$. Almost 30 years later, Schultz prepared (+)-cepharamine using a Hofmann-type rearrangement to introduce the ATA (not shown). ${ }^{139}$

Recent years have seen revived interest in hasubanans. An elegant method for the installation of the ATA was developed by
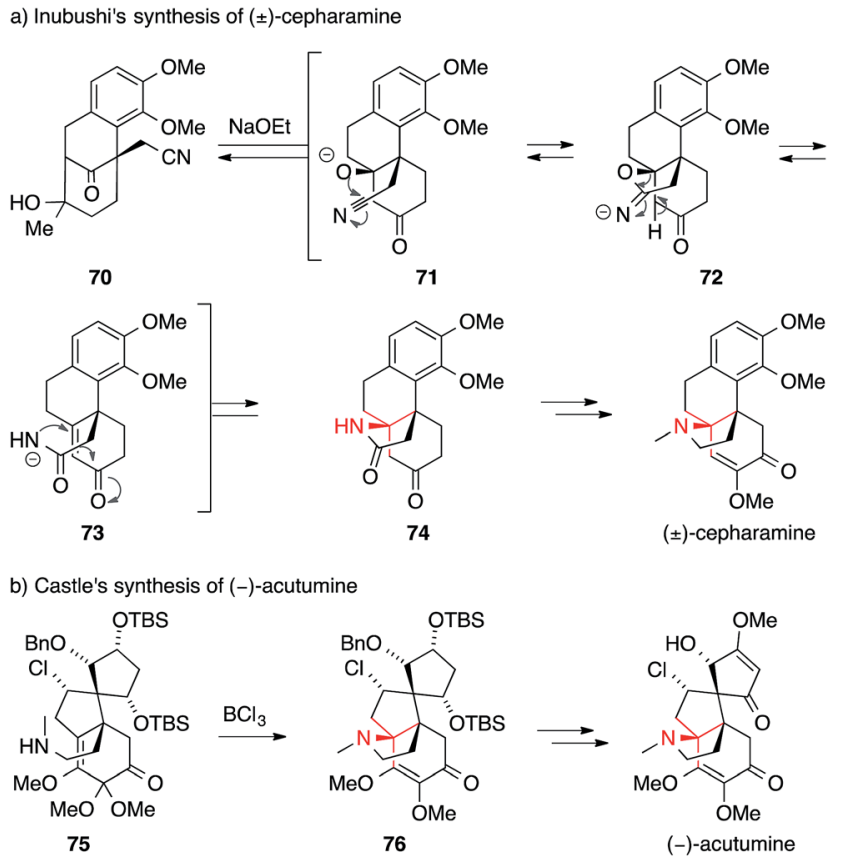

Scheme 22 Syntheses of hasubanan alkaloids by Inubushi (1969) and Castle (2009). Bn = benzyl, TBS = tert-butyldimethylsilyl. a) Reisman's synthesis of (-)-8-demethoxyrunanine

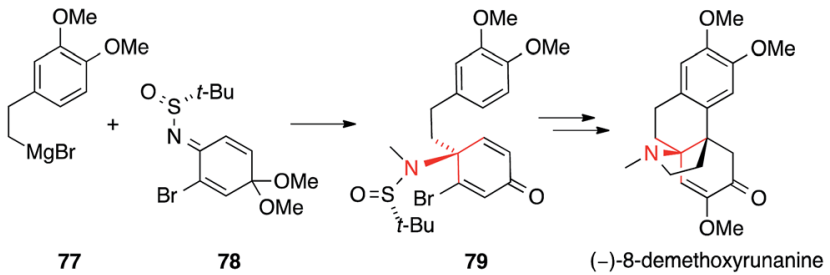

b) Herzon's synthesis of (-)-hasubanonine

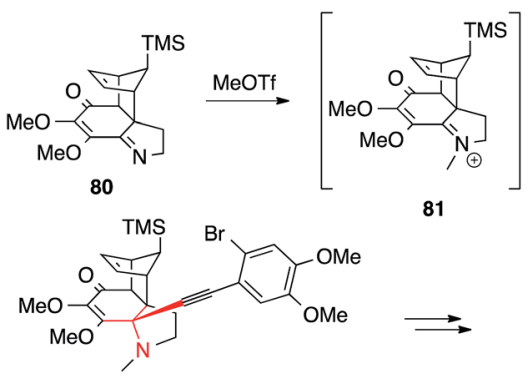

83

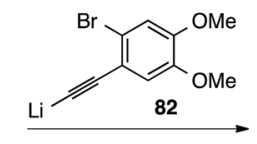

Scheme 23 Syntheses of hasubanan alkaloids by Reisman (2011) and Herzon (2011). $t$-Bu $=$ tert-butyl, TMS $=$ trimethylsilyl, OTf $=$ trifluoromethanesulfonate.

Castle, who closed the pyrrolidine ring of isohasubanonine through a $\mathrm{S}_{\mathrm{N}} 2^{\prime}$-reaction. ${ }^{140,147}$ Subsequently, this strategy was adapted to access (-)-acutumine (Scheme 22b) ${ }^{142}$ To this end, amine 75 was exposed to a Lewis acid to generate an allylic cation that was intercepted by the appended secondary amine. The resulting ATA-containing pyrrolidine $\mathbf{7 6}$ was then converted into (-)-acutumine.

In contrast to this approach, which sets the ATA at a relatively late stage in the synthesis, Reisman installed it at the beginning (Scheme 23a). ${ }^{144}$ Reaction of the chiral N-tert-butanesulfinimine $\mathbf{7 8}$ with phenethyl Grignard 77 provided sulfinamide 79 with a high degree of diastereoselectivity. Subsequently, $\mathbf{7 9}$ was converted into a series of hasubanan alkaloids such as (-)-8-demethoxyrunanine.

The first enantioselective synthesis of hasubanonine was published by Herzon (Scheme 23b). ${ }^{143}$ Methylation of iminoquinone Diels-Alder adduct $80(\mathbf{8 0} \rightarrow \mathbf{8 1})$, followed by addition of alkynyl lithium $\mathbf{8 2}$ gave amine $\mathbf{8 3}$, which was eventually transformed into optically pure (-)-hasubanonine. This strategy proved to be versatile, as many more hasubanan alkaloids, including (-)-runanine, (-)-delavayine, (+)-periglaucine B and $(-)$-acutumine, could be accessed by variation of the alkynyl species. ${ }^{143,145,146}$

\section{Stemona alkaloids}

Plants belonging to the family Stemonaceae, which are mostly found in Southeast Asia, have been used for centuries as insecticides and for the treatment of respiratory diseases. ${ }^{148-150}$ Phytochemical investigations led to the isolation of a variety of natural products known as Stemona alkaloids (Fig. 6). ${ }^{151,152}$ These polycyclic natural products possess highly complex 


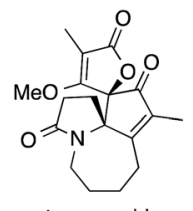

stemonamide

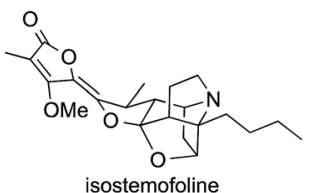

isostemofoline

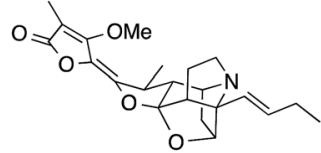

asparagamine $\mathrm{A}$

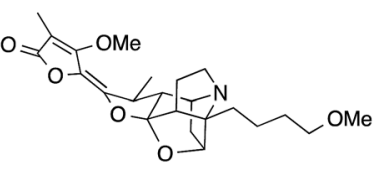

methoxystemofoline
Fig. 6 Representative Stemona alkaloids

structures weaving together pyrrolidines and butenolides, often through spiro fusions that contain ATAs.

The structural beauty of these molecules generated considerable interest in the synthetic community and stimulated the development of new synthetic methods for the installation of ATAs. ${ }^{151,152}$ The strategies employed range from classical additions to imines, ${ }^{\mathbf{1 5 3 , 1 5 4}}$ to radical cyclization cascades, ${ }^{155,156}$ radical allylations, ${ }^{157}$ semipinacol-Schmidt cascades, ${ }^{158,159}$ Schmidt reactions, ${ }^{\mathbf{1 6 0}}$ aza-Cope-Mannich reactions, ${ }^{\mathbf{1 6 1}}$ cyclopropane-Cope rearrangements ${ }^{\mathbf{1 6 2}}$ and catalytic 1,3-dipolar cycloadditions. ${ }^{\mathbf{1 6 3}}$

The first synthesis of a Stemona alkaloid, viz. isostemofoline, was published by Kende in 1999 and employed a highly unusual and elegant approach. ${ }^{162}$ The ATA was formed via rhodiumcatalyzed reaction of pyrrole $\mathbf{8 4}$ with vinyl diazoester $\mathbf{8 5}$. The

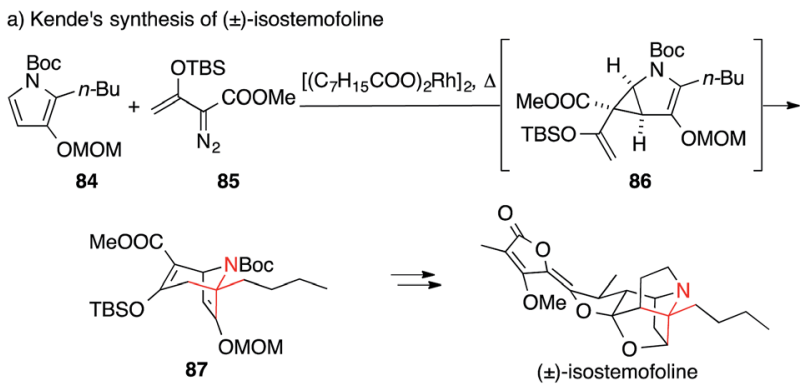

b) Ishibashi's synthesis of ( \pm )-stemonamide

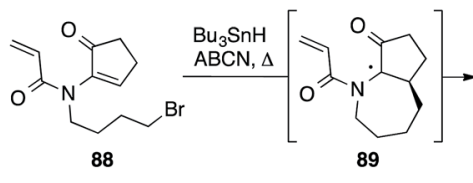

c) Zhang's synthesis of ( \pm )-stemonamide

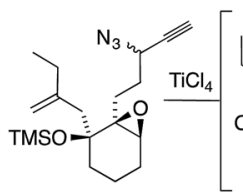

92

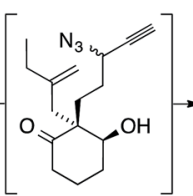

93

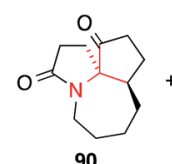

90

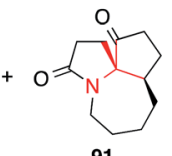

91
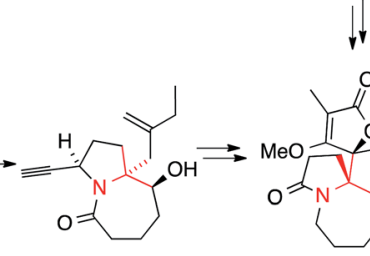

94

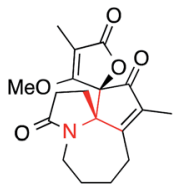

(士)-stemonamide

Scheme 24 Syntheses of Stemona alkaloids by Kende (1999), Ishibashi (2008) and Zhang (2011). ABCN =1,1'-azobis(cyclohexanecarbonitrile), Boc = tert-butyloxycarbonyl, MOM = methoxymethyl, TBS = tert-butyldimethylsilyl, TMS = trimethylsilyl.

a) Overman's synthesis of ( \pm )-asparagamine $A$

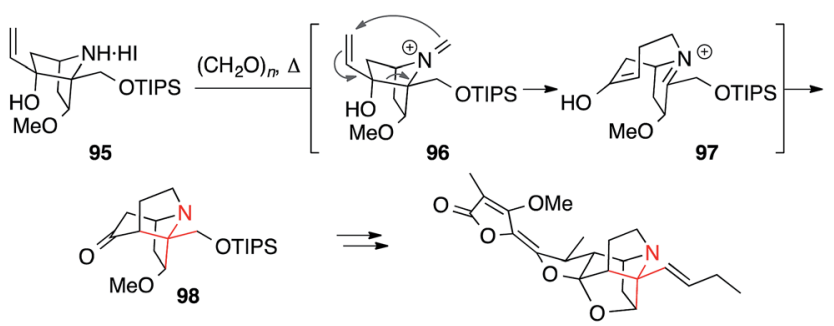

( \pm )-asparagamine A

b) Huang's synthesis of (+)-methoxystemofoline

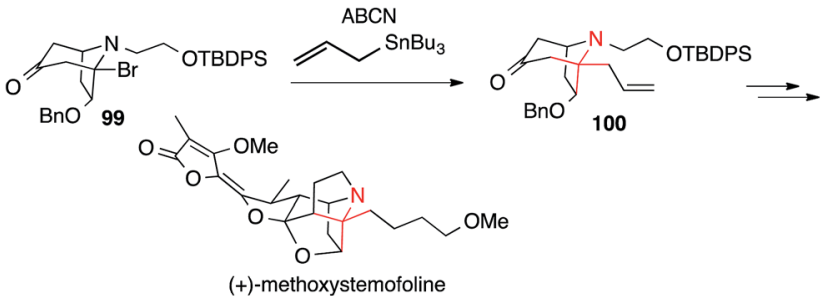

Scheme 25 Syntheses of Stemona alkaloids by Overman (2003) and Huang (2015). ABCN = 1,1'-azobis(cyclohexanecarbonitrile), $\mathrm{Bn}=$ benzyl, TBDPS = tert-butyldiphenylsilyl, TIPS = triisopropylsilyl.

resultant divinyl cyclopropane $\mathbf{8 6}$ underwent Cope rearrangement in situ to afford bicycle 87, which was then used as a key intermediate in the further assembly of the natural product (Scheme 24a).

More recently, two synthetic approaches aimed at members of the stemonamine group were published. Ishibashi developed an entry to racemic stemonamide and isostemonamide as well as their reduced derivatives stemonamine and isostemonamine, based on a radical cascade as the key step for the formation of the ATA (Scheme 24b) ${ }^{155,156}$ Treatment of the achiral precursor 88 with tributyltin hydride and 1,1'-azobis(cyclohexanecarbonitrile) (ABCN) at elevated temperatures effected a 7-endo-trig cyclization that likely yielded radical 89 as the proposed intermediate, which in turn underwent an unusual 5-endo-trig cyclization providing access to a separable mixture of isomers $\mathbf{9 0}$ and $\mathbf{9 1}$. Further transformations of these tricyclic compounds furnished stemonamide and some of its congeners.

An alternative approach to stemonamide and related Stemona alkaloids was published by Zhang (Scheme 24c). ${ }^{159}$ Based on his systematic studies on the reactivity of $\alpha$-hydroxy epoxides such as $\mathbf{9 2 ,}{ }^{\mathbf{1 6 4}}$ he developed a powerful cascade that combines a semipinacol rearrangement with an Aubé-Schmidt reaction $(\mathbf{9 2} \rightarrow \mathbf{9 4})$. The resulting amide 94 was obtained as a 5:1 mixture of diastereomers, reflecting the diastereomeric mixture of propargylic azides employed as substrates. Using this strategy and variations thereof, Zhang was able to synthesize stemonamide and three additional Stemona alkaloids, viz. maistemonine, stemonamine, and isomaistemonine. ${ }^{\mathbf{1 5 8 - 1 6 0}}$

The only synthesis of asparagamine A, an unsaturated derivative of stemonamide, was achieved by Overman in 2003. ${ }^{161}$ He installed the ATA using his signature aza-Cope-Mannich cascade (Scheme 25a). The synthesis of a precursor molecule 
suitable for this transformation commenced with a Diels-Alder reaction, forming an ATA that later took part in the rearrangement. Treatment of $\mathbf{9 5}$ with excess paraformaldehyde at elevated temperatures generated iminium ion 96, which underwent the aza-Cope-Mannich sequence to afford the ATA of asparagamine A (98, via intermediate $\mathbf{9 7})$. More recently, a radical allylation $(\mathbf{9 9} \rightarrow \mathbf{1 0 0})$ was utilized by Huang to set the ATA in (+)-methoxystemofoline at an early stage of the synthesis (Scheme 25b). ${ }^{157}$

\section{Indole alkaloids}

Indole alkaloids are a structurally and biosynthetically heterogeneous class of natural products characterized by an indole nucleus or derivative thereof. Several of them, albeit not the best known ones, contain ATAs (Fig. 7).

Kopsine, the first member of the so-called Kopsia alkaloids, was isolated as early as $1890,{ }^{165}$ but it took several decades before its complex structure, and those of its congeners, could be elucidated. ${ }^{166-173}$ All members of this family possess an ATA incorporated in a bicyclo[2.2.2] octane system. Thus, the kopsanes seem predestined for Diels-Alder reactions, and few syntheses fail to employ a [4+2] cycloaddition strategy. ${ }^{174-176}$ The routes used can be divided into two main categories: (a) intermolecular Diels-Alder reactions ${ }^{177-180}$ and (b) intramolecular Diels-Alder reactions. ${ }^{181-185}$

The very first synthesis of $( \pm$ )-aspidofractinine, completed in 1976, introduced an intermolecular Diels-Alder reaction to set the ATA using nitroethylene as a dienophile (not shown). ${ }^{177}$ Over time, phenyl vinyl sulfone emerged as a more practical dienophile ${ }^{178,179}$ and in 2009 the first enantioselective synthesis of (+)-aspidofractinine was reported by Spino using this reagent (Scheme 26a). ${ }^{180}$ In this case, imine 101 thermally isomerized to diene 102, which then underwent cycloaddition from the sterically more accessible convex side to afford sulfone $\mathbf{1 0 3}$.

The first successful intramolecular Diels-Alder approach to $( \pm)$-kopsanone and $( \pm)$-10,22-dioxokopsane was reported in 1983 by Magnus (Scheme 26b). ${ }^{181,182}$ They synthesized sulfide 104 as a suitable precursor, with the dienophile placed in the concave position. The cycloaddition reaction proceeded at $100{ }^{\circ} \mathrm{C}$ and provided intermediate 105 , which was transformed into ( \pm )-kopsanone in a few steps. Using a similar strategy, other indole alkaloids, $( \pm)$-kopsijasmine and $( \pm)$-kopsine, were prepared as racemates, ${ }^{1{ }^{84,185}}$ as well as (-)-kopsinilam and $(-)$-kopsinine in enantiomerically pure form. ${ }^{183}$

In a recent example for an alternative approach by Boger, a powerful radical transannular cyclization was applied to install the ATA of kopsinine (Scheme 26c). ${ }^{176}$ Upon treatment of xanthate 106 with $\mathrm{SmI}_{2}$, ATA 108 was formed as a single diastereomer. Presumably, a primary radical intermediate 107 is formed, which undergoes a radical cyclization followed by reduction and diastereoselective protonation of the ester enolate.

Lapidilectine B and lundurine A are two structurally related Kopsia alkaloids that contain two ATAs. Although not originating from the same organism, they show a similar scaffold with a bridged 8-membered ring fused to an indoline on one

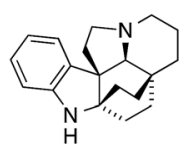

aspidofractinine

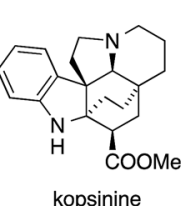

kopsinine
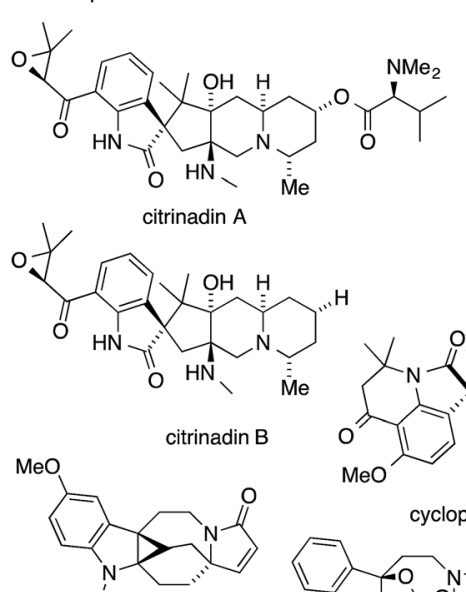

MeOOC

lundurine $\mathrm{A}$

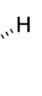

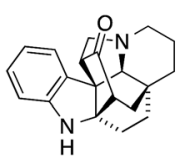

kopsanone
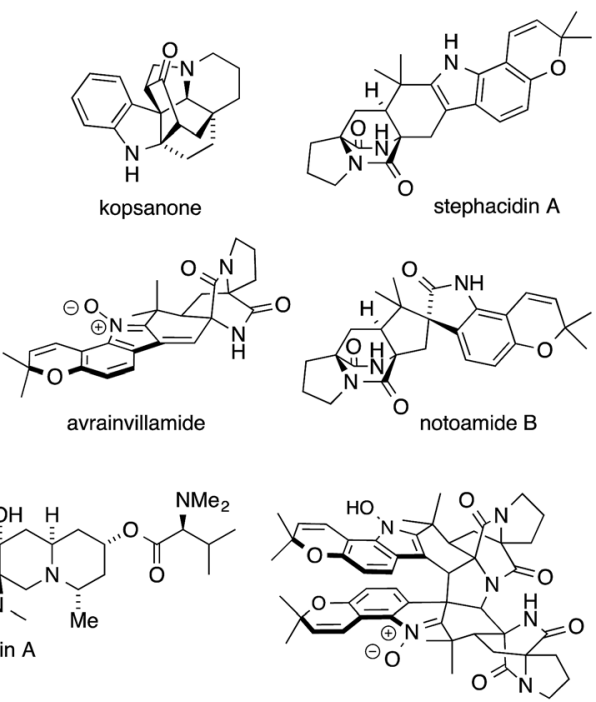

stephacidin B
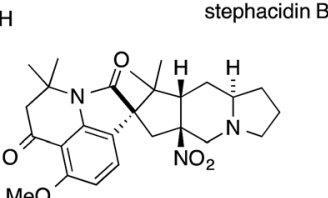

$\mathrm{MeO}$ cyclopiamine $\mathrm{B}$

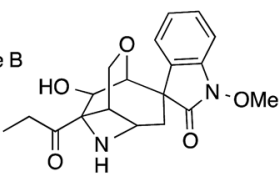

MeOOC'

lapidilectine B

gelsemoxonine

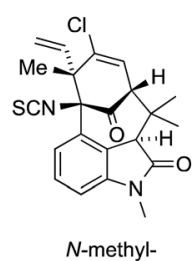

$\mathrm{N}$-methyl-
welwitindolinone $\mathrm{C}$

isothiocyanate
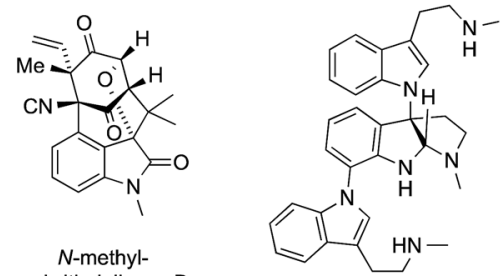

$N$-methylwelwitindolinone D

psychotrimine

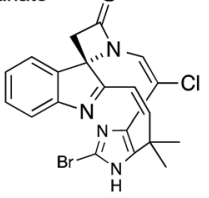

chartelline $\mathrm{C}$

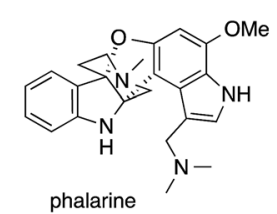

Fig. 7 Indole alkaloids featuring ATAs.

side and a 5-membered ring on the other. Lapidilectine A was isolated by Awang from the leaves of the tree Kopsia lapidilecta in 1992. ${ }^{186,187}$ Lundurines A-D were isolated from the Malaysian tree Kopsia tenuis, ${ }^{188}$ and shown to be effective at bypassing multidrug resistance in vincristine-resistant KB cells. ${ }^{189}$

Qin accomplished the first enantioselective synthesis of (-)-lundurine A in 2014 (Scheme 27a). ${ }^{190}$ The first ATA was established via the addition of allylmagnesium bromide to an iminium ion generated by in situ alkylation of imine 109 to form tetracycle 110. In order to establish the two fully substituted stereocenters on the indoline of $\mathbf{1 1 2}$, Qin resorted to an unusual intramolecular Simmons-Smith cyclopropanation of diiodide 


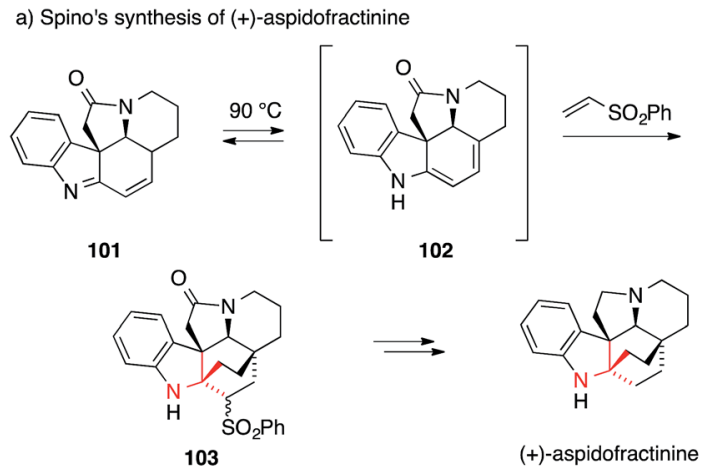

b) Magnus' synthesis of ( \pm )-kopsanone

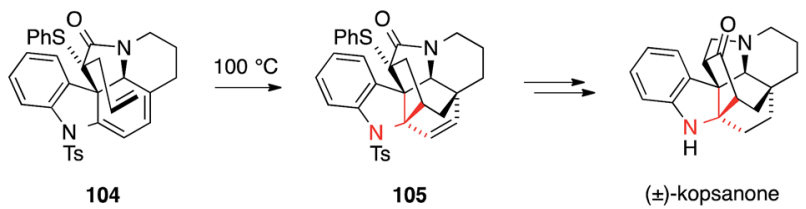

c) Boger's synthesis of ( \pm )-kopsinine

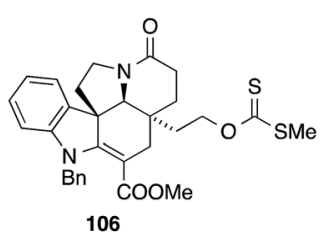
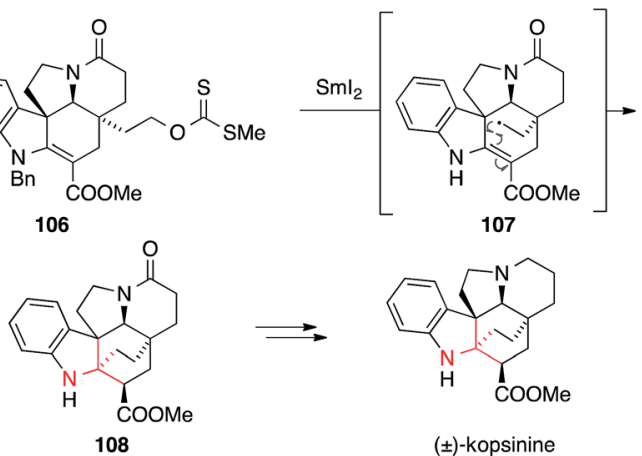

Scheme 26 Kopsia alkaloid syntheses by Spino (2009), Magnus (1983) and Boger (2013). Bn = benzyl, Ts = p-toluenesulfonyl.

111. Two other racemic syntheses of lundurine $A$ and $B$ have been reported by Nishida. ${ }^{\mathbf{1 9 1 - 1 9 3}}$ He employed a Curtius rearrangement and a 1,2-addition to an iminium ion for lundurine $\mathrm{B}^{\mathbf{1 9 3}}$ and a Tsuji-Trost amination and an indoxyl bisalkylation for the synthesis of lundurine A (not shown). ${ }^{\mathbf{1 9 1 , 1 9 2}}$

In 2001, Pearson employed a Smalley cyclization of aryl ketone azide $\mathbf{1 1 3}$ to furnish the spiroindoxyl 114 (Scheme 27b). ${ }^{\mathbf{1 9 4 , 1 9 5}}$ In the final steps of his lapidilectine B synthesis, he then used his trademark azaallyl anion [3+2] cycloaddition to establish the pyrrolidine ring $(\mathbf{1 1 5} \rightarrow \mathbf{1 1 6})$ as an inconsequential mixture of regioisomers.

The cycloaddition approach has not been limited to the kopsane alkaloids. Other indole alkaloids, such as stephacidin A and the notoamides, which bear two ATAs, were prepared by a presumably biomimetic $[4+2]$ cycloaddition.

Williams synthesized stephacidin A and notoamide B starting from imidate 117, which underwent base-mediated isomerization to 118 followed by intramolecular Diels-Alder reaction to afford diazabicyclo[2.2.2]octane 119 (Scheme 28). ${ }^{\mathbf{1 9 6}}$ This remarkable reaction sets both ATAs in a single step. Later that a) Qin's synthesis of (-)-lundurine $A$
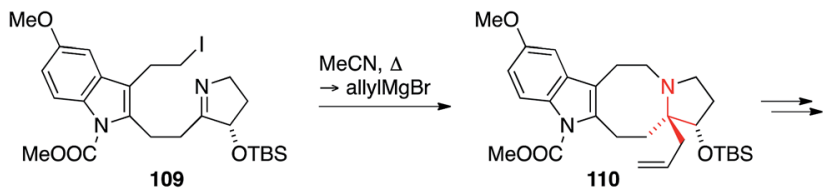<smiles>COc1ccc2c(c1)c1c(n2C(O)OC)CC[C@@]2(CC(I)I)[C@H](O[SbH3])CC(=O)N2CC1</smiles>
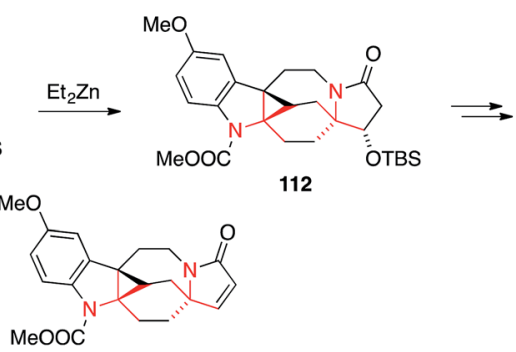

(-)-lundurine $\mathrm{A}$

b) Pearson's synthesis of $( \pm)$-lapidilectine $B$

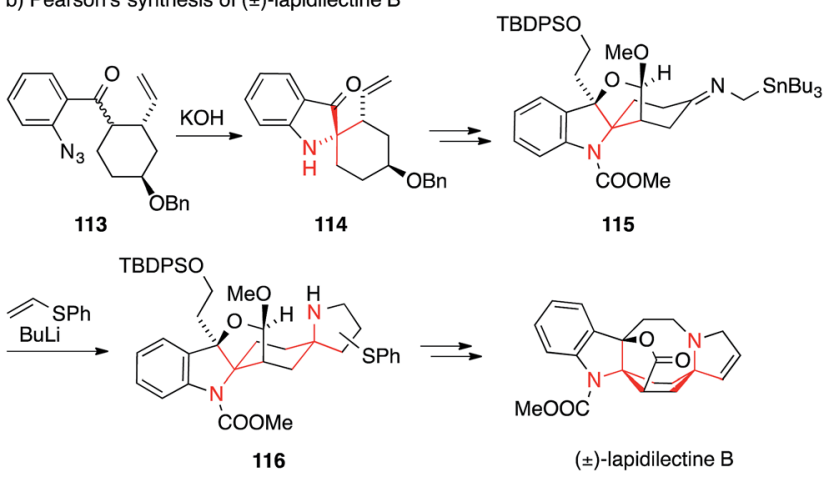

Scheme 27 Syntheses of Kopsia alkaloids by Qin (2014) and Pearson (2001). Bn = benzyl, TBDPS = tert-butyldiphenylsilyl, TBS = tertbutyldimethylsilyl.

year, stephacidin B was accessed via avrainvillamide using the same strategy. ${ }^{197}$

In 2005, Baran used the $\alpha$-alkylation of proline derivative $\mathbf{1 2 0}$ with complete chirality transfer, a method developed by Seebach, ${ }^{198}$ to set the first ATA of stephacidin A in 121 (Scheme 29). ${ }^{199}$ The second ATA present in 123 was installed by an intramolecular, stereocontrolled oxidative enolate coupling starting from diketopiperazine 122. Baran was then able to convert stephacidin A into avrainvillamide and stephacidin B following a biosynthetic proposal. ${ }^{200}$

A second synthesis of avrainvillamide and stephacidin B was accomplished concurrently by Myers (Scheme 30). ${ }^{201}$ In this case, the first ATA was installed by a Strecker-type addition of TMS cyanide to enamine $\mathbf{1 2 4}$ to form the $N$-Boc amino nitrile 125. The second ATA was then set by a very unusual radical transfer cyclization. Abstraction of a hydrogen atom in 126, followed by loss of toluene, generates an aminoacyl radical which attacks the enamide double bond and ejects a phenylthiyl radical to form the diketopiperazine 127.

Several members of a related family of prenylated spirooxindole alkaloids, namely cyclopiamine, citrinadin A and citrinadin B, also feature an asymmetric ATA. ${ }^{202-204}$ In 2013, Martin and Wood reported the first syntheses of citrinadin A and B. ${ }^{205,206}$ 

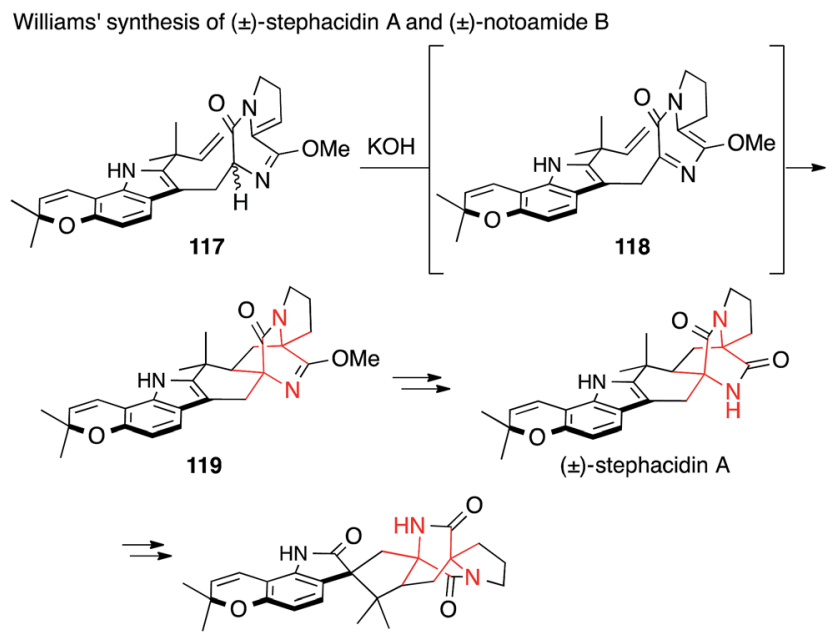

(士)-notoamide B

Scheme 28 Synthesis of prenylated indole alkaloids by Williams (2007).

In the case of citrinadin A, epoxide $\mathbf{1 2 8}$ was heated in the presence of methylamine to provide 1,2-amino alcohol 129 (Scheme 31a). ${ }^{205}$ Wood's approach employed an azide-mediated opening of epoxide 130 to establish the ATA in 131 (Scheme 31b). ${ }^{206}$ Both reactions are rare examples where an ATA has been set through a $\mathrm{S}_{\mathrm{N}} 2$ reaction.

More recently, Sarpong published his entry to the prenylated indole alkaloids cyclopiamine B and ent-citrinalin B (Scheme 32). The first ATA was set via a Hofmann rearrangement $(\mathbf{1 3 2} \rightarrow$ 133). ${ }^{207}$ The second, not asymmetric, ATA center was established by treating ent-citrinalin $\mathrm{B}$ with sodium hydride to effect the rearrangement of the chromanone to the tetrahydroquinolone

Baran' synthesis of (+)-stephacidin A, (+)-avrainvillamide and (-)-stephacidin B
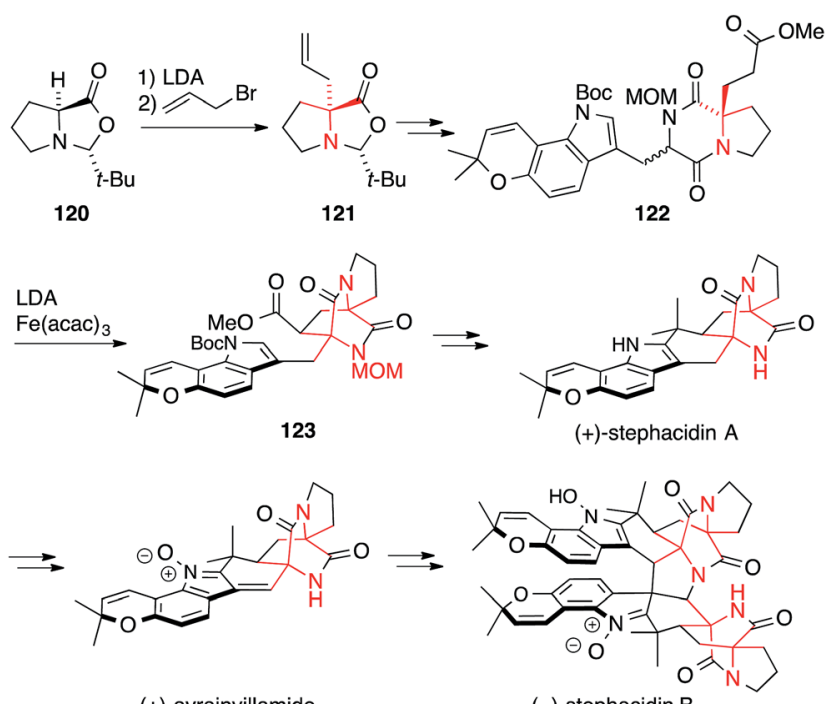

(+)-avrainvillamide

(-)-stephacidin B

Scheme 29 Synthesis of prenylated indole alkaloids by Baran (2005). acac $=$ acetylacetonate, Boc $=$ tert-butyloxycarbonyl, $t$-Bu $=$ tertbutyl, LDA = lithiumdiisopropylamide.
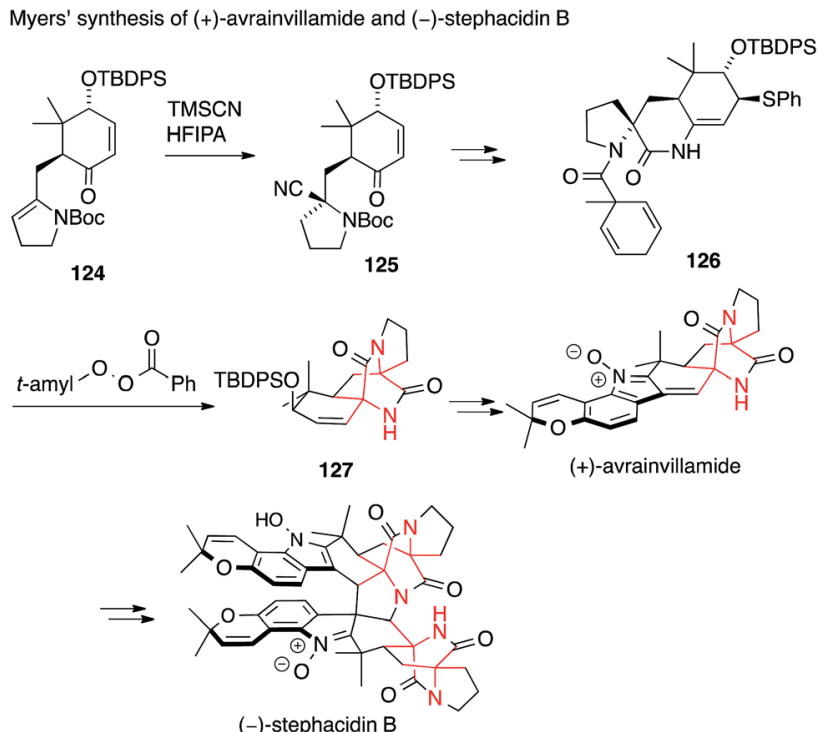

Scheme 30 Synthesis of prenylated indole alkaloids by Myers (2005). t-amyl = tert-amyl (2-methylbutyl), Boc $=$ tert-butyloxycarbonyl, HFIPA $=1,1,1,3,3,3$-hexafluoroisopropyl alcohol, TBDPS = tert-butyldiphenylsilyl, TMSCN = trimethylsilyl cyanide.

moiety present in cyclopiamine via retro-Michael/Michael addition. Using a similar approach, he was then able to synthesize the structurally related alkaloids stephacidin A and notoamide $\mathrm{B}^{208}$

Two alkaloids closely related to notoamide B, marcfortine $\mathrm{B}$ and $\mathrm{C}$, were synthesized by Trost using a Michael addition and a radical cyclization to set the two ATAs (not shown). ${ }^{\mathbf{2 0 9 , 2 1 0}}$

Gelsemoxonine is an indole alkaloid with an ATA that is part of a azetidine, a rare structural motif. It is also a member of the

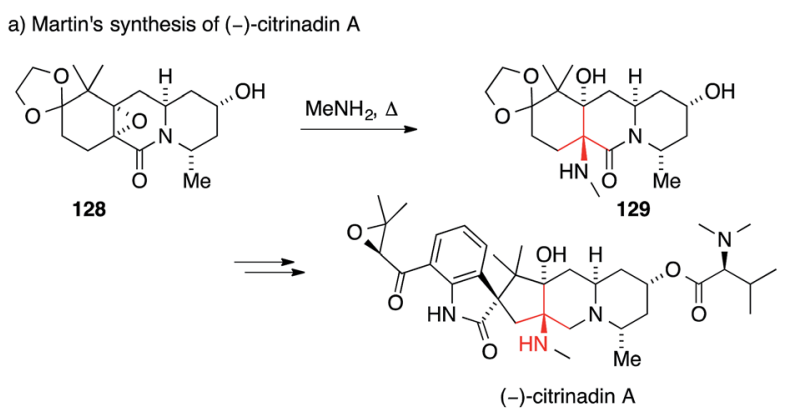

b) Wood's synthesis of (+)-citrinadin B

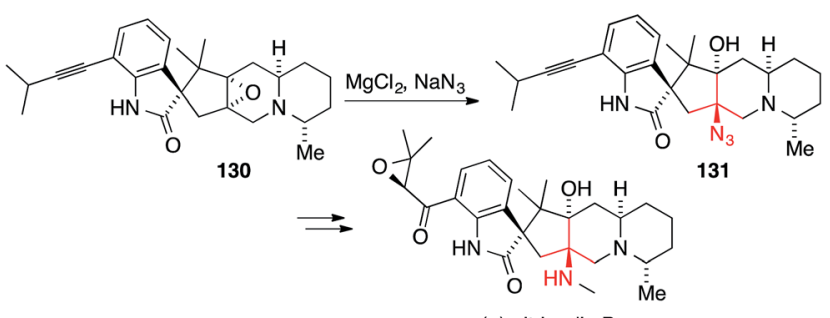

(+)-citrinadin B

Scheme 31 Syntheses of prenylated indole alkaloids by Martin (2013) and Wood (2013). 
Sarpong's synthesis of (-)-cyclopiamine B

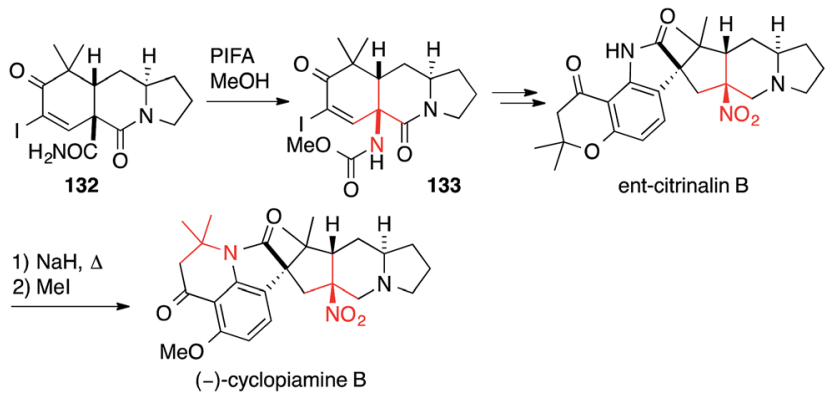

Scheme 32 Synthesis of ent-citrinalin B and (-)-cyclopiamine B by Sarpong (2015). PIFA = (Bis(trifluoroacetoxy)iodo) benzene.

Gelsemium spirooxindole family, a large alkaloid family with highly compact, strained and complex structures, which have attracted considerable synthetic activity. ${ }^{211-213}$ In 2011, Fukuyama accomplished a total synthesis of gelsemoxonine that employed an intramolecular epoxide opening of $\mathbf{1 3 4}$ to install the ATA (Scheme 33a). ${ }^{\mathbf{2 1 4}}$ Recently, Carreira published an elegant entry to gelsemoxonine, setting the ATA 136 via a diastereoselective propynyllithium addition to isoxazoline 135 (Scheme 33b). ${ }^{215}$

The welwitindolinones are another class of indole alkaloids with an ATA that is not part of the indole-derived moiety itself. The first welwitindolinone natural products (Fig. 7) were isolated by Moore in 1994 from the cyanobacteria Hapalosiphom welwitschii and Westiella intracta. ${ }^{216}$ All welwitindolinones known so far feature a [4.3.1] bicyclic framework, which, in some cases, contains a modified ATA that bears an isothiocyanate or isonitrile functional group. ${ }^{217,218}$

Being a considerable challenge for total synthesis, the welwitindolinones have become popular targets. ${ }^{219}$ The first total synthesis of $\mathrm{N}$-methylwelwitindolinone $\mathrm{D}$ isonitrile was accomplished by Rawal in $2011^{220-222}$ using Kim's oxime rearrangement to install the isothiocyanide $(\mathbf{1 3 7} \rightarrow \mathbf{1 3 8}$, Scheme 34a). ${ }^{\text {223,224 }}$ Desulfuration of 138 then gave the naturally occuring

a) Fukuyama's synthesis of (-)-gelsemoxonine

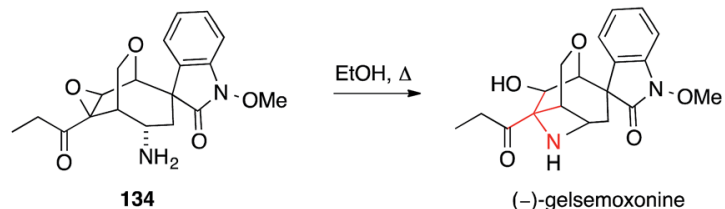

b) Carreira's synthesis of $( \pm)$-gelsemoxonine

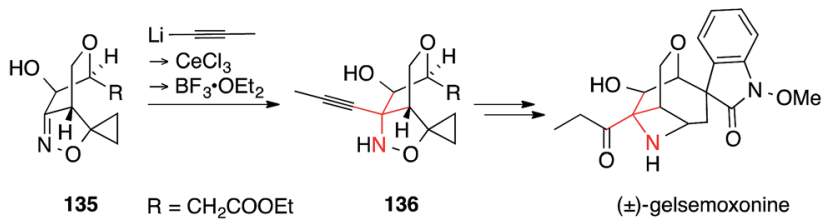

Scheme 33 Syntheses of gelsemoxonine by Fukuyama (2011) and Carreira (2013). Boc = tert-butyloxycarbonyl.

a) Rawal's synthesis of (-)-N-methylwelwitindolinone $D$ isonitrile
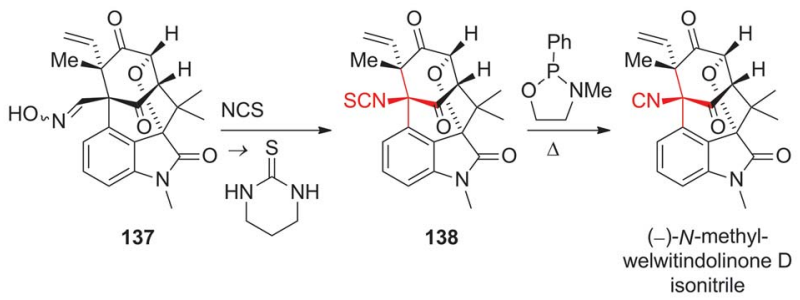

b) Garg's synthesis of (-)- $\mathrm{N}$-methylwelwitindolinone $\mathrm{C}$ isothiocyanate

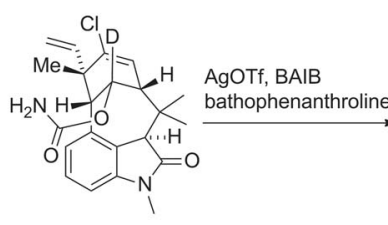

139

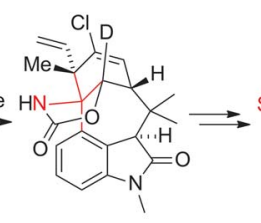

140

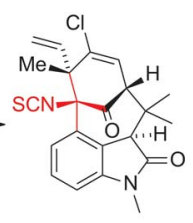

$(-)-N-$ methylwelwitindolinone $\mathrm{C}$ isothiocyanate

Scheme 34 Syntheses of welwitindolinones by Rawal (2011) and Garg (2011). $\mathrm{BAIB}=$ (diacetoxyiodo)benzene, $\mathrm{NCS}=\mathrm{N}$-chlorosuccinimide, $\mathrm{OTf}=$ trifluoromethanesulfonate $\mathrm{Ph}=$ phenyl.

isonitrile. Martin completed a synthesis that intercepts Rawal's synthesis in 2012. ${ }^{225}$

Garg's total synthesis of $\mathrm{N}$-methylwelwitindolinone $\mathrm{C}$ isothiocyanate used an intramolecular Ag-mediated nitrene $\mathrm{C}, \mathrm{H}$ insertion of amide 139 as the critical step, which furnished carbamate 140 (Scheme 34b).226,227 To improve the regioselectivity and yield of this late stage transformation, the authors beautifully exploited the deuterium kinetic isotope effect. ${ }^{228}$

Both Rawal and Garg were able to subsequently synthesize several members of the welwitindolinone family by varying their initial strategies. ${ }^{222,228-230}$ In addition, Hatakeyama recently accomplished another synthesis of $(-)-N$-methylwelwitindolinone $\mathrm{C}$ isothiocyanate using an endgame similar to Rawal's. ${ }^{231}$

Two examples of reactions which have been specifically developed to set an ATA, both explored by the Baran laboratory, are shown in Scheme 35.

In the synthesis of chartelline $\mathrm{C}$, the ATA was set via a cascade reaction initiated by the bromination of indole 141 at $185{ }^{\circ} \mathrm{C}$ resulting in 142 (Scheme 35a). Amide attack furnished intermediate 143, which then rearranged in a 1,5-shift to give the ring contracted spiro- $\beta$-lactam $144 .^{232,233}$ For the synthesis of psychotrimine, a coupling of indole 147 with 2-iodoaniline (146) was developed to yield 148, which then underwent further cyclization to give 149 (Scheme 35b). ${ }^{234}$ This method was also used for the syntheses of psychotetramine, ${ }^{235}$ kapakahine B and kapakahine $\mathrm{F}^{236,237}$

Another interesting way to install an ATA in a structurally complex indole alkaloid was published by Danishefsky (Scheme 36). ${ }^{238}$ In his synthesis of the furanobisindole alkaloid phalarine, amino acid derivative $\mathbf{1 5 0}$ was treated with formaldehyde and acid to set the ATA in a diastereoselective fashion $\mathbf{1 5 0} \rightarrow$ 152). It is not clear, however, whether this reaction proceeds via a 1,2-Wagner-Meerwein shift (possible intermediate 153) or 


$$
\text { a) Baran's synthesis of ( } \pm \text { )-chartelline } C
$$

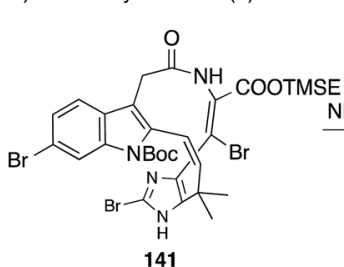

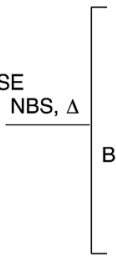

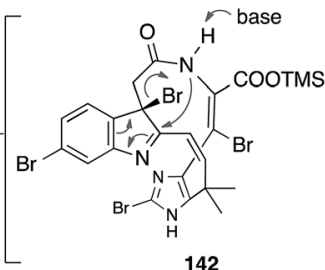
$\stackrel{\mathrm{K}_{2} \mathrm{CO}_{3}}{\longrightarrow}$

b) Baran's synthesis of ( \pm )-psychotrimine

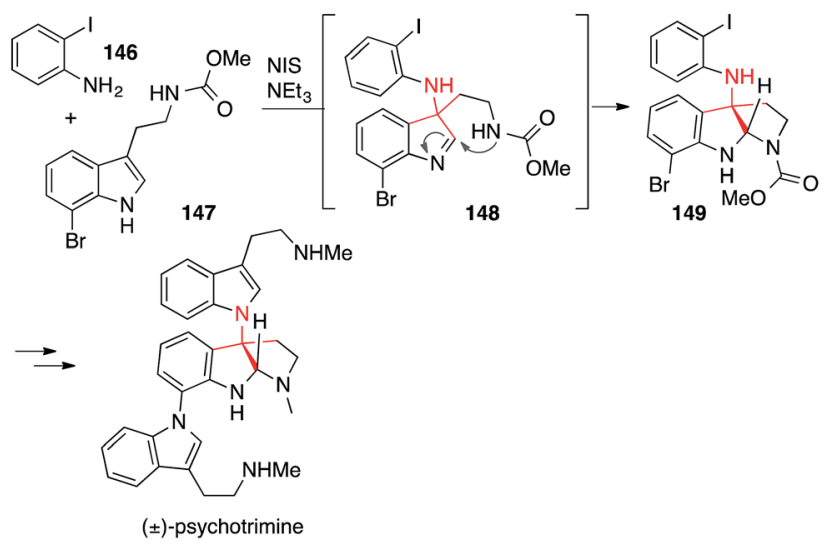

Scheme 35 Baran's syntheses of chartelline $C$ (2006) and psychotrimine (2008). Bn = benzyl, Boc $=$ tert-butyloxycarbonyl, NBS $=N$ bromosuccinimide, NIS $=N$-iodosuccinimide, TMSE $=2$-(trimethylsilyl)ethyl.

Danishefsky's synthesis of (-)-phalarine
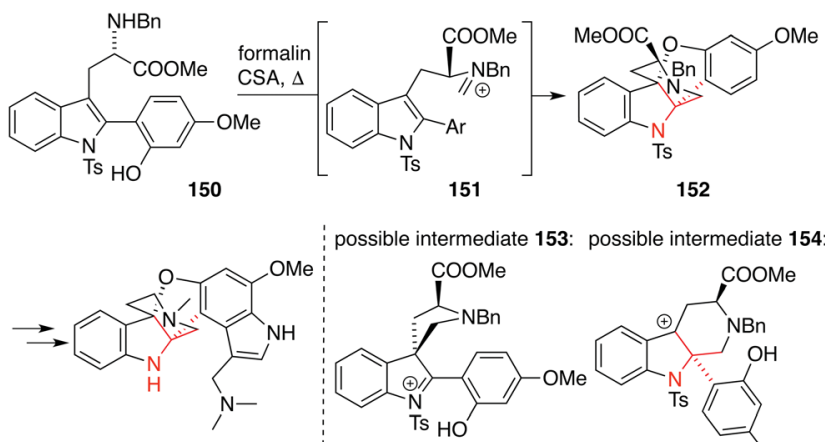

possible intermediate 153: possible intermediate 154

(-)-phalarine

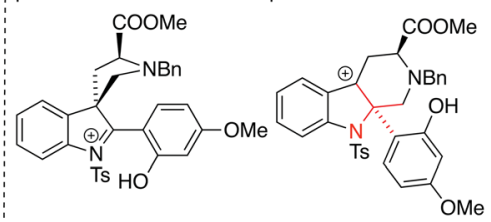

Scheme 36 Danishefsky's synthesis of phalarine (2010). Bn = benzyl, $\mathrm{CSA}=$ camphorsulfonic acid.

a Pictet-Spengler reaction (possible intermediate 154) starting from iminium intermediate $\mathbf{1 5 1 .}$

\section{Cephalotaxines}

Due to their interesting chemical structure and antileukemic activities, the cephalotaxines, isolated from the Japanese plum yew (Cephalotaxus harringtonii), have emerged as popular targets for natural product synthesis (Fig. 8). ${ }^{239}$

The first synthesis of cephalotaxine itself was reported by Weinreb in 1972 (Scheme 37a). ${ }^{240}$ Conversion of enamine 155 into diketone $\mathbf{1 5 6}$ set the stage for a Lewis-acid catalyzed cyclization to yield tertiary amine 158 (via intermediate 157). Weinreb was able to synthesize cephalotaxine in six additional steps with an overall yield of $20 \%$, setting a high bar for the following syntheses.

In 1988, Fuchs utilized an intramolecular [4+2] nitrosoDiels-Alder cycloaddition to assemble the benzazepine 161 from hydroxamic acid 159 (via intermediate 160, Scheme $37 b) .{ }^{241}$

Tietze published a formal asymmetric synthesis of $(-)$-cephalotaxine in 1999 that is based on palladium catalysis

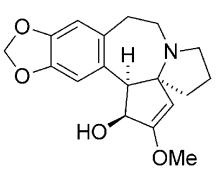

cephalotaxine

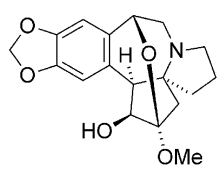

drupacine

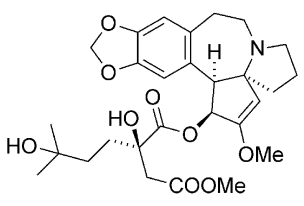

harringtonine
Fig. 8 Representative cephalotaxines.

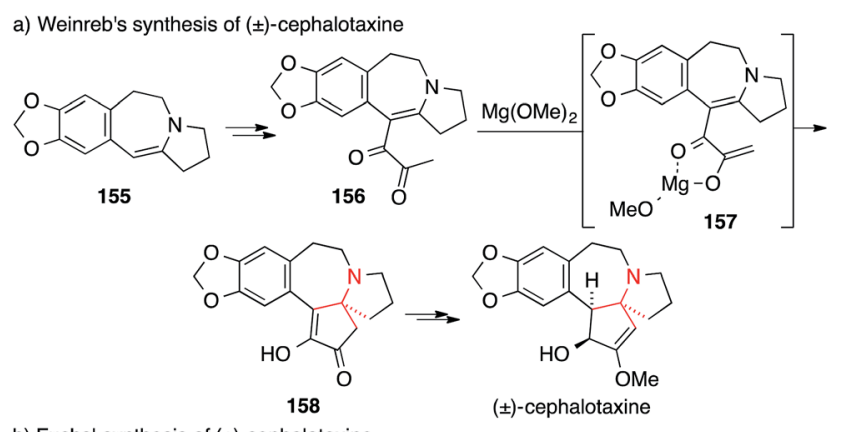

b) Fuchs' synthesis of ( \pm )-cephalotaxine

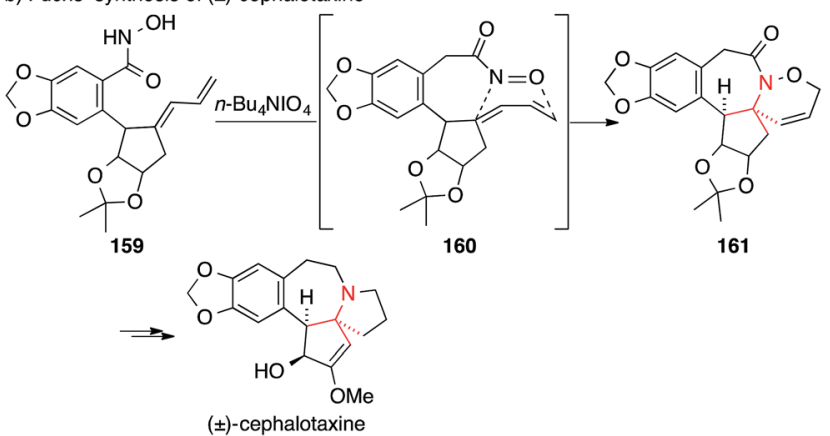

Scheme 37 Syntheses of Cephalotaxine by Weinreb (1972) and Fuchs (1988). 
a) Tietze's synthesis of (-)-cephalotaxine

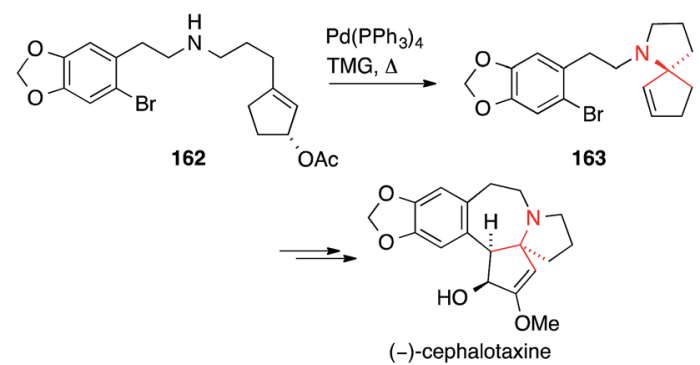

b) Li's synthesis of ( \pm )-cephalotaxine<smiles>C=CCCCCN1CCc2cc3c(cc2C1C(=O)OCC)OCO3</smiles><smiles>C=CC[N+]1(CCCOC(=O)OCC)CCc2cc3c(cc2C1C(=O)OCC)OCO3</smiles><smiles>C=CCC1(CCCCOC(=O)OCC)CCc2cc3c(cc2C1(CC=C)OCC)OCO3</smiles><smiles>COC1=CC23CCCN2CCc2cc4c(cc2[C@@H]3[C@H]1O)OCO4</smiles>

( \pm )-cephalotaxine

Scheme 38 Syntheses of cephalotaxine by Tietze (1999) and Li (2003). $\mathrm{Ac}=$ acetyl, $\mathrm{TMG}=1,1,3,3$-tetramethylguanidine.

(Scheme 38a). ${ }^{242}$ A Tsuji-Trost allylation on secondary amine 162 established the ATA and afforded 163 which was converted into cephalotaxine via a subsequent Heck reaction. A similar Tsuji-Trost allylation was used by Stoltz in 2007 in his synthesis of drupacine and cephalotaxine. ${ }^{243}$

A $[2,3]$ sigmatropic rearrangement was utilized by $\mathrm{Li}$ to convert quaternary ammonium ion 165 to the $\alpha$-tertiary amino ester $166\left(164 \rightarrow\right.$ 166, Scheme 38b). ${ }^{244}$

A rather unusual approach for the asymmetric synthesis of (-)-cephalotaxine was pursued by Royer, who introduced the

a) Royer's synthesis of (-)-cephalotaxine

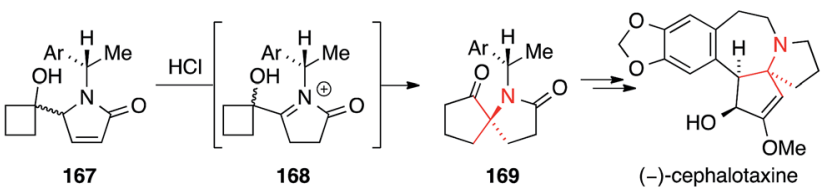

b) Gin's synthesis of (-)-cephalotaxine

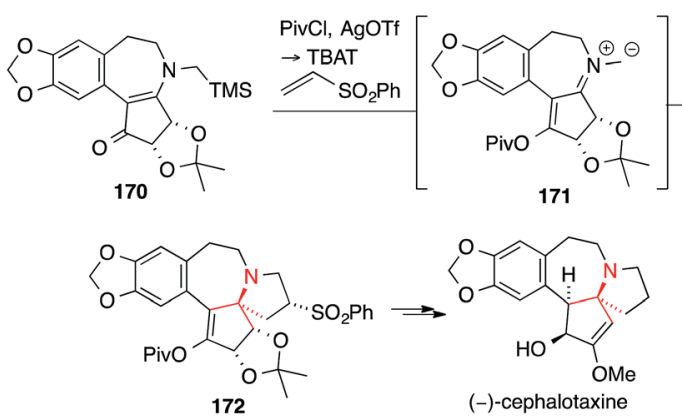

Scheme 39 Syntheses of cephalotaxines by Royer (2004) and Gin (2006). Ar $=$ aryl, OTf $=$ trifluoromethanesulfonate, Piv = pivaloyl, $\mathrm{TBAT}=$ tetrabutylammonium difluorotriphenylsilicate.

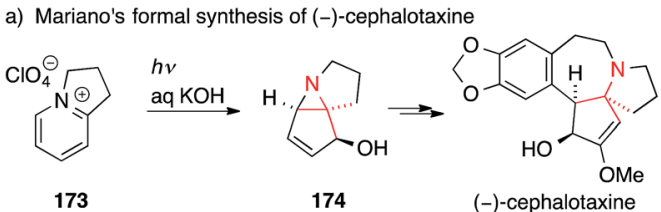

b) Hayes' formal synthesis of (-)-cephalotaxine

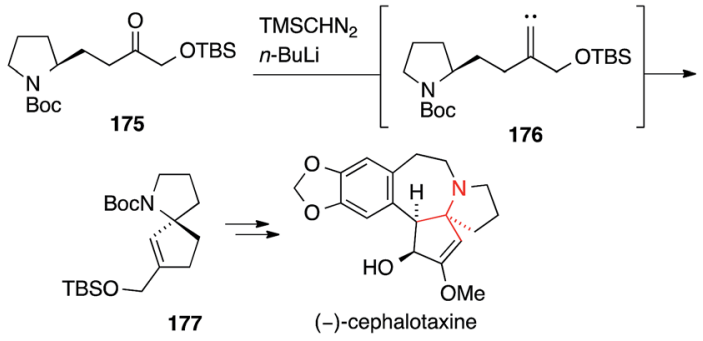

c) Ishibashi's synthesis of (-)-cephalotaxine

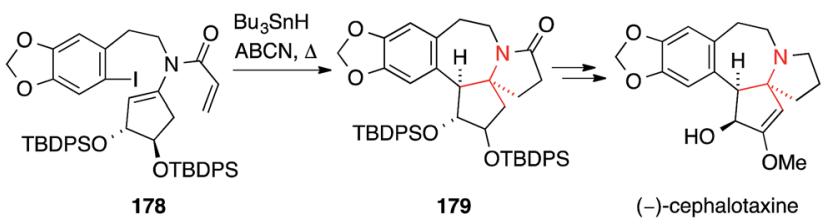

Scheme 40 Syntheses of cephalotaxine by Mariano (2006), Hayes (2008) and Ishibashi (2008). ABCN = 1,1'-azobis(cyclohexanecarbonitrile), Boc = tert-butyloxycarbonyl, TBS = tert-butyldimethylsilyl, TBDPS = tert-butyldiphenylsilyl, TMS = trimethylsilyl.

ATA on key intermediate 169 via semipinacol rearrangement of chiral $\alpha$-hydroxyiminium 168. The latter was generated by acidcatalyzed isomerization and protonation of pyrrolinone 167 (Scheme 39a). ${ }^{245}$

Another synthesis was developed by Gin, who transformed vinylogous amide 170 into azomethine ylide 171 which then underwent 1,3-dipolar cycloaddition with phenyl vinyl sulfone to yield 172 (Scheme 39b). ${ }^{\mathbf{2 4 6 , 2 4 7}}$ The unexpected yet advantageous stereochemical outcome of this cycloaddition was confirmed by X-ray analysis.

In 2006, Mariano used a photochemical cyclization of a bicyclic pyridinium ion 173 to afford aziridine 174, which was then transformed into the natural product (Scheme 40a). ${ }^{248}$ Hayes' synthetic route towards (-)-cephalotaxine made use of an alkylidene carbene 1,5-C,H-insertion starting from ketone 175 to furnish spiro[4.4] azanonane 177, which corresponds to the skeleton of cephalotaxine $(\mathbf{1 7 5} \rightarrow \mathbf{1 7 7}$, Scheme $40 \mathrm{~b}){ }^{249}$

Ishibashi chose a radical cyclization approach to synthesize cephalotaxine (Scheme 40c). ${ }^{250}$ Treatment of aryl iodide 178 with tributyltin hydride and a radical initiator resulted in a 7endo cyclization followed by a 5-endo cyclization that, after hydrogen transfer, yielded 179. Additional functional group manipulations allowed them to intercept an intermediate that had previously been used to synthesize (-)-cephalotaxine. ${ }^{251}$

A host of other methods have been used for the installation of the ATA in cephalotaxines. ${ }^{239}$ These include alkylation, ${ }^{252,253}$ Claisen rearrangement, ${ }^{254}$ Michael addition, ${ }^{255,256}$ Schmidt 
reaction, ${ }^{257}$ addition to an imine,${ }^{258}$ transannular cyclization ${ }^{259}$ and oxidative rearrangement. ${ }^{251}$

\section{Erythrina alkaloids}

Erythrina alkaloids were discovered at the end of the $19^{\text {th }}$ century, when extracts of Erythrina trees were found to possess curare-like neuromuscular activities. ${ }^{260}$ Due to their biological activities and interesting structures (Fig. 9), several total syntheses of these natural products have been carried out and many creative ways to install ATAs have been developed in this context. ${ }^{261}$

In 1990, the group of Ishibashi published the synthesis of $( \pm)$-3-demethoxyerythratidinone using an intramolecular Pummerer-like rearrangement of the enamine 180, setting the stage for a Pictet-Spengler-type reaction $(\mathbf{1 8 1} \rightarrow \mathbf{1 8 2})$ to furnish the ATA (Scheme 41a). ${ }^{262}$ Thirteen years later, the same group published an oxidative radical cyclization starting from enamine 183 to obtain the skeleton of 3-demethoxyerythratidinone 182 (Scheme 41b). ${ }^{263}$

Tsuda's approach featured an intermolecular photochemical $[2+2]$ cyclization to install the ATA, starting from bicycle 184 and diene 185 (Scheme 41c). In the following steps, a ring expansion of the four-membered ring in $\mathbf{1 8 6}$ furnished the six-membered ring by a formal 1,3-migration of a vinylcyclobutane, affording the scaffold of erysotrine. ${ }^{264}$

Funk accomplished the synthesis of isophellibiline via an approach that relies on pericyclic reactions (Scheme 42a). ${ }^{\mathbf{2 6 5}}$ Heating of dioxine 187 resulted in retro-Diels-Alder reaction to afford dehydroalanine derivative 188, which then underwent intramolecular $[4+2]$ cycloaddition to yield lactam 189. The latter was converted into isophellibinine in a few steps.

Recently, Sarpong developed a new methodology to furnish ATAs and applied it to the synthesis of cocculolidine (Scheme 42b). ${ }^{266}$ Propargylic alcohol 190 underwent cycloisomerization upon heating to form benz $[g]$ indolizinone 191 which was then transformed to cocculidine in two additional steps.

A short and elegant synthesis of 3-demethoxyerythratidinone was accomplished by Streuff in 2015 (Scheme 43a). He used a titanium(III)-catalyzed reductive Umpolung $(192 \rightarrow 194)$ to assemble the 1,1-disubstituted tetrahydroisoquinoline core of the Erythrina alkaloids. ${ }^{267}$ In the same year, Ciufolini set the same ATA via an oxidative dearomatizative cyclization of an oxazoline 195, yielding spiropiperidine 197 presumably via intermediate 196 (Scheme 43b). ${ }^{268,269}$

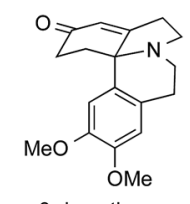

3-demethoxyerythratidinone
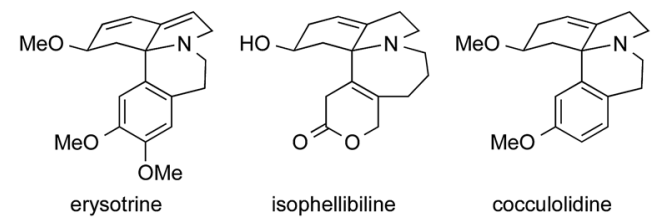

Fig. 9 Representative Erythrina alkaloids.
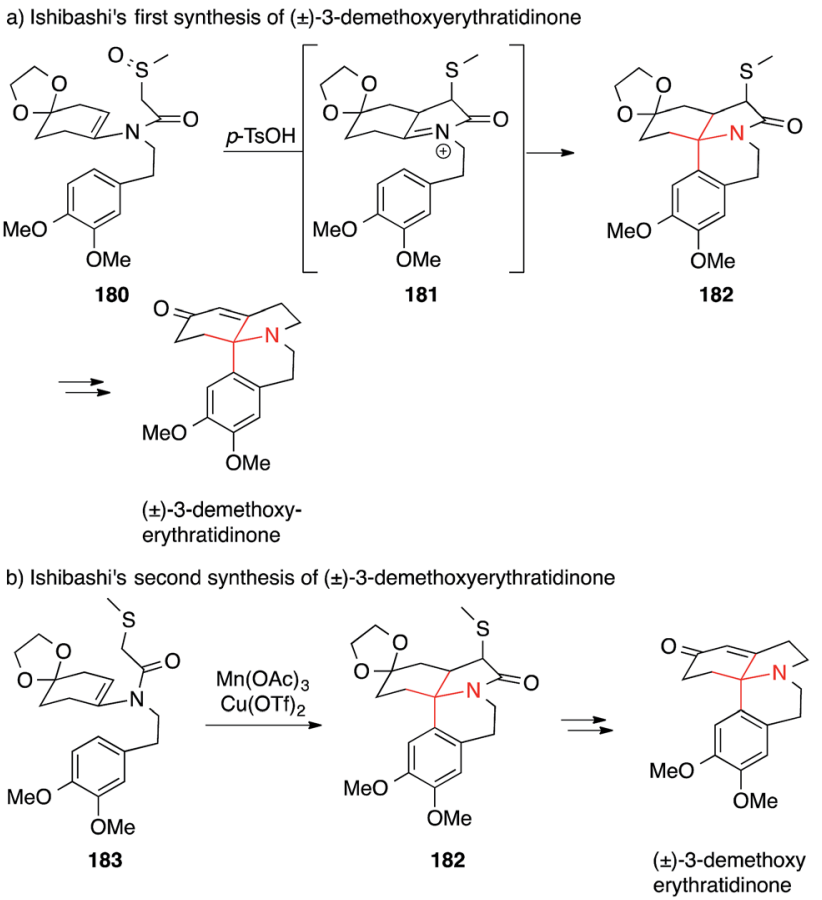

c) Tsuda's synthesis of $( \pm$ )-erysotrine

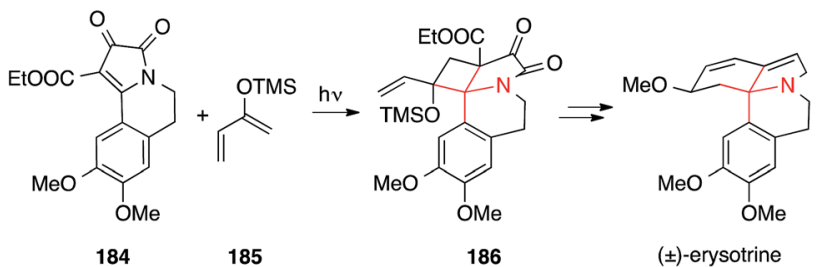

Scheme 41 Syntheses of Erythrina alkaloids by Ishibashi (1990 and 2003) and Tsuda (1992). Ac = acetyl, OTf = trifluoromethanesulfonate, TMS = trimethylsilyl, $p-\mathrm{TsOH}=$ para-toluenesulfonic acid.

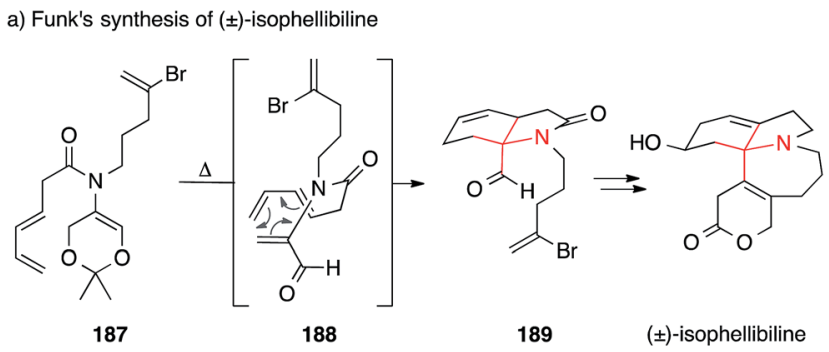

b) Sarpong's synthesis of ( \pm )-cocculidine

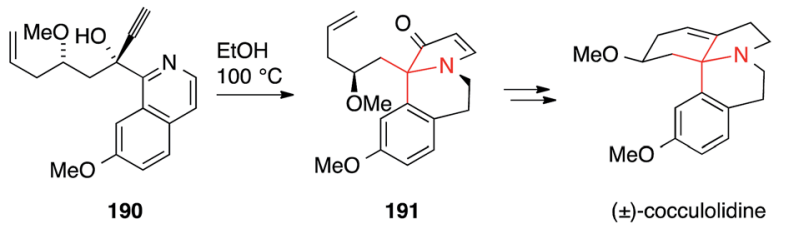

Scheme 42 Syntheses of Erythrina alkaloids by Funk (2012) and Sarpong (2013). 
a) Streuff's synthesis of ( \pm )-3-demethoxyerythratidinone

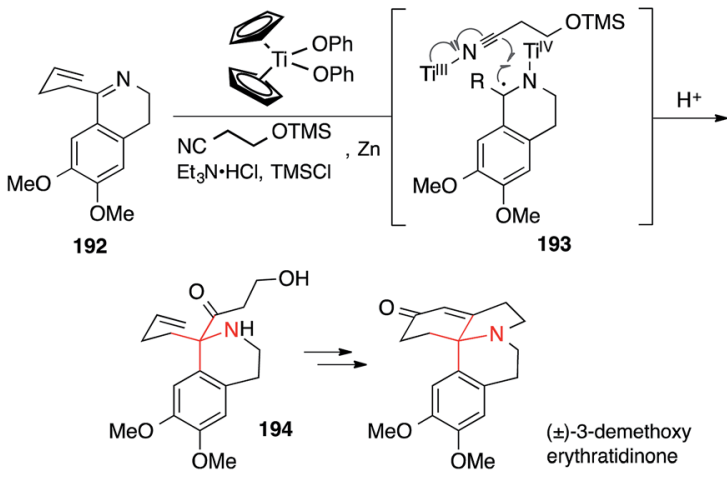

b) Ciufolini's synthesis of (+)-3-demethoxyerythratidinone

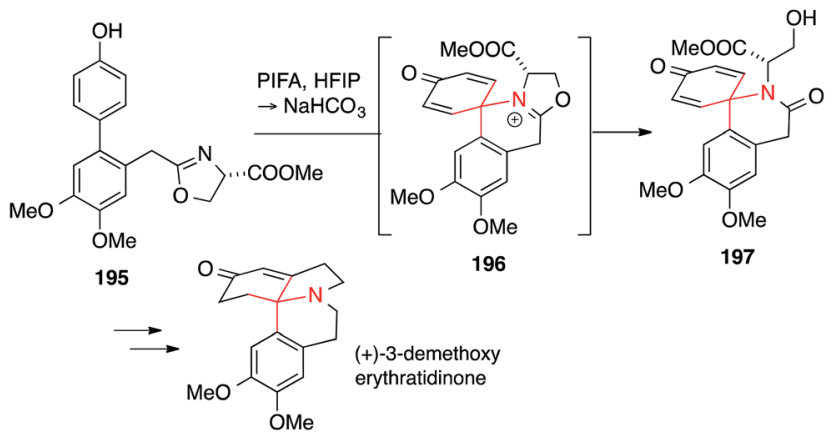

Scheme 43 Syntheses of Erythrina alkaloids by Streuff (2015) and Ciufolini (2015). HFIP =1,1,1,3,3,3-hexafluoroisopropyl alcohol, PIFA = (bis(trifluoroacetoxy)iodo)benzene, TMS = trimethylsilyl.

Other methods used to install the ATA in Erythrina alkaloids include 1,2-addition of organometallic reagents to sulfinimines or iminium ions, ${ }^{270-272}$ Schmidt reaction, ${ }^{273}$ Diels-Alder reactions, ${ }^{274}$ Michael addition, ${ }^{275} \mathrm{~N}$-acyliminium Pictet-Spengler reaction $^{276-278}$ and Heck reaction. ${ }^{279}$

\section{Indolizidine and quinolizidine alkaloids}

A range of alkaloids that belong to the indolizidine and quinolizidine structural class feature an ATA in their carbon skeleton. $^{280}$ They include natural products as diverse as the cylindricines, ${ }^{280,281} \quad$ FR901483, ${ }^{282} \quad$ himandrines, lepadiformines $^{283}$ and halichlorine ${ }^{284}$ (Fig. 10).

The first synthesis of cylindricine alkaloids (viz. cylindricine A, D and E) was accomplished by Snider utilizing a double Michael addition of ammonia to divinylketone 198 which gave the ATA 199, a direct precursor of cylindricine A (Scheme $44 \mathrm{a}){ }^{285}$ Variations of this approach have been used several times in the synthesis of cylindricines. ${ }^{286}$

In 2003, Padwa published a synthesis featuring a Michael addition/dipolar cycloaddition cascade between butadiene 201 and oxime 200 to form 203 via intermediate 202 (Scheme 44b) ${ }^{287}$

The Hsung synthesis of enantiomerically pure cylindricine $\mathrm{C}$ relies on a nucleophilic attack of a diene on $\mathrm{N}$-acyliminium ion 205 starting from ketone 204 (Scheme 45). ${ }^{28,289}$ This vinylogous
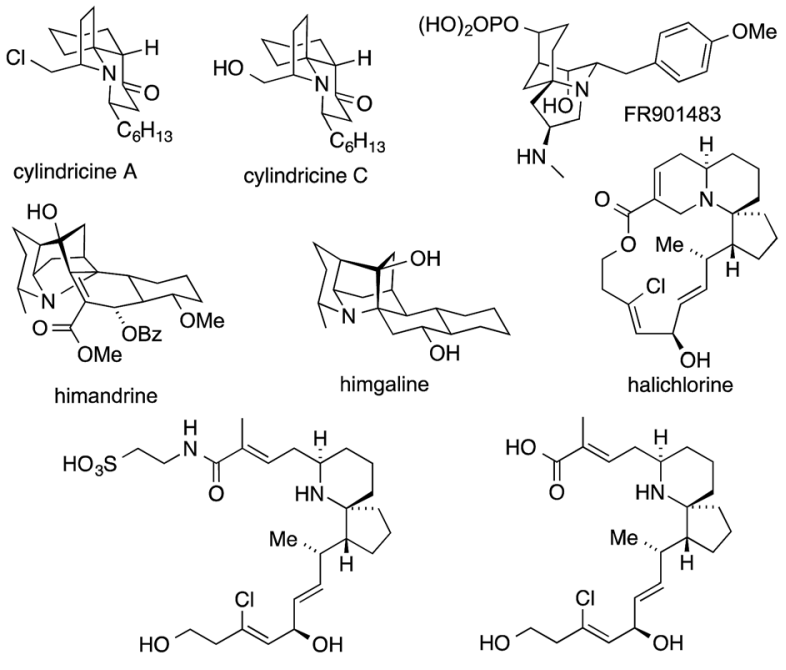

halichlorine

tauropinnaic acid

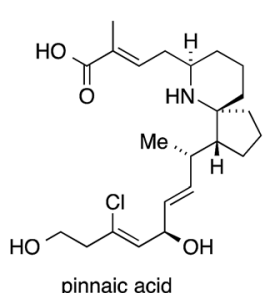

Fig. 10 Selection of quinolizidine alkaloids, including halichlorine and the closely related alkaloids tauropinnaic acid and pinnaic acid

aza-Prins approach was based on a synthesis published by Kibayashi in $2005 .^{290}$

Additional strategies to synthesize the ATA in cylindricine alkaloids involve mainly Michael additions, ${ }^{286,291,292}$ Grignard additions to an imine, ${ }^{293}$ a cycloaddition of an alkyne to a pyrrole derivative, ${ }^{294}$ and carboazidation. ${ }^{295}$

FR901483, an alkaloid isolated from the fermentation broth of a Cladobotryum species with an intricate tricyclic structure, ${ }^{282}$ proved to be an equally popular synthetic target. A biomimetic approach was employed by Sorensen in his enantioselective synthesis (Scheme 46a). ${ }^{296}$

The oxidative azaspiroannulation of amine $\mathbf{2 0 7}$ promoted by (diacetoxyiodo)benzene resulted in the formation of spiroamine 208, an intermediate on the way to the natural product. The same year, Ciufolini set the ATA via a closely related oxidative spiroannulation (not shown, for an example of the methodology see Scheme $43 \mathrm{~b}) .{ }^{297}$

An alternative to this strategy was found by Wang. ${ }^{298}$ In this case, an Aubé-Schmidt reaction of azide 209 provided access to lactam 212, featuring the ATA of FR901483 $(209 \rightarrow$ 212, Scheme 46b). Additional synthetic strategies to set the ATA in FR901483 include a triple Michael addition, ${ }^{299}$ a one-pot bisalkylation, ${ }^{\mathbf{3 0 0 , 3 0 1}}$ an aza-Cope rearrangement/Mannich cyclization ${ }^{\mathbf{3 0 2 , 3 0 3}}$ and an oxidative dearomatization. ${ }^{297}$

The members of the galbulimima alkaloid family, such as himgaline and himandrine, also possess an ATA-containing quinolizidine core (Fig. 10). Exploring a biosynthetic hypothesis, Chackalamannil used an intramolecular Michael addition to convert GB 13 to himgaline via ketone 213 (Scheme 47a). ${ }^{304,305}$ In an interesting variation of this apporach, Movassaghi converted enone 214 via its $\alpha$-chloroester 215 to hexacyclic amine 216, which could then be transformed into himandrine. (Scheme 47b). ${ }^{304}$

In 1996, Uemura disclosed a small series of unusual marine alkaloids featuring ATAs. One of these compounds, 
a) Snider's synthesis of ( \pm )-cylindricine $A$

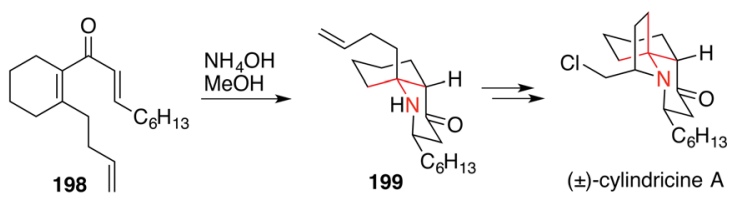

b) Padwa's synthesis of ( \pm )-cylindricine $C$
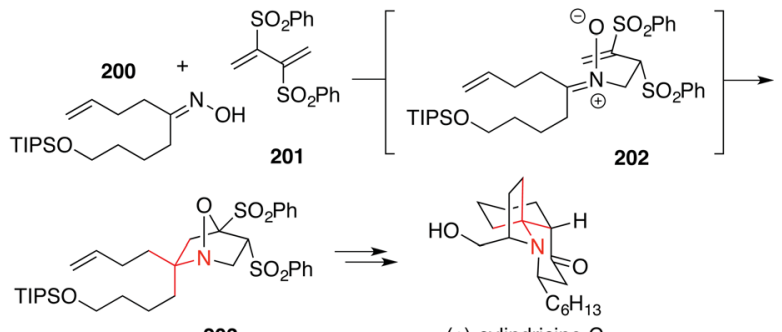

203

( \pm -)cylindricine $\mathrm{C}$

Scheme 44 Synthesis of cylindricines by Snider (1997) and Padwa (2003). Boc $=$ tert-butyloxycarbonyl, TBDPS $=$ tert-butyldiphenylsilyl.

halichlorine, was isolated from the marine sponge Halichondria okadai and was found to selectively inhibit the induction of vascular cell adhesion molecule-1 (VCAM-1). ${ }^{306}$ Pinnaic acid and tauropinnaic acid were recovered from bivalve Pinna muricata.$^{307,308}$ All three molecules present a challenging 6-aza-spiro [4.5]decane core containing the ATA. The latter two lack a quinolizidine moiety, but are included in this chapter due to their close structural relationship.

Danishefsky and Trauner were the first to report the synthesis of $(+)$-halichlorine in $1999^{309}$ followed by a synthesis of pinnaic acid in 2001 (Scheme 48). ${ }^{310,311}$ They used Meyers' lactam 217 as a chiral precursor, which was combined with allyltrimethylsilane in a Sakurai reaction to install the ATA in 218. Intermediate $\mathbf{2 1 9}$ could be diversified to reach both halichlorine and pinnaic acid. These syntheses established the absolute configuration of halichlorine and confirmed the stereochemistry at C-14 and C-17 of pinnaic acid.

A related apporach employing a different type of $\mathrm{N}$-acyl iminium ion was used by Heathcock in 2004 for the synthesis of halichlorine, pinnaic acid and tauropinnaic acid (Scheme 49a). ${ }^{312}$ Treatment of carbamate acetal 220 with allyl trimethylsilane and titanium tetrachloride furnished ATA-bearing

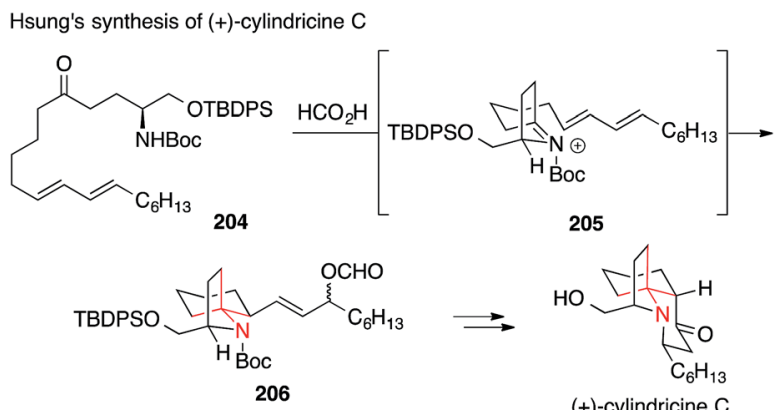

Scheme 45 Synthesis of cylindricine $C$ by Hsung (2004). Boc = tertbutyloxycarbonyl, TBDPS = tert-butyldiphenyl-silyl. a) Sorensen's synthesis of (-)-FR901483
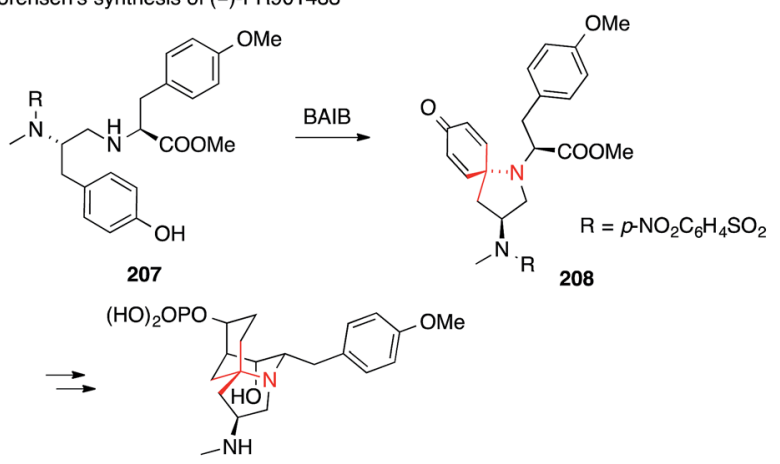

(-)-FR901483

b) Wang's synthesis of (-)-FR901483

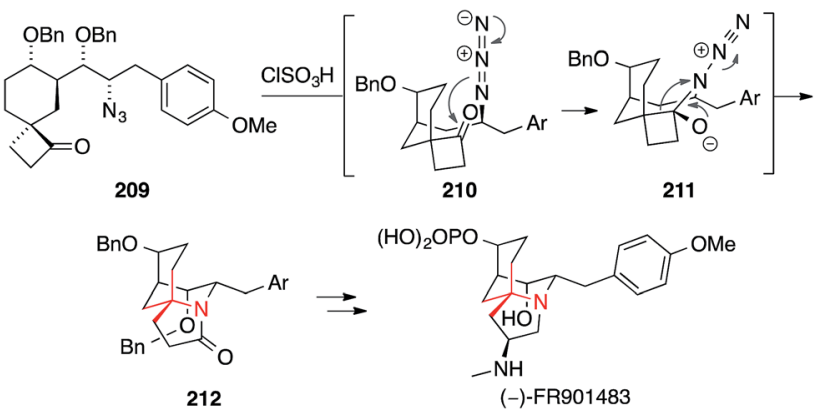

Scheme 46 Syntheses of FR901483 by Sorensen (2000) and Wang (2012). Ar = aryl, BAIB = (diacetoxyiodo)benzene, $\mathrm{Bn}=$ benzyl, TBDPS $=$ tert-butyldiphenylsilyl.

carbamate $\mathbf{2 2 1}$ with a high degree of stereoselectivity. This key intermediate could be transformed into all three natural products.

In 2007, Arimoto reported his version of an asymmetric synthesis of pinnaic acid using a Beckmann rearrangement to install the ATA (Scheme 49b). ${ }^{313}$ The enantiomerically pure bicyclic ketone $\mathbf{2 2 2}$ was treated with a bulky hydroxylamine
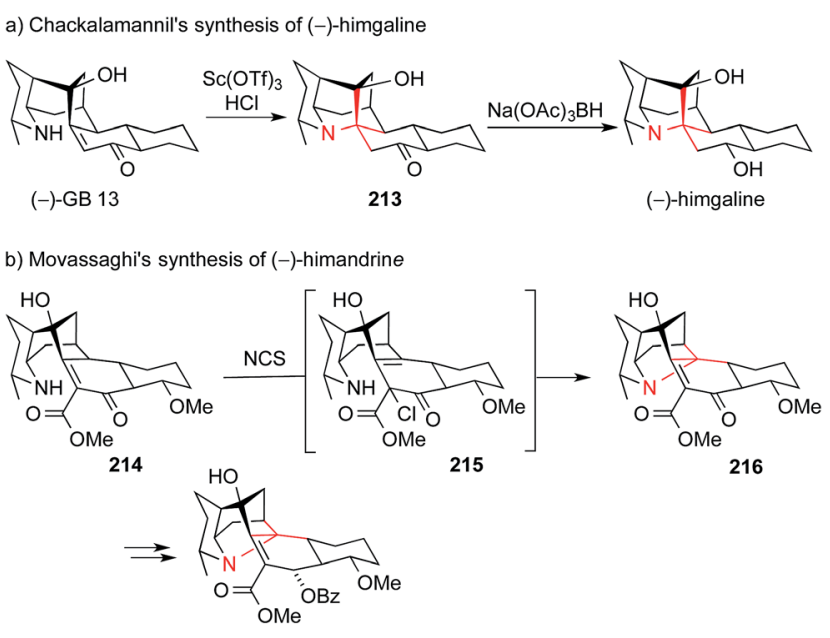

(-)-himandrine

Scheme 47 Synthesis of galbulimima alkaloids by Chackalamannil (2009) and Movassaghi (2009). Ac = acetyl, Bz = benzoyl, NCS =Nchlorosuccinimide, OTf $=$ trifluoromethanesulfonate. 
Danishefsky-Trauner synthesis of (+)-halichlorine and pinnaic acid

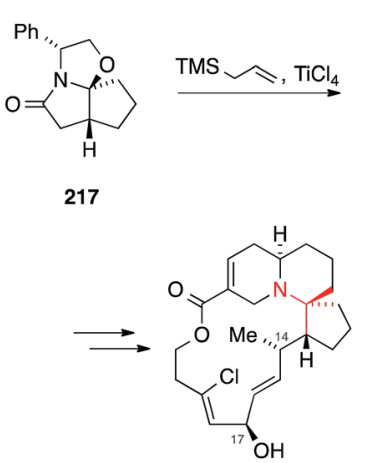

(+)-halichlorine<smiles>C=CC[C@]12CCC[C@]1([14CH3])CC(=O)N2[C@H](CO)c1ccccc1</smiles>

218

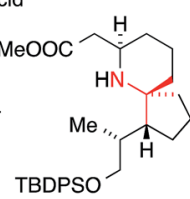

219
Scheme 48 Synthesis of halichlorine and pinnaic acid by Danishefsky and Trauner (1999). TBDPS = tert-butyldiphenylsilyl, TMS = trimethylsilyl.

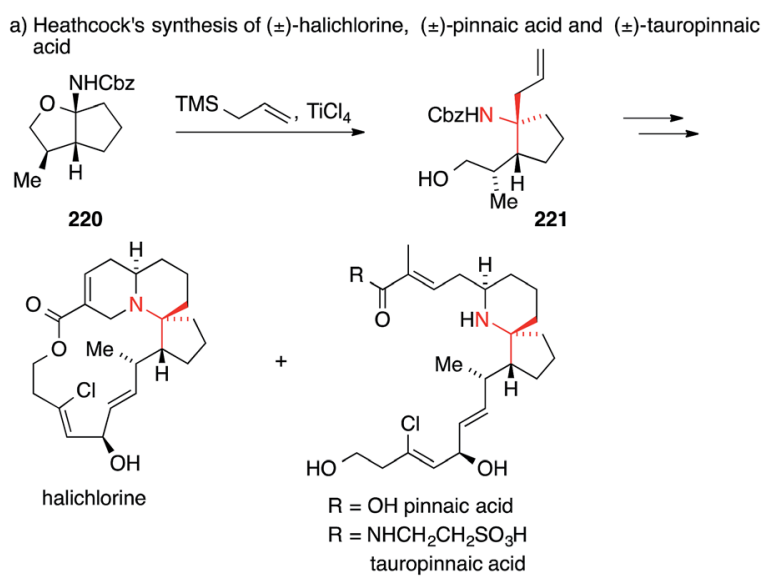

b) Arimoto's synthesis of pinnaic acid

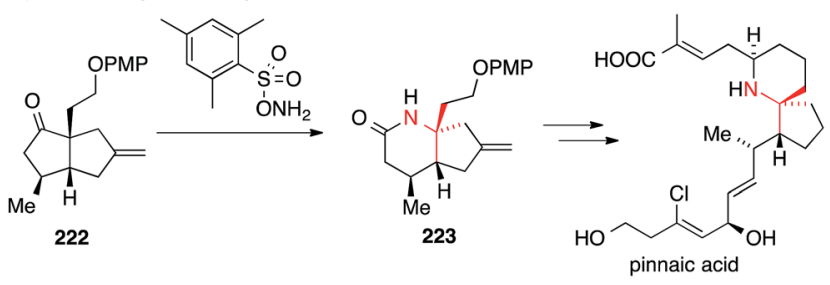

Scheme 49 Syntheses of halichlorine, pinnaic acid and tauropinnaic acid by Heathcock (2004) and Arimoto (2007). Cbz = benzyloxycarbonyl, $\mathrm{PMP}=p$-methoxyphenyl, TMS = trimethylsilyl.

reagent to afford the desired lactam $\mathbf{2 2 3}$, which was then converted into the natural product.

\section{Lactacystine and salinosporamide}

In 1991, Omura isolated the unusual natural product lactacystin from Streptomyces sp. OM-6519 and identified it as a proteasome inhibitor (Fig. 11)..$^{314,315} \mathrm{~A}$ structurally related $\beta$-lactone, salinosporamide A, which shows similar biological activity, was subsequently isolated from a marine bacterium, Salinispora tropica. ${ }^{316}$

Both compounds possess a densely functionalized $\gamma$-lactam core with three contiguous stereocenters, one of which is of the
ATA type. Their significant biological activity has stimulated a large number of total syntheses, ${ }^{317}$ and a variety of methods for the installation of the ATA motif have been applied..$^{318-345}$

In pioneering work, Corey reported five total syntheses of lactacystin between 1992 and 1998. ${ }^{318-320,326,327}$ The Corey group showed that the ATA can be installed using an aldol addition of $\alpha$-amino acid derivative 224 (via intermediate 225, Scheme 50a). Other groups also contributed to this field in the 1990s. ${ }^{321-325,328}$ In most cases, the strategy applied for the installation of the ATA motif involved an alkylation or aldol reaction of an $\alpha$-amino acid derivative. ${ }^{318-322,324,326-328}$ By contrast, Shibasaki introduced the ATA with a catalytic enantioselective Strecker reaction (Scheme 50b). ${ }^{317,334}$ In this work, phosphinoylimine 226 was converted to aminonitrile 227 using a gadolinium catalyst and the chiral ligand $\mathbf{A}$.

Another unusual approach was taken by Wardrop ${ }^{346}$ in his formal synthesis and Hayes ${ }^{338}$ in his total synthesis of lactacystin (Scheme 50c). Both groups explored an intramolecular carbene insertion into a $\mathrm{C}, \mathrm{H}$-bond to form the five-membered heterocyclic core. Hayes converted the enantiomerically pure
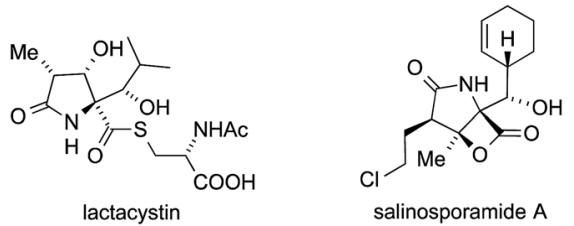

Fig. 11 Lactacystin and salinosporamide A.

a) Corey's synthesis of (+)-lactacystin

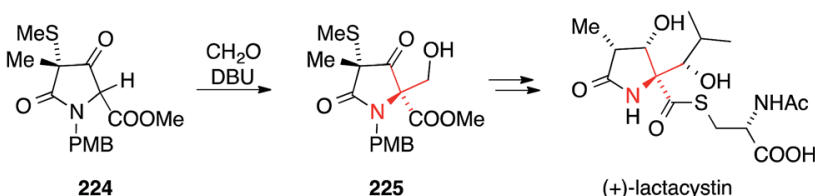

b) Shibasaki's synthesis of (+)-lactacystin
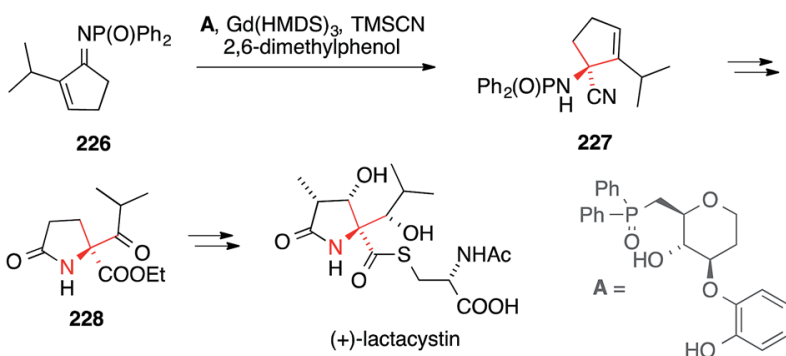

227

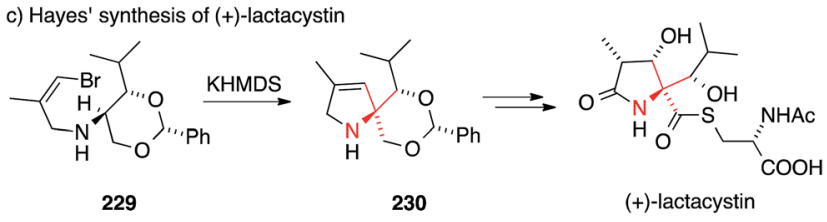

Scheme 50 Syntheses of lactacystin by Corey (1992), Shibasaki (2006) and Hayes (2008). Ac = acetyl, DBU =1,8-diazabicycloundec-7-ene, HMDS = bis(trimethylsilyl)amine, PMB = paramethoxybenzyl, TMS = trimethylsilyl. 


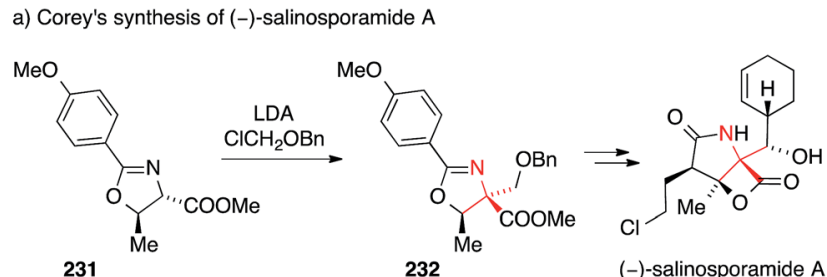

b) Sato's synthesis of (-)-salinosporamide A

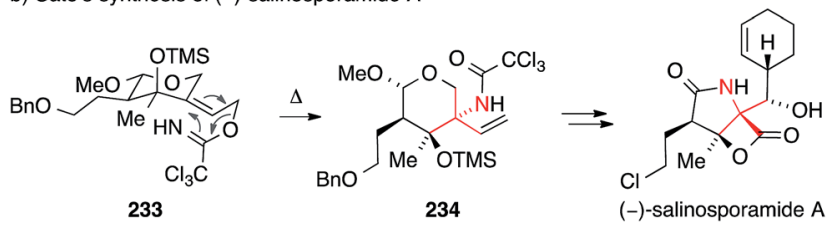

Scheme 51 Syntheses of salinosporamide A by Corey (2004) and Sato (2011). $\mathrm{Bn}=$ benzyl, LDA = lithium diisopropylamide, TMS = trimethylsilyl.

vinyl bromide 229 to the corresponding vinylidene carbene, which underwent cyclization to afford 230 in high yield.

The first synthesis of salinosporamide was reported by Corey in $2004 . .^{30,331}$ In this case, the ATA was installed by alkylation of threonine-derived oxazoline $\mathbf{2 3 1}$ with chloromethyl benzyl ether (via intermediate 232, Scheme 51a).

A more recent synthesis of salinosporamide A published by Sato and Chid uses a stereoselective Overman rearrangement to install the ATA (Scheme 51b). ${ }^{343}$ Heating of the highly functionalized trichloroacetimidate 233 provided trichloroacetamide $\mathbf{2 3 4}$ as a key intermediate.

Other syntheses of salinosporamide and lactacystine used different strategies for the formation of the ATA, such as intramolecular aldol reactions, ${ }^{336,337}$ intramolecular acylations, ${ }^{332}$ acid catalyzed cyclizations of malonates, ${ }^{335,339}$ indiumcatalyzed Conia-ene reactions, ${ }^{341} \mathrm{C}, \mathrm{H}$-alkynylation ${ }^{347}$ and enzymatic desymmetrizations of prochiral ATAs. ${ }^{\mathbf{3 4 0}}$

\section{Manzacidins}

The manzacidins, a small family of bromopyrrole alkaloids, have attracted considerable attention from the synthetic community despite, or maybe because of their relatively simple structures. Manzacidins A-C (Fig. 12) were first isolated form the Okinawan sponge Hymeniacidon sp. by Kobayashi in $1991,{ }^{348}$ followed by the isolation of manzacidin D from the 'living fossil' sponge Astrosclera willeyana ${ }^{349}$ and $N$-methylmanzacidin $\mathrm{C}$ from Axinella brevistyla. ${ }^{350}$

In 2000, Ohfune reported the synthesis of manzacidins A and C via a Strecker reaction and assigned the absolute configuration of these natural products (not shown). ${ }^{351}$ In 2002, DuBois synthesized manzazidin $\mathrm{C}$ using an elegant oxidative $\mathrm{C}, \mathrm{H}-$ insertion that involved sulfamate 235 (via intermediate 236, Scheme 52a). ${ }^{352}$ One year later, he used a similar strategy to set the ATA in tetrodotoxin (see chapter 14, Scheme 54c). ${ }^{353}$

Leighton accomplished the synthesis of manzacidin $\mathrm{C}$ employing their asymmetric silane-promoted [3+2]
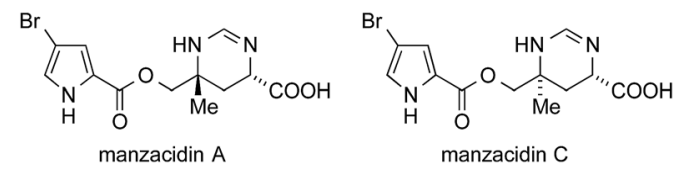

Fig. 12 Manzacidin A and C.

cycloaddition methodology (Scheme 52b). ${ }^{354}$ Exposure of alkene 237 and hydrazone 238 to chiral silane $R, R$-B gave pyrazolidine 239, thus setting both stereocenters of the target molecule, including the ATA, in a single step. Intermediate 239 was subsequently converted to manzacidin C via reductive $\mathrm{N}, \mathrm{N}$ bond cleavage.

A more recent formal synthesis of manzacidins $\mathrm{A}$ and $\mathrm{C}$, published by Ichikawa, features a rare allyl cyanate/isocyanate rearrangement as the key step (Scheme 53). ${ }^{355}$ To this end, he synthesized carbamate $\mathbf{2 4 0}$, which was converted to allyl cyanate $\mathbf{2 4 1}$ by in situ dehydration. The subsequent rearrangement with chirality transfer gave isocyanate $\mathbf{2 4 2}$, which was then transformed into manzacidin A. The synthesis of manzacidin $\mathrm{C}$ was accomplished analogously from a diastereoisomer of carbamate $240 .{ }^{355}$

Several other synthetic approaches toward these molecules have been reported. These strategies for the installation of the ATA moiety involve diastereoselective nitrene insertion, ${ }^{352}$ 1,3dipolar cycloaddition, ${ }^{356,357}$ Hofmann rearrangement, ${ }^{358}$ diastereoselective iodocyclization, ${ }^{359,360}$ Grignard addition to an imine $^{361}$ and a variety of other methods. ${ }^{362-366}$ Indeed, manzacidines remain targets of great interest for synthetic chemists. In 2015, Inoue published a synthesis of manzacidin A using a radical-based decarbonylative coupling (not shown). ${ }^{367}$ Recently the relative stereochemistry of manzacidin $\mathrm{B}$, which possesses an additional stereocenter, was revised using total synthesis. ${ }^{362,363,365}$

a) Du Bois' synthesis of (-)-manzacidin $\mathrm{A}$

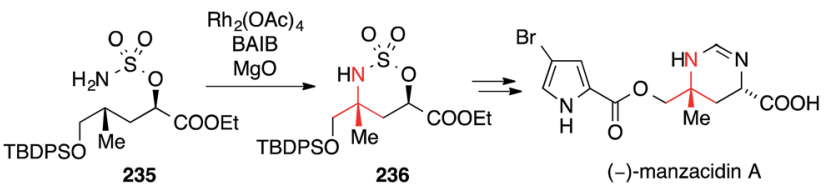

b) Leighton's synthesis of (+)-manzacidin $\mathrm{C}$

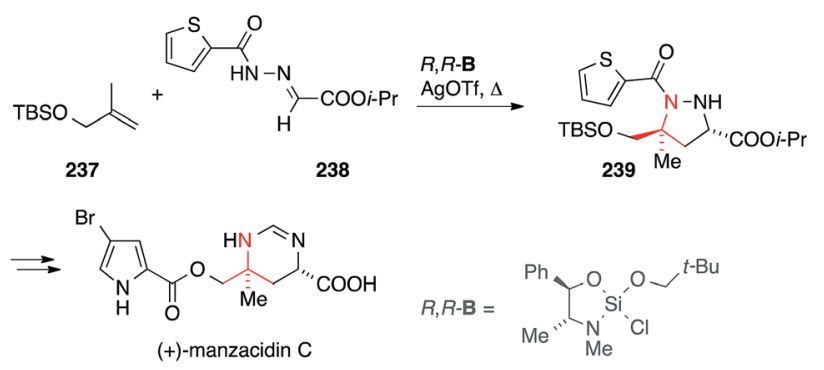

Scheme 52 Syntheses of manzacidins by DuBois (2002) and Leighton (2008). Ac $=$ acetyl, BAIB $=$ (diacetoxyiodo)benzene, OTf $=$ trifluoromethanesulfonate, $i-\operatorname{Pr}=$ iso-propyl, TBDPS $=$ tertbutyldiphenylsilyl. 
Ichikawa's synthesis of (-)-manzacidin A

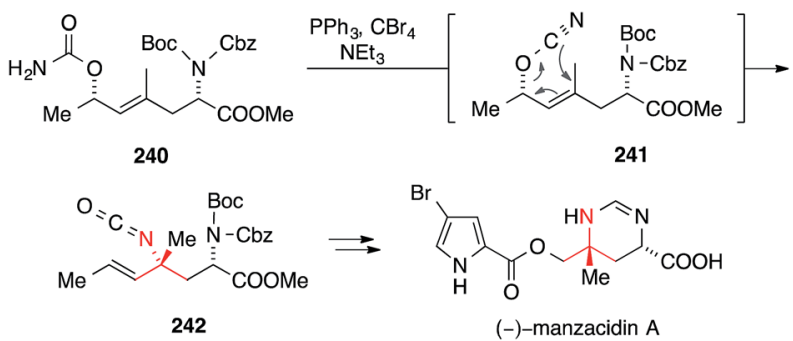

Scheme 53 Synthesis of manzacidin A by Ichikawa (2012). Boc = tertbutyloxycarbonyl, $\mathrm{Cbz}=$ benzyloxycarbonyl.

\section{Tetrodotoxin}

Tetrodotoxin (TTX) was first isolated from the Fugu puffer fish in $1909 .{ }^{368,369}$ Its structure was independently reported by Hirata-Goto, ${ }^{370}$ Tsuda $^{371}$ and Woodward ${ }^{372}$ in the 1960s. Their assignment was confirmed by X-ray crystallography, which also established the absolute configuration of the molecule. ${ }^{373,374}$ TTX features a highly functionalized heteroadamantane framework that contains an ortho-acid and is fused to a cyclic guanidinium moiety via an ATA motif. The molecule is an extremely powerful and selective blocker of voltage-gated sodium channels and is widely used as a research tool in neuroscience. ${ }^{375-379}$ Due to its intriguing structure and bioactivity, attempts to synthesize TTX have been made from an early stage and activity in this field has recently increased significantly. ${ }^{380}$

a) Kishi's synthesis of ( \pm )-TTX

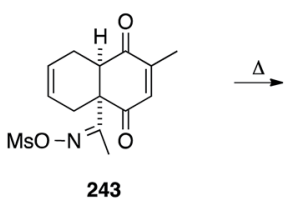

243

b) Isobe's synthesis of (-)-TTX

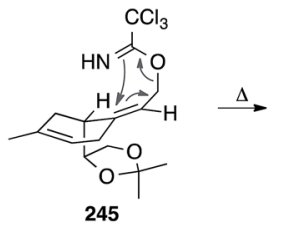

c) DuBois' synthesis of (-)-TTX
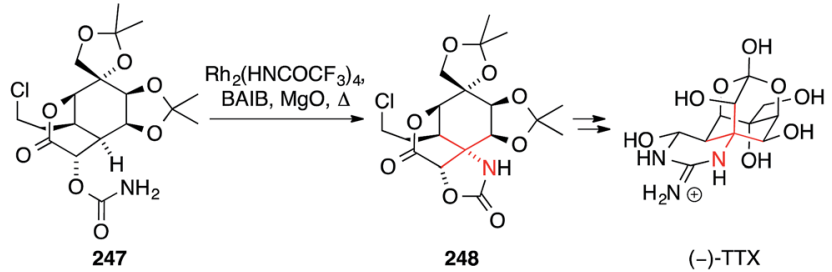

Scheme 54 Syntheses of tetrodotoxin (TTX) by Kishi (1972), Isobe (2003) and DuBois (2003). Ac = acetyl, BAIB = (diacetoxyiodo) benzene, $\mathrm{Ms}=$ methanesulfonyl, $\mathrm{Ph}=$ phenyl, .
The first total synthesis of TTX was accomplished by Kishi in 1972 (Scheme 54a). ${ }^{\text {381-384 }}$ In his approach, the ATA was formed using a Beckmann rearrangement of oxime 243, which was synthesized using a regioselective Diels-Alder reaction. The resulting key intermediate $\mathbf{2 4 4}$ was converted into TTX using a series of stereoselective redox transformations, ring cleavage and the installation of the cyclic guanidine with newly developed methodology. Although the Kishi synthesis was not enantioselective, it still stands as one of the strategically most elegant approaches to a natural product featuring an ATA motif.

After a 30 year lull, Isobe published the first enantioselective synthesis of TTX wherein the ATA motif was installed with a stereoselective Overman rearrangement (Scheme 54b). ${ }^{385-387}$ To this end, an allylic alcohol was converted to trichloroacetimidate $\mathbf{2 4 5}$, which underwent rearrangement to yield trichloroacetamide 246. Compound 246 bears all the carbon atoms of TTX and could be converted into the natural product in a series of steps.

Shortly thereafter, DuBois developed an enantioselective approach to TTX that involved his signature nitrene insertion chemistry (Scheme 54c). ${ }^{353}$ Exposure of the key intermediate, carbamate $\mathbf{2 4 7}$, to a hypervalent iodine reagent and magnesium oxide in the presence of a rhodium catalyst led to the formation of oxazolidinone 248, which bears the ATA motif. Insertion into other possible $\mathrm{C}, \mathrm{H}$-bonds was largely avoided through careful engineering of the substrate.

\section{Miscellaneous alkaloids}

ATA's occur in many other alkaloids that cannot easily be categorized along the biosynthetic and structural lines shown above. An example is gracilamine, which was isolated in 2005 by Ünver and Kaya from the Amaryllidacae species Galanthus gracilis. ${ }^{388}$ In 2012, the first synthesis of gracilamine was disclosed by Ma (Scheme 55a). ${ }^{389}$ It relies on a potentially biomimetic, stereoselective and intramolecular [3+2] cycloaddition, transforming 249 into the highly functionalized pyrrolidine $\mathbf{2 5 0}$.

In a recent synthesis, Gao set the ATA via an intramolecular Mannich annulation (Scheme 55b) ${ }^{390}$ First, $\alpha$-ketoester 252 was condensed with amine 251. The resulting iminium ion 253 then underwent a diastereoselective Mannich reaction to furnish the hexacyclic scaffold 254 of gracilamine.

The amathaspiramides A-F are a family of marine alkaloids isolated from the bryozoan Amathia wilsoni in 1999 (Fig. 13). ${ }^{391}$ They feature an unusual spirocyclic core consisting of a pyrrolidine fused to a pyrrolidinone moiety. ${ }^{391}$

The first total synthesis of a member of this family, viz. amathaspiramide F, was disclosed by Trauner in 2002 (Scheme 56a). ${ }^{392}$ In this work, the proline-derived $N, N$-acetal 255 was converted to the corresponding silyl ketene acetal, which underwent a diastereoselective Michael addition to the nitro olefin 256, establishing the ATA of 257. Subsequently, Ohfune published his approach to amathaspiramide $\mathrm{F}$ which utilizes an enolate Claisen rearrangement for the same purpose (not shown). ${ }^{393}$

In 2012, Fukuyama reported the asymmetric synthesis of the entire amathaspiramide family (Scheme 56b). ${ }^{394}$ In their work, 
a) Ma's synthesis of ( \pm )-gracilamine

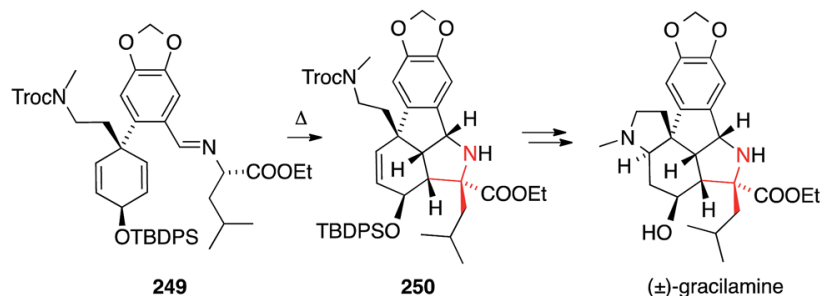

b) Gao's synthesis of ( \pm )-gracilamine
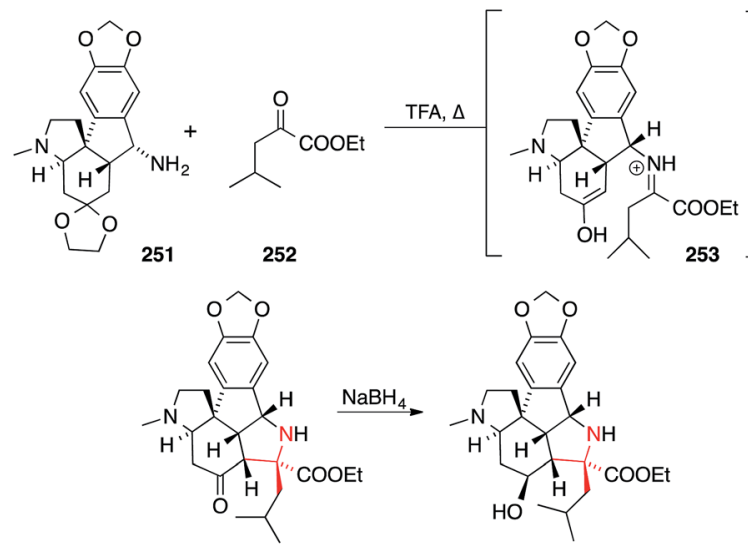

254

$( \pm)$-gracilamine

Scheme 55 Syntheses of gracilamine by Ma (2012) and Gao (2014). TBDPS $=$ tert-butyldiphenylsilyl, Troc $=2,2,2$-trichlorethoxycarbonyl, TFA = trifluoroacetic acid.

the benzyl ester $\mathbf{2 5 8}$ bearing a quaternary stereocenter was first deprotected and the resulting acid converted to the corresponding amine via Curtius rearrangement. After hydrolysis of the resulting isocyanate, the intermediate amino ester underwent cyclization to afford the pyrrolidinone 259 , which could be converted into all members of the family.

In Tambar's asymmetric synthesis of amanthaspiramide $\mathrm{F}$, proline derivative $\mathbf{2 6 0}$ underwent a palladium-catalyzed allylic substitution of carbonate $\mathbf{2 6 1}$ to yield an intermediary quarternary ammonium ion 262, which, after deprotonation, engaged in a stereoselective [2,3] Stevens rearrangement via 263 (Scheme 57a). ${ }^{395}$ The resulting ATA-containing pyrrolidine 264 was converted into amathaspiramide $\mathrm{F}$.

More recently, Lee used a formal [3+2] cycloaddition between lithium(trimethylsilyl)diazomethane 266 and $\alpha, \beta$ unsaturated ester 265 to set the ATA in amanthaspiramide C
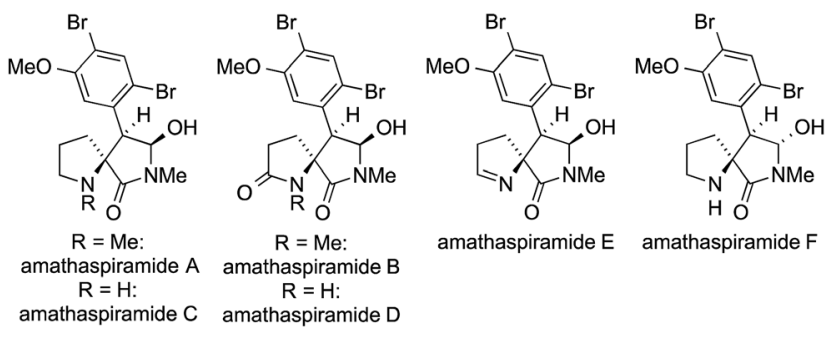

Fig. 13 The amathaspiramides A-F. a) Trauner's synthesis of (-)-amathaspiramide $F$

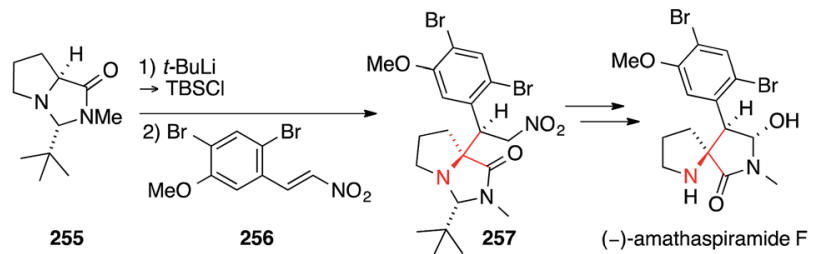

b) Fukuyama's syntheses of ( \pm )-amathaspiramides

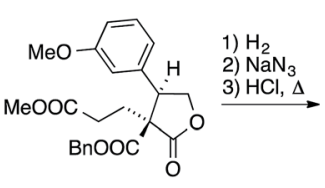

258

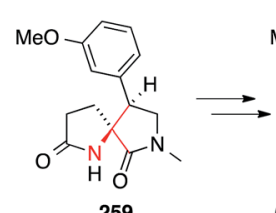

259

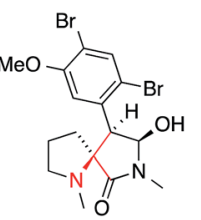

( \pm )-amathaspiramide $\mathrm{A}$
Scheme 56 Syntheses of amathaspiramides by Trauner (2002) and Fukuyama (2012). Bn = benzyl, $t$-Bu $=$ tert-butyl, TBS $=$ tertbutyldimethylsilyl.

(via intermediate 267, Scheme 57b). ${ }^{396}$ The N,N-bond in pyrazoline 268 was cleaved by treatment with $p$-TsOH and additional transformations led to the total synthesis of amathaspiramide $\mathrm{C}$ and the formal synthesis of all the other amathaspiramides.

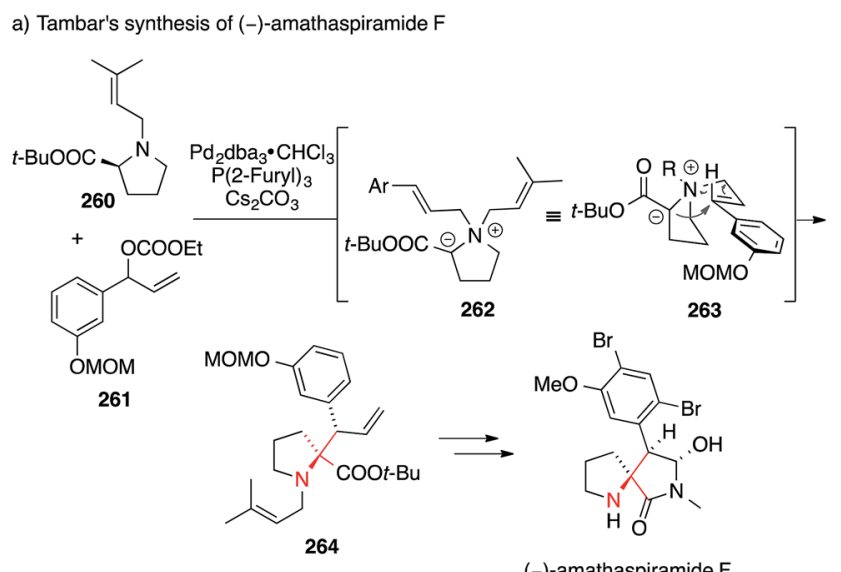

b) Lee's synthesis of ( \pm )-amathaspiramide C

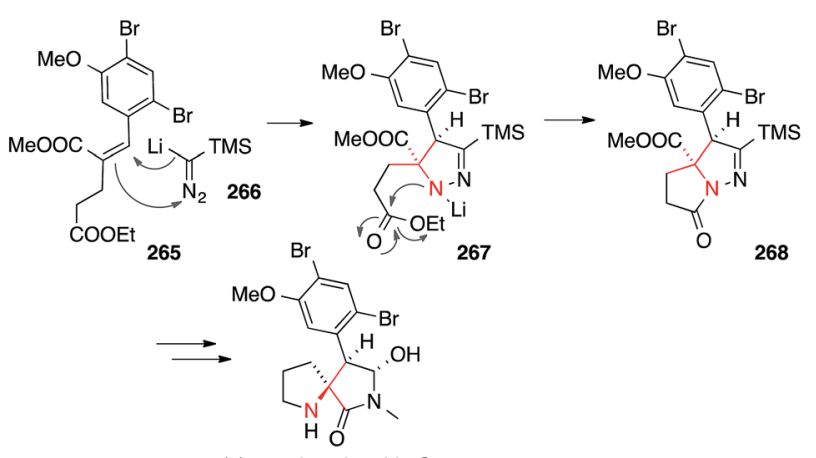

( \pm )-amathaspiramide $\mathrm{C}$

Scheme 57 Syntheses of amathaspiramides by Tambar (2013) and Lee (2015). $t$-Bu = tert-butyl, $\mathrm{dba}=$ dibenzylideneacetone, $\mathrm{MOM}=$ methoxymethyl, TMS = trimethylsilyl. 


\section{Conclusions}

Herein, we have provided a survey of syntheses that feature the installation of an $\alpha$-tertiary amine (ATA) as a common thread. This structural motif is widespread amongst alkaloids and has physicochemical consequences, such as increased lipophilicity and chromatographic mobility that distinguishes its bearers from other basic amines. Since ATAs also occur in drug candidates and building blocks for functional materials, our review is intended to provide a useful reference for medicinal chemists and colleagues active in the material sciences. It may also provide a baseline for the development of additional and hopefully more efficient methods for the synthesis of target molecules containing $\alpha$-tertiary amines.

\section{Acknowledgements}

We thank the Deutsche Forschungsgemeinschaft (SFB 749) for financial support. We are also grateful to the Deutsche Telekom Foundation (Ph.D. Scholarship to N. V.). We thank Felix Hartrampf, Benjamin Williams, Daniel W. Terwilliger, Dr Henry Toombs Ruane and David Konrad for helpful discussions and for proofreading the manuscript.

\section{Notes and references}

1 G. A. Cordell, The Alkaloids, Elsevier, London, 1998.

2 P. M. Dewick, Medicinal Natural Products; A Biosynthetic Approach, Wiley-VCH, Weinheim, third edn, 2009.

3 M. Wink, in Studies in Natural Products Chemistry, Elsevier, 2000, vol. 21, ch. Interference of Alkaloids with Neuroreceptors and Ion Channels, pp. 3-122.

4 G. A. Cordell, M. L. Quinn-Beattie and N. R. Farnsworth, Phytother. Res., 2001, 15, 183-205.

5 J. Clayden, M. Donnard, J. Lefranc and D. J. Tetlow, Chem. Commun., 2011, 47, 4624-4639.

6 G. Dake, Tetrahedron, 2006, 62, 3467-3492.

7 S. A. A. El Bialy, H. Braun and L. F. Tietze, Synthesis, 2004, 2249-2262.

8 S. H. Kang, S. Y. Kang, H.-S. Lee and A. J. Buglass, Chem. Rev., 2005, 105, 4537-4558.

9 A. Sharma and J. F. Hartwig, Nature, 2015, 517, 600-604.

10 L. Huang, M. Arndt, K. Gooßen, H. Heydt and L. J. Gooßen, Chem. Rev., 2015, 115, 2596-2697.

11 A. Glisan King and J. Meinwald, Chem. Rev., 1996, 96, 11051122.

12 P. Laurent, B. Lebrun, J.-C. Braekman, D. Daloze and J. M. Pasteels, Tetrahedron, 2001, 57, 3403-3412.

13 R. Robinson, J. Chem. Soc., Trans., 1917, 111, 762-768.

14 B. K. Blount and R. Robinson, J. Chem. Soc., 1933, 15111512.

15 C. Schöpf and G. Lehmann, Liebigs Ann. Chem., 1935, 518, 1-37.

16 K. Alder, H. Betzing, R. Kuth and H.-A. Dortmann, Liebigs Ann. Chem., 1959, 620, 73-87.

17 R. I. Longley and W. S. Emerson, J. Am. Chem. Soc., 1950, 72, 3079-3081.
18 K. Alder and H. A. Dortmann, Chem. Ber., 1953, 86, 15441554.

19 K. Alder, H. Wirtz and H. Koppelberg, Liebigs Ann. Chem., 1956, 601, 138-154.

20 B. Tursch, C. Chome, J. C. Braekman and D. Daloze, Bull. Soc. Chim. Belg., 1973, 82, 699-703.

21 D. H. Gnecco Medina, D. S. Grierson and H.-P. Husson, Tetrahedron Lett., 1983, 24, 2099-2102.

22 C. Yue, J. Royer and H.-P. Husson, J. Org. Chem., 1992, 57, 4211-4214.

23 M. F. Mechelke and A. I. Meyers, Tetrahedron Lett., 2000, 41, 4339-4342.

24 E. C. Davison, A. B. Holmes and I. T. Forbes, Tetrahedron Lett., 1995, 36, 9047-9050.

25 T. Itoh, N. Yamazaki and C. Kibayashi, Org. Lett., 2002, 4, 2469-2472.

26 R. K. Hill and L. A. Renbaum, Tetrahedron, 1982, 38, 19591963.

27 T. C. Coombs, Y. Zhang, E. C. Garnier-Amblard and L. S. Liebeskind, J. Am. Chem. Soc., 2009, 131, 876-877.

28 S. Roy and C. Spino, Org. Lett., 2006, 8, 939-942.

29 M. Arbour, S. Roy, C. Godbout and C. Spino, J. Org. Chem., 2009, 74, 3806-3814.

30 F. A. Davis and R. Edupuganti, Org. Lett., 2010, 12, 848-851.

31 F. A. Davis, J. Org. Chem., 2006, 71, 8993-9003.

32 J. W. Daly, I. Karle, C. W. Myers, T. Tokuyama, J. A. Waters and B. Witkop, Proc. Natl. Acad. Sci. U. S. A., 1971, 68, 18701875.

33 J. W. Daly, J. Nat. Prod., 1998, 61, 162-172.

34 E. X. Albuquerque, K. Kuba and J. Daly, J. Pharmacol. Exp. Ther., 1974, 189, 513-524.

35 A. J. Lapa, E. X. Albuquerque, J. M. Sarvey, J. Daly and B. Witkop, Exp. Neurol., 1975, 47, 558-580.

36 A. T. Eldefrawi, M. E. Eldefrawi, E. X. Albuquerque, A. C. Oliveira, N. Mansour, M. Adler, J. W. Daly, G. B. Brown, W. Burgermeister and B. Witkop, Proc. Natl. Acad. Sci. U. S. A., 1977, 74, 2172-2176.

37 K. Takahashi, A. E. Jacobson, C. P. Mak, B. Witkop, A. Brossi, E. X. Albuquerque, J. E. Warnick, M. A. Maleque, A. Bavoso and J. V. Silverton, J. Med. Chem., 1982, 25, 919-925.

38 C. E. Spivak, M. A. Maleque, A. C. Oliveira, L. M. Masukawa, T. Tokuyama, J. W. Daly and E. X. Albuquerque, Mol. Pharmacol., 1982, 21, 351-361.

39 A. Sinclair and R. A. Stockman, Nat. Prod. Rep., 2007, 24, 298-326.

40 T. Fukuyama, L. V. Dunkerton, M. Aratani and Y. Kishi, J. Org. Chem., 1975, 40, 2011-2012.

41 M. Aratani, L. V. Dunkerton, T. Fukuyama, Y. Kishi, H. Kakoi, S. Sugiura and S. Inoue, J. Org. Chem., 1975, 40, 2009-2011.

42 S. C. Carey, M. Aratani and Y. Kishi, Tetrahedron Lett., 1985, 26, 5887-5890.

43 E. J. Corey, J. F. Arnett and G. N. Widiger, J. Am. Chem. Soc., 1975, 97, 430-431.

44 T. Ibuka, H. Minakata, Y. Mitsui, E. Tabushi, T. Taga and Y. Inubushi, Chem. Lett., 1981, 10, 1409-1412. 
45 T. Ibuka, Y. Mitsui, K. Hayashi, H. Minakata and Y. Inubushi, Tetrahedron Lett., 1981, 22, 4425-4428.

46 T. Ibuka, H. Minakata, Y. Mitsui, K. Hayashi, T. Taga and Y. Inubushi, Chem. Pharm. Bull., 1982, 30, 2840-2859.

47 N. Maezaki, H. Fukuyama, S. Yagi, T. Tanaka and C. Iwata, J. Chem. Soc., Chem. Commun., 1994, 1835-1836.

48 D. Kim and C. Won Park, Chem. Commun., 1997, 2263-2264. 49 G. Stork and K. Zhao, J. Am. Chem. Soc., 1990, 112, 58755876.

50 Y. Adachi, N. Kamei, S. Yokoshima and T. Fukuyama, Org. Lett., 2011, 13, 4446-4449.

51 Y. Adachi, N. Kamei, S. Yokoshima and T. Fukuyama, Org. Lett., 2014, 16, 1273.

52 M. S. Karatholuvhu, A. Sinclair, A. F. Newton, M.-L. Alcaraz, R. A. Stockman and P. L. Fuchs, J. Am. Chem. Soc., 2006, 128, 12656-12657.

53 G. M. Williams, S. D. Roughley, J. E. Davies, A. B. Holmes and J. P. Adams, J. Am. Chem. Soc., 1999, 121, 4900-4901.

54 E. C. Davison, M. E. Fox, A. B. Holmes, S. D. Roughley, C. J. Smith, G. M. Williams, J. E. Davies, P. R. Raithby, J. P. Adams, I. T. Forbes, N. J. Press and M. J. Thompson, J. Chem. Soc., Perkin Trans. 1, 2002, 1494-1514.

55 M. Glanzmann, C. Karalai, B. Ostersehlt, U. Schön, C. Frese and E. Winterfeldt, Tetrahedron, 1982, 38, 2805-2810.

56 J. J. Venit, M. DiPierro and P. Magnus, J. Org. Chem., 1989, 54, 4298-4301.

57 S. A. Godleski, D. J. Heacock, J. D. Meinhart and S. van Wallendael, J. Org. Chem., 1983, 48, 2101-2103.

58 W. Carruthers and S. A. Cumming, J. Chem. Soc., Chem. Commun., 1983, 360-361.

59 D. Tanner and P. Somfai, Tetrahedron Lett., 1985, 26, 38833886.

60 D. Tanner and P. Somfai, Tetrahedron, 1986, 42, 5657-5664.

61 D. Tanner, M. Sellen and J. E. Baeckvall, J. Org. Chem., 1989, 54, 3374-3378.

62 D. J. Wardrop, W. Zhang and C. L. Landrie, Tetrahedron Lett., 2004, 45, 4229-4231.

63 R. W. Fitch and F. A. Luzzio, Ultrason. Sonochem., 1997, 4, 99-107.

64 O. Y. Provoost, S. J. Hedley, A. J. Hazelwood and J. P. A. Harrity, Tetrahedron Lett., 2006, 47, 331-333.

65 P. Compain, J. Goré and J.-M. Vatèle, Tetrahedron, 1996, 52, 6647-6664.

66 D. Tanner, L. Hagberg and A. Poulsen, Tetrahedron, 1999, 55, 1427-1440.

67 S. Kim, H. Ko, T. Lee and D. Kim, J. Org. Chem., 2005, 70, 5756-5759.

68 D. L. Comins, Y.-M. Zhang and X. Zheng, Chem. Commun., 1998, 2509-2510.

69 J. D. Winkler and P. M. Hershberger, J. Am. Chem. Soc., 1989, 111, 4852-4856.

70 X. Q. Ma and D. R. Gang, Nat. Prod. Rep., 2004, 21, 752-772.

71 K. Bödeker, Liebigs Ann. Chem., 1881, 208, 363-367.

72 G. Stork, R. A. Kretchmer and R. H. Schlessinger, J. Am. Chem. Soc., 1968, 90, 1647-1648.

73 W. A. Ayer, W. R. Bowman, G. A. Cooke and A. C. Soper, Tetrahedron Lett., 1966, 7, 2021-2026.
74 W. A. Ayer, W. R. Bowman, T. C. Joseph and P. Smith, J. Am. Chem. Soc., 1968, 90, 1648-1650.

75 A. Padwa, M. A. Brodney, J. P. Marino and S. M. Sheehan, J. Org. Chem., 1997, 62, 78-87.

76 K. Wiesner and L. Poon, Tetrahedron Lett., 1967, 8, 49374940.

77 H. Dugas, M. E. Hazenberg, Z. Valenta and K. Wiesner, Tetrahedron Lett., 1967, 8, 4931-4936.

78 K. Wiesner, V. Musil and K. J. Wesner, Tetrahedron Lett., 1968, 9, 5643-5646.

79 K. Wiesner, L. Poon, I. Jirkovský and M. Fishman, Can. J. Chem., 1969, 47, 433-444.

80 C. H. Heathcock, E. Kleinman and E. S. Binkley, J. Am. Chem. Soc., 1978, 100, 8036-8037.

81 E. Kleinman and C. H. Heathcock, Tetrahedron Lett., 1979, 20, 4125-4128.

82 C. H. Heathcock, E. F. Kleinman and E. S. Binkley, J. Am. Chem. Soc., 1982, 104, 1054-1068.

83 K. Nakahara, K. Hirano, R. Maehata, Y. Kita and H. Fujioka, Org. Lett., 2011, 13, 2015-2017.

84 D. A. Evans and J. R. Scheerer, Angew. Chem., Int. Ed., 2005, 44, 6038-6042.

85 H. Yang, R. G. Carter and L. N. Zakharov, J. Am. Chem. Soc., 2008, 130, 9238-9239.

86 H. Yang and R. G. Carter, J. Org. Chem., 2010, 75, 49294938.

87 G. A. Kraus and Y. S. Hon, J. Am. Chem. Soc., 1985, 107, 4341-4342.

88 P. A. Grieco and Y. Dai, J. Am. Chem. Soc., 1998, 120, 51285129.

89 E. Wenkert, B. Chauncy, K. G. Dave, A. R. Jeffcoat, F. M. Schell and H. P. Schenk, J. Am. Chem. Soc., 1973, 95, 8427-8436.

90 E. Wenkert and C. A. Broka, J. Chem. Soc., Chem. Commun., 1984, 714-715.

91 G. A. Kraus and Y. S. Hon, Heterocycles, 1987, 25, 377-386.

92 W. A. Ayer and L. S. Trifonov, in The Alkaloids, ed. G. A. Cordell and A. Brossi, Academic, New York, 1994, vol. 45, pp. 233-266.

93 F. A. L. Anet and C. R. Eves, Can. J. Chem., 1958, 36, 902909.

94 D. F. Fischer and R. Sarpong, J. Am. Chem. Soc., 2010, 132, 5926-5927.

95 C. Tsukano, L. Zhao, Y. Takemoto and M. Hirama, Eur. J. Org. Chem., 2010, 4198-4200.

96 C. Yuan, C.-T. Chang and D. Siegel, J. Org. Chem., 2013, 78, 5647-5668.

97 M. Azuma, T. Yoshikawa, N. Kogure, M. Kitajima and H. Takayama, J. Am. Chem. Soc., 2014, 136, 11618-11621.

98 D. Schumann, H.-J. Müller and A. Naumann, Liebigs Ann. Chem., 1982, 2057-2061.

99 D. Schumann, H. J. Muller and A. Naumann, Liebigs Ann. Chem., 1982, 1700-1705.

100 D. Schumann and A. Naumann, Liebigs Ann. Chem., 1983, 220-225. 
101 H. Morita, K. I. Ishiuchi, A. Haganuma, T. Hoshino, Y. Obara, N. Nakahata and J. I. Kobayashi, Tetrahedron, 2005, 61, 1955-1960.

102 B. B. Liau and M. D. Shair, J. Am. Chem. Soc., 2010, 132, 9594-9595.

103 A. S. Lee, B. B. Liau and M. D. Shair, J. Am. Chem. Soc., 2014, 136, 13442-13452.

104 H. Li, X. Wang and X. Lei, Angew. Chem., Int. Ed., 2012, 51, 491-495.

105 J. Zhang, J. Wu, B. Hong, W. Ai, X. Wang, H. Li and X. Lei, Nat. Commun., 2014, 5, 4614.

106 Y.-R. Yang, Z.-W. Lai, L. Shen, J.-Z. Huang, X.-D. Wu, J.-L. Yin and K. Wei, Org. Lett., 2010, 12, 3430-3433.

107 Y.-R. Yang, L. Shen, J.-Z. Huang, T. Xu and K. Wei, J. Org. Chem., 2011, 76, 3684-3690.

108 S.-H. Hou, Y.-Q. Tu, L. Liu, F.-M. Zhang, S.-H. Wang and X.-M. Zhang, Angew. Chem., Int. Ed., 2013, 52, 11373-11376.

109 Y. Xia and A. P. Kozikowski, J. Am. Chem. Soc., 1989, 111, 4116-4117.

110 L. Qian and R. Ji, Tetrahedron Lett., 1989, 30, 2089-2090.

111 A. P. Kozikowski, Y. Xia, E. R. Reddy, W. Tuckmantel, I. Hanin and X. C. Tang, J. Org. Chem., 1991, 56, 4636-4645.

112 A. P. Kozikowski, G. Campiani, P. Aagaard and M. McKinney, J. Chem. Soc., Chem. Commun., 1993, 860862.

113 I. Y. C. Lee, M. H. Jung, H. W. Lee and J. Y. Yang, Tetrahedron Lett., 2002, 43, 2407-2409.

114 T. Koshiba, S. Yokoshima and T. Fukuyama, Org. Lett., 2009, 11, 5354-5356.

115 M. K. M. Tun, D.-J. Wüstmann and S. B. Herzon, Chem. Sci., 2011, 2, 2251-2253.

116 S. M. A. Sohel and T. Opatz, ARKIVOC, 2014, i, 92-108.

117 Y. Hirasawa, J. Kobayashi and H. Morita, Heterocycles, 2009, 77, 679-729.

118 G. T. Ha, R. K. Wong and Y. Zhang, Chem. Biodiversity, 2011, 8, 1189-1204.

119 S. R. Tudhope, J. A. Bellamy, A. Ball, D. Rajasekar, M. AzadiArdakani, H. S. Meera, J. M. Gnanadeepam, R. Saiganesh, F. Gibson, L. He, C. H. Behrens, G. Underiner, J. Marfurt and N. Favre, Org. Process Res. Dev., 2012, 16, 635-642.

120 R. Ding, B.-F. Sun and G.-Q. Lin, Org. Lett., 2012, 14, 44464449.

121 J. D. White, Y. Li, J. Kim and M. Terinek, Org. Lett., 2013, 15, 882-885.

122 Y. Hirasawa, H. Morita and J. Kobayashi, Org. Lett., 2004, 6, 3389-3391.

123 Y. Hirasawa, J. Kobayashi, Y. Obara, N. Nakahata, N. Kawahara, Y. Goda and H. Morita, Heterocycles, 2006, 68, 2357-2364.

124 B. L. Nilsson, L. E. Overman, J. R. de Alaniz and J. M. Rohde, J. Am. Chem. Soc., 2008, 130, 11297-11299.

125 R. A. Altman, B. L. Nilsson, L. E. Overman, J. R. de Alaniz, J. M. Rohde and V. Taupin, J. Org. Chem., 2010, 75, 75197534.

126 X. Cheng and S. P. Waters, Org. Lett., 2010, 12, 205-207.

127 W. A. Denne, S. R. Johns, J. A. Lamberton and A. M. Mathieson, Tetrahedron Lett., 1971, 12, 3107-3108.
128 W. A. Denne, S. R. Johns, J. A. Lamberton and A. M. Mathieson, Tetrahedron Lett., 1973, 14, 794.

129 E. J. Corey and R. D. Balanson, J. Am. Chem. Soc., 1974, 96, 6516-6517.

130 D. M. Ryckman and R. V. Stevens, J. Am. Chem. Soc., 1987, 109, 4940-4948.

131 M. Matsui, in The Alkaloids: Chemistry and Pharmacology, ed. B. Arnold, Elsevier Academic Press, 1988, vol. 33, pp. 307-347.

132 Y. Inubushi, T. Ibuka and M. Kitano, Tetrahedron Lett., 1969, 10, 1611-1614.

133 D. A. Evans, C. A. Bryan and G. M. Wahl, J. Org. Chem., 1970, 35, 4122-4127.

134 T. Ibuka, K. Tanaka and Y. Inubushi, Tetrahedron Lett., 1970, 11, 4811-4814.

135 Y. Inubushi, M. Kitano and T. Ibuka, Chem. Pharm. Bull., 1971, 19, 1820-1841.

136 T. Ibuka, K. Tanaka and Y. Inubushi, Tetrahedron Lett., 1972, 13, 1393-1396.

137 T. Ibuka, K. Tanaka and Y. Inubushi, Chem. Pharm. Bull., 1974, 22, 782-798.

138 T. Ibuka, K. Tanaka and Y. Inubushi, Chem. Pharm. Bull., 1974, 22, 907-921.

139 A. G. Schultz and A. Wang, J. Am. Chem. Soc., 1998, 120, 8259-8260.

140 S. B. Jones, L. He and S. L. Castle, Org. Lett., 2006, 8, 37573760.

141 F. Li, S. S. Tartakoff and S. L. Castle, J. Am. Chem. Soc., 2009, 131, 6674-6675.

142 F. Li, S. S. Tartakoff and S. L. Castle, J. Org. Chem., 2009, 74, 9082-9093.

143 S. B. Herzon, N. A. Calandra and S. M. King, Angew. Chem., Int. Ed., 2011, 50, 8863-8866.

144 K. V. Chuang, R. Navarro and S. E. Reisman, Angew. Chem., Int. Ed., 2011, 50, 9447-9451.

145 S. M. King, N. A. Calandra and S. B. Herzon, Angew. Chem., Int. Ed., 2013, 52, 3642-3645.

146 N. A. Calandra, S. M. King and S. B. Herzon, J. Org. Chem., 2013, 78, 10031-10057.

147 D. K. Nielsen, L. L. Nielsen, S. B. Jones, L. Toll, M. C. Asplund and S. L. Castle, J. Org. Chem., 2009, 74, 1187-1199.

148 G.-W. Qin and R.-S. Xu, Med. Res. Rev., 1998, 18, 375-382. 149 R.-S. Xu, in Studies in Natural Products Chemistry, ed. R. Atta ur, Elsevier, 2000, vol. vol. 21, Part B, pp. 729-772.

150 H. S. Chung, P. M. Hon, G. Lin, P. P. H. But and H. Dong, Planta Med., 2003, 69, 914-920.

151 R. Aloise Pilli and M. da Conceição Ferreira de Oliveira, Nat. Prod. Rep., 2000, 17, 117-127.

152 R. A. Pilli, G. B. Rosso and M. da Conceição Ferreira de Oliveira, Nat. Prod. Rep., 2010, 27, 1908-1937.

153 A. S. Kende, J. I. Martin Hernando and J. B. J. Milbank, Org. Lett., 2001, 3, 2505-2508.

154 A. S. Kende, J. I. Martin Hernando and J. B. J. Milbank, Tetrahedron, 2002, 58, 61-74.

155 T. Taniguchi and H. Ishibashi, Tetrahedron, 2008, 64, 87738779. 
156 T. Taniguchi, G. Tanabe, O. Muraoka and H. Ishibashi, Org. Lett., 2008, 10, 197-199.

157 P.-Q. Huang, S.-Y. Huang, L.-H. Gao, Z.-Y. Mao, Z. Chang and A.-E. Wang, Chem. Commun., 2015, 51, 4576-4578.

158 Y.-M. Zhao, P. Gu, Y.-Q. Tu, C.-A. Fan and Q. Zhang, Org. Lett., 2008, 10, 1763-1766.

159 Z.-H. Chen, Z.-M. Chen, Y.-Q. Zhang, Y.-Q. Tu and F.-M. Zhang, J. Org. Chem., 2011, 76, 10173-10186.

160 Z.-H. Chen, Y.-Q. Zhang, Z.-M. Chen, Y.-Q. Tu and F.-M. Zhang, Chem. Commun., 2011, 47, 1836-1838.

161 M. Brüggemann, A. I. McDonald, L. E. Overman, M. D. Rosen, L. Schwink and J. P. Scott, J. Am. Chem. Soc., 2003, 125, 15284-15285.

162 A. S. Kende, T. L. Smalley and H. Huang, J. Am. Chem. Soc., 1999, 121, 7431-7432.

163 C. Fang, C. S. Shanahan, D. H. Paull and S. F. Martin, Angew. Chem., Int. Ed., 2012, 51, 10596-10599.

164 P. Gu, Y.-M. Zhao, Y. Q. Tu, Y. Ma and F. Zhang, Org. Lett., 2006, 8, 5271-5273.

165 M. Greshoff, Ber. Dtsch. Chem. Ges., 1890, 23, 3537-3550.

166 A. R. Battersby and H. Gregory, J. Chem. Soc., 1963, 22-32.

167 C. Djerassi, H. Schmid, W. G. Kump, A. R. Battersby, J. M. Wilson, R. J. Owellen, D. J. Lecount and H. Budzikiewicz, Helv. Chim. Acta, 1963, 46, 742-751.

168 B. W. Bycroft, D. Schumann, M. B. Patel and H. Schmid, Helv. Chim. Acta, 1964, 47, 1147-1152.

169 D. Schumann, B. W. Bycroft and H. Schmid, Experientia, 1964, 20, 202-203.

170 H. Achenbach and K. Biemann, J. Am. Chem. Soc., 1965, 87, 4944-4950.

171 J. M. F. Filho, B. Gilbert, M. Kitagawa, L. A. P. Leme and L. J. Durham, J. Chem. Soc. C, 1966, 1260-1266.

172 B. M. Craven, B. Gilbert and L. A. P. Leme, Chem. Commun., 1968, 955-956.

173 B. Craven, Acta Crystallogr., Sect. B: Struct. Sci., 1969, 25, 2131-2139.

174 H. Kinoshita, T. Ohnuma, T. Oishi and Y. Ban, Chem. Lett., 1986, 15, 927-930.

175 D. Cartier, M. Ouahrani and J. Lévy, Tetrahedron Lett., 1989, 30, 1951-1954.

176 J. Xie, A. L. Wolfe and D. L. Boger, Org. Lett., 2013, 15, 868870.

177 Y. Ban, Y. Honma and T. Oishi, Tetrahedron Lett., 1976, 17, 1111-1114.

178 M. E. Kuehne and P. J. Seaton, J. Org. Chem., 1985, 50, 47904796.

179 E. Wenkert and S. Liu, J. Org. Chem., 1994, 59, 7677-7682.

180 D. Gagnon and C. Spino, J. Org. Chem., 2009, 74, 6035-6041.

181 T. Gallagher and P. Magnus, J. Am. Chem. Soc., 1983, 105, 2086-2087.

182 P. Magnus, T. Gallagher, P. Brown and J. C. Huffman, J. Am. Chem. Soc., 1984, 106, 2105-2114.

183 P. Magnus and P. Brown, J. Chem. Soc., Chem. Commun., 1985, 184-186.

184 P. Magnus, I. R. Matthews, J. Schultz, R. Waditschatka and J. C. Huffman, J. Org. Chem., 1988, 53, 5772-5776.
185 P. Magnus, T. Katoh, I. R. Matthews and J. C. Huffman, J. Am. Chem. Soc., 1989, 111, 6707-6711.

186 K. Awang, T. Sévenet, A. Hamid, A. Hadi, B. David and M. Païs, Tetrahedron Lett., 1992, 33, 2493-2496.

187 K. Awang, T. Sévenet, M. Païs and A. H. A. Hadi, J. Nat. Prod., 1993, 56, 1134-1139.

188 T.-S. Kam, K. Yoganathan and C.-H. Chuah, Tetrahedron Lett., 1995, 36, 759-762.

189 T.-S. Kam, K.-H. Lim, K. Yoganathan, M. Hayashi and K. Komiyama, Tetrahedron, 2004, 60, 10739-10745.

190 S. Jin, J. Gong and Y. Qin, Angew. Chem., Int. Ed., 2015, 54, 2228-2231.

191 S. Arai, M. Nakajima and A. Nishida, Angew. Chem., Int. Ed., 2014, 53, 5569-5572.

192 S. Arai, M. Nakajima and A. Nishida, Angew. Chem., Int. Ed., 2014, 53, 14295.

193 M. Hoshi, O. Kaneko, M. Nakajima, S. Arai and A. Nishida, Org. Lett., 2014, 16, 768-771.

194 W. H. Pearson, I. Y. Lee, Y. Mi and P. Stoy, J. Org. Chem., 2004, 69, 9109-9122.

195 W. H. Pearson, Y. Mi, I. Y. Lee and P. Stoy, J. Am. Chem. Soc., 2001, 123, 6724-6725.

196 T. J. Greshock, A. W. Grubbs, S. Tsukamoto and R. M. Williams, Angew. Chem., Int. Ed., 2007, 46, 2262-2265.

197 G. D. Artman III, A. W. Grubbs and R. M. Williams, J. Am. Chem. Soc., 2007, 129, 6336-6342.

198 D. Seebach, M. Boes, R. Naef and W. B. Schweizer, J. Am. Chem. Soc., 1983, 105, 5390-5398.

199 P. S. Baran, C. A. Guerrero, N. B. Ambhaikar and B. D. Hafensteiner, Angew. Chem., Int. Ed., 2005, 44, 606609.

200 P. S. Baran, C. A. Guerrero, B. D. Hafensteiner and N. B. Ambhaikar, Angew. Chem., Int. Ed., 2005, 44, 38923895 .

201 S. B. Herzon and A. G. Myers, J. Am. Chem. Soc., 2005, 127, 5342-5344.

202 R. F. Bond, J. C. A. Boeyens, C. W. Holzapfel and P. S. Steyn, J. Chem. Soc., Perkin Trans. 1, 1979, 1751-1761.

203 M. Tsuda, Y. Kasai, K. Komatsu, T. Sone, M. Tanaka, Y. Mikami and J. I. Kobayashi, Org. Lett., 2004, 6, 30873089.

204 T. Mugishima, M. Tsuda, Y. Kasai, H. Ishiyama, E. Fukushi, J. Kawabata, M. Watanabe, K. Akao and J. Kobayashi, J. Org. Chem., 2005, 70, 9430-9435.

205 Z. Bian, C. C. Marvin and S. F. Martin, J. Am. Chem. Soc., 2013, 135, 10886-10889.

206 K. Kong, J. A. Enquist, M. E. McCallum, G. M. Smith, T. Matsumaru, E. Menhaji-Klotz and J. L. Wood, J. Am. Chem. Soc., 2013, 135, 10890-10893.

207 E. V. Mercado-Marin, P. Garcia-Reynaga, S. Romminger, E. F. Pimenta, D. K. Romney, M. W. Lodewyk, D. E. Williams, R. J. Andersen, S. J. Miller, D. J. Tantillo, R. G. S. Berlinck and R. Sarpong, Nature, 2014, 509, 318324.

208 E. V. Mercado-Marin and R. Sarpong, Chem. Sci., 2015, 6, 5048-5052. 
209 B. M. Trost, D. A. Bringley, T. Zhang and N. Cramer, J. Am. Chem. Soc., 2013, 135, 16720-16735.

210 B. M. Trost, N. Cramer and H. Bernsmann, J. Am. Chem. Soc., 2007, 129, 3086-3087.

211 W. G. Beyersbergen van Henegouwen, R. M. Fieseler, F. P. J. T. Rutjes and H. Hiemstra, Angew. Chem., Int. Ed., 1999, 38, 2214-2217.

212 H. Lin and S. J. Danishefsky, Angew. Chem., Int. Ed., 2003, 42, 36-51.

213 X. Zhou, T. Xiao, Y. Iwama and Y. Qin, Angew. Chem., Int. Ed., 2012, 51, 4909-4912.

214 J. Shimokawa, T. Harada, S. Yokoshima and T. Fukuyama, J. Am. Chem. Soc., 2011, 133, 17634-17637.

215 S. Diethelm and E. M. Carreira, J. Am. Chem. Soc., 2013, 135, 8500-8503.

216 K. Stratmann, R. E. Moore, R. Bonjouklian, J. B. Deeter, G. M. L. Patterson, S. Shaffer, C. D. Smith and T. A. Smitka, J. Am. Chem. Soc., 1994, 116, 9935-9942.

217 J. I. Jimenez, U. Huber, R. E. Moore and G. M. L. Patterson, J. Nat. Prod., 1999, 62, 569-572.

218 J. C. Menéndez, in Bioactive Heterocycles $V$, ed. M. Khan, Springer, Berlin Heidelberg, 2007, vol. 11, ch. 63, pp. 63101.

219 J. L. Wood, Nat. Chem., 2012, 4, 341-343.

220 J. A. MacKay, R. L. Bishop and V. H. Rawal, Org. Lett., 2005, 7, 3421-3424.

221 V. Bhat, K. M. Allan and V. H. Rawal, J. Am. Chem. Soc., 2011, 133, 5798-5801.

222 K. M. Allan, K. Kobayashi and V. H. Rawal, J. Am. Chem. Soc., 2012, 134, 1392-1395.

223 K. Jae Nyoung and E. K. Ryu, Tetrahedron Lett., 1993, 34, 8283-8284.

224 J. N. Kim, K. S. Jung, H. J. Lee and J. S. Son, Tetrahedron Lett., 1997, 38, 1597-1598.

225 T.-H. Fu, W. T. McElroy, M. Shamszad and S. F. Martin, Org. Lett., 2012, 14, 3834-3837.

226 X. Tian, A. D. Huters, C. J. Douglas and N. K. Garg, Org. Lett., 2009, 11, 2349-2351.

227 A. D. Huters, K. W. Quasdorf, E. D. Styduhar and N. K. Garg, J. Am. Chem. Soc., 2011, 133, 15797-15799.

228 K. W. Quasdorf, A. D. Huters, M. W. Lodewyk, D. J. Tantillo and N. K. Garg, J. Am. Chem. Soc., 2012, 134, 1396-1399.

229 N. A. Weires, E. D. Styduhar, E. L. Baker and N. K. Garg, J. Am. Chem. Soc., 2014, 136, 14710-14713.

230 E. D. Styduhar, A. D. Huters, N. A. Weires and N. K. Garg, Angew. Chem., Int. Ed., 2013, 52, 12422-12425.

231 K. Komine, Y. Nomura, J. Ishihara and S. Hatakeyama, Org. Lett., 2015, 17, 3918-3921.

232 P. S. Baran, R. A. Shenvi and C. A. Mitsos, Angew. Chem., Int. Ed., 2005, 44, 3714-3717.

233 P. S. Baran and R. A. Shenvi, J. Am. Chem. Soc., 2006, 128, 14028-14029.

234 T. Newhouse and P. S. Baran, J. Am. Chem. Soc., 2008, 130, 10886-10887.

235 K. Foo, T. Newhouse, I. Mori, H. Takayama and P. S. Baran, Angew. Chem., Int. Ed., 2011, 50, 2716-2719.
236 T. Newhouse, C. A. Lewis and P. S. Baran, J. Am. Chem. Soc., 2009, 131, 6360-6361.

237 T. Newhouse, C. A. Lewis, K. J. Eastman and P. S. Baran, J. Am. Chem. Soc., 2010, 132, 7119-7137.

238 C. Li, C. Chan, A. C. Heimann and S. J. Danishefsky, Angew. Chem., Int. Ed., 2007, 46, 1448-1450.

239 H. Abdelkafi and B. Nay, Nat. Prod. Rep., 2012, 29, 845-869.

240 S. M. Weinreb and J. Auerbach, J. Am. Chem. Soc., 1975, 97, 2503-2506.

241 T. P. Burkholder and P. L. Fuchs, J. Am. Chem. Soc., 1988, 110, 2341-2342.

242 L. F. Tietze and H. Schirok, J. Am. Chem. Soc., 1999, 121, 10264-10269.

243 Q. Liu, E. M. Ferreira and B. M. Stoltz, J. Org. Chem., 2007, 72, 7352-7358.

244 W.-D. Z. Li and Y.-Q. Wang, Org. Lett., 2003, 5, 2931-2934.

245 L. Planas, J. Pérard-Viret and J. Royer, J. Org. Chem., 2004, 69, 3087-3092.

246 J. D. Eckelbarger, J. T. Wilmot and D. Y. Gin, J. Am. Chem. Soc., 2006, 128, 10370-10371.

247 J. D. Eckelbarger, J. T. Wilmot, M. T. Epperson, C. S. Thakur, D. Shum, C. Antczak, L. Tarassishin, H. Djaballah and D. Y. Gin, Chem.-Eur. J., 2008, 14, 42934306.

248 Z. Zhao and P. S. Mariano, Tetrahedron, 2006, 62, 72667273.

249 A. Hameed, A. J. Blake and C. J. Hayes, J. Org. Chem., 2008, 73, 8045-8048.

250 T. Taniguchi and H. Ishibashi, Org. Lett., 2008, 10, 41294131.

251 M. E. Kuehne, W. G. Bornmann, W. H. Parsons, T. D. Spitzer, J. F. Blount and J. Zubieta, J. Org. Chem., 1988, 53, 3439-3450.

252 M. Ikeda, S. A. A. El Bialy, K. Hirose, M. Kotake, T. Sato, S. M. M. Bayomi, I. A. Shehata, A. M. Abdelal, L. M. Gad and T. Yakura, Chem. Pharm. Bull., 1999, 47, 983-987.

253 S. Suga, M. Watanabe and J. Yoshida, J. Am. Chem. Soc., 2002, 124, 14824-14825.

254 S. Yasuda, T. Yamada and M. Hanaoka, Tetrahedron Lett., 1986, 27, 2023-2026.

255 H. Ishibashi, M. Okano, H. Tamaki, K. Maruyama, T. Yakura and M. Ikeda, J. Chem. Soc., Chem. Commun., 1990, 1436-1437.

256 L. F. Tietze, H. Braun, P. L. Steck, S. A. A. El Bialy, N. Tölle and A. Düfert, Tetrahedron, 2007, 63, 6437-6445.

257 Y.-M. Zhao, P. Gu, H.-J. Zhang, Q.-W. Zhang, C.-A. Fan, Y.-Q. Tu and F.-M. Zhang, J. Org. Chem., 2009, 74, 32113213.

258 Y. Koseki, H. Sato, Y. Watanabe and T. Nagasaka, Org. Lett., 2002, 4, 885-888.

259 X. Lin, R. W. Kavash and P. S. Mariano, J. Am. Chem. Soc., 1994, 116, 9791-9792.

260 K. Folkers and R. T. Major, J. Am. Chem. Soc., 1937, 59, 1580-1581.

261 E. Reimann, in Progress in the Chemistry of Organic Natural Products, ed. W. Herz, H. Falk and G. W. Kirby, Springer, Vienna, 2007, vol. 88, ch. 1, pp. 1-62. 
262 H. Ishibashi, T. Sato, M. Takahashi, M. Hayashi, K. Ishikawa and M. Ikeda, Chem. Pharm. Bull., 1990, 38, 907-911.

263 S. Chikaoka, A. Toyao, M. Ogasawara, O. Tamura and H. Ishibashi, J. Org. Chem., 2003, 68, 312-318.

264 T. Sano, J. Toda, T. Ohshima and Y. Tsuda, Chem. Pharm. Bull., 1992, 40, 873-878.

265 R. L. Funk and J. Belmar, Tetrahedron Lett., 2012, 53, 176178.

266 S. T. Heller, T. Kiho, A. R. H. Narayan and R. Sarpong, Angew. Chem., Int. Ed., 2013, 52, 11129-11133.

267 H.-T. Luu, S. Wiesler, G. Frey and J. Streuff, Org. Lett., 2015, 17, 2478-2481.

268 N. A. Braun, M. Ousmer, J. D. Bray, D. Bouchu, K. Peters, E.-M. Peters and M. A. Ciufolini, J. Org. Chem., 2000, 65, 4397-4408.

269 M. Paladino, J. Zaifman and M. A. Ciufolini, Org. Lett., 2015, 17, 3422-3425.

270 T. Kawasaki, N. Onoda, H. Watanabe and T. Kitahara, Tetrahedron Lett., 2001, 42, 8003-8006.

271 J. M. Joo, R. A. David, Y. Yuan and C. Lee, Org. Lett., 2010, 12, 5704-5707.

272 K. V. Chuang, R. Navarro and S. E. Reisman, Chem. Sci., 2011, 2, 1086-1089.

273 M. A. le Dreau, D. Desmaele, F. Dumas and J. d'Angelo, J. Org. Chem., 1993, 58, 2933-2935.

274 Y. Yoshida, K. Mohri, K. Isobe, T. Itoh and K. Yamamoto, J. Org. Chem., 2009, 74, 6010-6015.

275 K. Shimizu, M. Takimoto, Y. Sato and M. Mori, J. Organomet. Chem., 2006, 691, 5466-5475.

276 H. Fukumoto, T. Esumi, J. Ishihara and S. Hatakeyama, Tetrahedron Lett., 2003, 44, 8047-8049.

277 Q. Wang and A. Padwa, Org. Lett., 2006, 8, 601-604.

278 F. Zhang, N. S. Simpkins and A. J. Blake, Org. Biomol. Chem., 2009, 7, 1963-1979.

279 J. H. Rigby, C. Deur and M. J. Heeg, Tetrahedron Lett., 1999, 40, 6887-6890.

280 J. W. Daly, T. F. Spande and H. M. Garraffo, J. Nat. Prod., 2005, 68, 1556-1575.

281 S. M. Weinreb, Chem. Rev., 2006, 106, 2531-2549.

282 K. Sakamato, E. Tsujii, F. Abe, T. Nakanishi, M. Yamashite, N. Shigematsu, S. Izumi and M. Okuhara, J. Antibiot., 1996, 49, 37-44.

283 J. F. Biard, S. Guyot, C. Roussakis, J. F. Verbist, J. Vercauteren, J. F. Weber and K. Boukef, Tetrahedron Lett., 1994, 35, 2691-2694.

284 D. L. J. Clive, M. L. Yu, J. Wang, V. S. C. Yeh and S. Z. Kang, Chem. Rev., 2005, 105, 4483-4514.

285 B. B. Snider and T. Liu, J. Org. Chem., 1997, 62, 5630-5633. 286 B. M. Trost and M. T. Rudd, Org. Lett., 2003, 5, 4599-4602. 287 A. C. Flick, M. J. A. Caballero and A. Padwa, Org. Lett., 2008, 10, 1871-1874.

288 J. Liu, R. P. Hsung and S. D. Peters, Org. Lett., 2004, 6, 39893992.

289 J. Liu, J. J. Swidorski, S. D. Peters and R. P. Hsung, J. Org. Chem., 2005, 70, 3898-3902.
290 H. Abe, S. Aoyagi and C. Kibayashi, J. Am. Chem. Soc., 2005, 127, 1473-1480.

291 J. F. Liu and C. H. Heathcock, J. Org. Chem., 1999, 64, 82638266.

292 G. A. Molander and M. Rönn, J. Org. Chem., 1999, 64, 51835187.

293 T. Arai, H. Abe, S. Aoyagi and C. Kibayashi, Tetrahedron Lett., 2004, 45, 5921-5924.

294 G. Pandey and V. Janakiram, Chem.-Eur. J., 2015, 21, 13120-13126.

295 G. Lapointe, K. Schenk and P. Renaud, Org. Lett., 2011, 13, $4774-4777$.

296 G. Scheffler, H. Seike and E. J. Sorensen, Angew. Chem., Int. Ed., 2000, 39, 4593-4596.

297 M. Ousmer, N. A. Braun and M. A. Ciufolini, Org. Lett., 2001, 3, 765-767.

298 A.-J. Ma, Y.-Q. Tu, J.-B. Peng, Q.-Y. Dou, S.-H. Hou, F.-M. Zhang and S.-H. Wang, Org. Lett., 2012, 14, 36043607.

299 S. Ieda, T. Kan and T. Fukuyama, Tetrahedron Lett., 2010, 51, 4027-4029.

300 H.-H. Huo, H.-K. Zhang, X.-E. Xia and P.-Q. Huang, Org. Lett., 2012, 14, 4834-4837.

301 H.-H. Huo, X.-E. Xia, H.-K. Zhang and P.-Q. Huang, J. Org. Chem., 2013, 78, 455-465.

302 K. M. Brummond and J. L. Lu, Org. Lett., 2001, 3, 13471349.

303 K. M. Brummond and S.-P. Hong, J. Org. Chem., 2005, 70, 907-916.

304 M. Movassaghi, M. Tjandra and J. Qi, J. Am. Chem. Soc., 2009, 131, 9648-9650.

305 D. A. Evans, D. J. Adams and E. E. Kwan, J. Am. Chem. Soc., 2012, 134, 8162-8170.

306 M. Kuramoto, C. Tong, K. Yamada, T. Chiba, Y. Hayashi and D. Uemura, Tetrahedron Lett., 1996, 37, 3867-3870.

307 T. Chou, M. Kuramoto, Y. Otani, M. Shikano, K. Yazawa and D. Uemura, Tetrahedron Lett., 1996, 37, 3871-3874.

308 J. Kobayashi and M. Ishibashi, Chem. Rev., 1993, 93, 17531769.

309 D. Trauner, J. B. Schwarz and S. J. Danishefsky, Angew. Chem., Int. Ed., 1999, 38, 3542-3545.

310 M. W. Carson, G. Kim and S. J. Danishefsky, Angew. Chem., Int. Ed., 2001, 40, 4453-4456.

311 M. W. Carson, G. Kim, M. F. Hentemann, D. Trauner and S. J. Danishefsky, Angew. Chem., Int. Ed., 2001, 40, 44504452.

312 H. S. Christie and C. H. Heathcock, Proc. Natl. Acad. Sci. U. S. A., 2004, 101, 12079-12084.

$313 \mathrm{~S} . \mathrm{Xu}, \mathrm{H}$. Arimoto and D. Uemura, Angew. Chem., Int. Ed., 2007, 46, 5746-5749.

314 S. Omura, K. Matsuzaki, T. Fujimoto, K. Kosuge, T. Furuya, S. Fujita and A. Nakagawa, J. Antibiot., 1991, 44, 117-118.

315 S. Omura, T. Fujimoto, K. Otoguro, K. Matsuzaki, R. Moriguchi, H. Tanaka and Y. Sasaki, J. Antibiot., 1991, 44, 113-116. 
316 R. H. Feling, G. O. Buchanan, T. J. Mincer, C. A. Kauffman, P. R. Jensen and W. Fenical, Angew. Chem., Int. Ed., 2003, 42, 355-357.

317 M. Shibasaki, M. Kanai and N. Fukuda, Chem.-Asian J., 2007, 2, 20-38.

318 E. J. Corey and G. A. Reichard, J. Am. Chem. Soc., 1992, 114, 10677-10678.

319 E. J. Corey and G. A. Reichard, Tetrahedron Lett., 1993, 34, 6973-6976.

320 E. J. Corey and S. Choi, Tetrahedron Lett., 1993, 34, 69696972.

321 T. Sunazuka, T. Nagamitsu, K. Matsuzaki, H. Tanaka, S. Omura and A. B. Smith, J. Am. Chem. Soc., 1993, 115, 5302 .

322 H. Uno, J. E. Baldwin and A. T. Russell, J. Am. Chem. Soc., 1994, 116, 2139-2140.

323 N. Chida, J. Takeoka, N. Tsutsumi and S. Ogawa, J. Chem. Soc., Chem. Commun., 1995, 793-794.

324 T. Nagamitsu, T. Sunazuka, H. Tanaka, S. Ōmura, P. A. Sprengeler and A. B. Smith, J. Am. Chem. Soc., 1996, 118, 3584-3590.

325 N. Chida, J. Takeoka, K. Ando, N. Tsutsumi and S. Ogawa, Tetrahedron, 1997, 53, 16287-16298.

326 E. J. Corey, W. Li and T. Nagamitsu, Angew. Chem., Int. Ed., 1998, 37, 1676-1679.

327 E. J. Corey, W. Li and G. A. Reichard, J. Am. Chem. Soc., 1998, 120, 2330-2336.

328 J. S. Panek and C. E. Masse, Angew. Chem., Int. Ed., 1999, 38, 1093-1095.

329 H. Ooi, N. Ishibashi, Y. Iwabuchi, J. Ishihara and S. Hatakeyama, J. Org. Chem., 2004, 69, 7765-7768.

330 L. R. Reddy, P. Saravanan and E. J. Corey, J. Am. Chem. Soc., 2004, 126, 6230-6231.

331 L. R. Reddy, J.-F. Fournier, B. V. S. Reddy and E. J. Corey, Org. Lett., 2005, 7, 2699-2701.

332 A. Endo and S. J. Danishefsky, J. Am. Chem. Soc., 2005, 127, 8298-8299.

333 E. P. Balskus and E. N. Jacobsen, J. Am. Chem. Soc., 2006, 128, 6810-6812.

334 N. Fukuda, K. Sasaki, T. V. R. S. Sastry, M. Kanai and M. Shibasaki, J. Org. Chem., 2006, 71, 1220-1225.

335 N. P. Mulholland, G. Pattenden and I. A. S. Walters, Org. Biomol. Chem., 2006, 4, 2845-2846.

336 G. Ma, H. Nguyen and D. Romo, Org. Lett., 2007, 9, 21432146.

337 T. Ling, V. R. Macherla, R. R. Manam, K. A. McArthur and B. C. M. Potts, Org. Lett., 2007, 9, 2289-2292.

338 C. J. Hayes, A. E. Sherlock, M. P. Green, C. Wilson, A. J. Blake, M. D. Selby and J. C. Prodger, J. Org. Chem., 2008, 73, 2041-2051.

339 N. P. Mulholland, G. Pattenden and I. A. S. Walters, Org. Biomol. Chem., 2008, 6, 2782-2789.

340 T. Fukuda, K. Sugiyama, S. Arima, Y. Harigaya, T. Nagamitsu and S. Ōmura, Org. Lett., 2008, 10, 4239-4242.

341 K. Takahashi, M. Midori, K. Kawano, J. Ishihara and S. Hatakeyama, Angew. Chem., Int. Ed., 2008, 47, 6244-6246.
342 Y. Sato, H. Fukuda, M. Tomizawa, T. Masaki, M. Shibuya, N. Kanoh and Y. Iwabuchi, Heterocycles, 2010, 81, 22392246.

343 Y. Kaiya, J.-I. Hasegawa, T. Momose, T. Sato and N. Chida, Chem.-Asian J., 2011, 6, 209-219.

344 N. Satoh, S. Yokoshima and T. Fukuyama, Org. Lett., 2011, 13, 3028-3031.

345 H. Nguyen, G. Ma, T. Gladysheva, T. Fremgen and D. Romo, J. Org. Chem., 2011, 76, 2-12.

346 D. J. Wardrop and E. G. Bowen, Chem. Commun., 2005, 5106-5108.

347 S. Yoshioka, M. Nagatomo and M. Inoue, Org. Lett., 2015, 17, 90-93.

348 J. Kobayashi, F. Kanda, M. Ishibashi and H. Shigemori, J. Org. Chem., 1991, 56, 4574-4576.

349 T. Jahn, G. M. König, A. D. Wright, G. Wörheide and J. Reitner, Tetrahedron Lett., 1997, 38, 3883-3884.

350 S. Tsukamoto, K. Tane, T. Ohta, S. Matsunaga, N. Fusetani and R. W. M. van Soest, J. Nat. Prod., 2001, 64, 1576-1578.

351 K. Namba, T. Shinada, T. Teramoto and Y. Ohfune, J. Am. Chem. Soc., 2000, 122, 10708-10709.

352 P. M. Wehn and J. Du Bois, J. Am. Chem. Soc., 2002, 124, 12950-12951.

353 A. Hinman and J. Du Bois, J. Am. Chem. Soc., 2003, 125, 11510-11511.

354 K. Tran, P. J. Lombardi and J. L. Leighton, Org. Lett., 2008, 10, 3165-3167.

355 Y. Ichikawa, K. Okumura, Y. Matsuda, T. Hasegawa, M. Nakamura, A. Fujimoto, T. Masuda, K. Nakano and H. Kotsuki, Org. Biomol. Chem., 2012, 10, 614-622.

356 T. Kano, T. Hashimoto and K. Maruoka, J. Am. Chem. Soc., 2006, 128, 2174-2175.

357 M. P. Sibi, L. M. Stanley and T. Soeta, Org. Lett., 2007, 9, 1553-1556.

358 Y. Wang, X. Liu and L. Deng, J. Am. Chem. Soc., 2006, 128, 3928-3930.

359 J. C. S. Woo and D. B. MacKay, Tetrahedron Lett., 2003, 44, 2881-2883.

360 C. Drouin, J. C. S. Woo, D. B. MacKay and R. M. A. Lavigne, Tetrahedron Lett., 2004, 45, 7197-7199.

361 J. C. Lanter, H. F. Chen, X. Q. Zhang and Z. H. Sui, Org. Lett., 2005, 7, 5905-5907.

362 T. Shinada, E. Ikebe, K. Oe, K. Namba, M. Kawasaki and Y. Ohfune, Org. Lett., 2007, 9, 1765-1767.

363 T. Shinada, E. Ikebe, K. Oe, K. Namba, M. Kawasaki and Y. Ohfune, Org. Lett., 2010, 12, 2170.

364 K. Oe, T. Shinada and Y. Ohfune, Tetrahedron Lett., 2008, 49, 7426-7429.

365 K. Sankar, H. Rahman, P. P. Das, E. Bhimireddy, B. Sridhar and D. K. Mohapatra, Org. Lett., 2012, 14, 1082-1085.

366 T. Yoshimura, T. Kinoshita, H. Yoshioka and T. Kawabata, Org. Lett., 2013, 15, 864-867.

367 M. Nagatomo, H. Nishiyama, H. Fujino and M. Inoue, Angew. Chem., Int. Ed., 2015, 54, 1537-1541.

368 Y. Tahara, J. Pharm. Soc. Jpn., 1909, 29, 587-625.

369 Y. Tahara, Biochem. Z., 1911, 30, 255-275. 
370 T. Goto, Y. Kishi, S. Takahash and Y. Hirata, Tetrahedron, 1965, 21, 2059-2088.

371 K. Tsuda, O. Amakasu, S. Ikuma, M. Kawamura, C. Tamura, R. Tachikawa and K. Sakai, Chem. Pharm. Bull., 1964, 12, 1357-1374.

372 R. B. Woodward and J. Z. Gougoutas, J. Am. Chem. Soc., 1964, 86, 5030.

373 A. Furusaki, Y. Tomiie and I. Nitta, Bull. Chem. Soc. Jpn., 1970, 43, 3325-3331.

374 A. Furusaki, Y. Tomiie and I. Nitta, Bull. Chem. Soc. Jpn., 1970, 43, 3332-3341.

375 F. A. Fuhrman, Ann. N. Y. Acad. Sci., 1986, 479, 1-14.

376 C. Y. Kao, Ann. N. Y. Acad. Sci., 1986, 479, 52-67.

377 W. Ulbricht, H. H. Wagner and J. Schmidtmayer, Ann. N. Y. Acad. Sci., 1986, 479, 68-83.

378 R. E. Weiss and R. Horn, Ann. N. Y. Acad. Sci., 1986, 479, 152-161.

379 B. K. Krueger, J. F. Worley and R. J. French, Ann. N. Y. Acad. Sci., 1986, 479, 257-268.

380 J. Chau and M. A. Ciufolini, Mar. Drugs, 2011, 9, 2046-2074.

381 Y. Kishi, F. Nakatsubo, M. Aratani, T. Goto, S. Inoue and H. Kakoi, Tetrahedron Lett., 1970, 11, 5129-5132.

382 Y. Kishi, F. Nakatsubo, M. Aratani, T. Goto, S. Inoue, H. Kakoi and S. Sugiura, Tetrahedron Lett., 1970, 11, 5127-5128.

383 Y. Kishi, M. Aratani, T. Fukuyama, F. Nakatsub, T. Goto, S. Inoue, H. Tanino, S. Sugiura and H. Kakoi, J. Am. Chem. Soc., 1972, 94, 9217-9219.
384 Y. Kishi, T. Fukuyama, M. Aratani, F. Nakatsub, T. Goto, S. Inoue, H. Tanino, S. Sugiura and H. Kakoi, J. Am. Chem. Soc., 1972, 94, 9219-9221.

385 T. Nishikawa, M. Asai, N. Ohyabu, N. Yamamoto, Y. Fukuda and M. Isobe, Tetrahedron, 2001, 57, 3875-3883.

386 N. Ohyabu, T. Nishikawa and M. Isobe, J. Am. Chem. Soc., 2003, 125, 8798-8805.

387 T. Nishikawa, D. Urabe and M. Isobe, Angew. Chem., Int. Ed., 2004, 43, 4782-4785.

388 N. Ünver and G. İ. Kaya, Turk. J. Chem., 2005, 29, 547-553.

389 S. Tian, W. Zi and D. Ma, Angew. Chem., Int. Ed., 2012, 51, 10141-10144.

390 Y. Shi, B. Yang, S. Cai and S. Gao, Angew. Chem., Int. Ed., 2014, 53, 9539-9543.

391 B. D. Morris and M. R. Prinsep, J. Nat. Prod., 1999, 62, 688693.

392 C. C. Hughes and D. Trauner, Angew. Chem., Int. Ed., 2002, 41, 4556-4559.

393 K. Sakaguchi, M. Ayabe, Y. Watanabe, T. Okada, K. Kawamura, T. Shinada and Y. Ohfune, Tetrahedron, 2009, 65, 10355-10364.

394 K. Chiyoda, J. Shimokawa and T. Fukuyama, Angew. Chem., Int. Ed., 2012, 51, 2505-2508.

395 A. Soheili and U. K. Tambar, Org. Lett., 2013, 15, 5138-5141.

396 M. O'Connor, C. Sun and D. Lee, Angew. Chem., Int. Ed., 2015, 127, 10101-10104. 